\title{
O SISTEMA RENINA-ANGIOTENSINA NA DOENÇA PERIODONTAL INDUZIDA EXPERIMENTALMENTE EM RATOS
}

FACULDADE DE ODONTOLOGIA DE BAURU

UNIVERSIDADE DE SÃO PAULO

MARTA DA CUNHA LIMA

2011 



\section{O sistema renina-angiotensina na doença periodontal}

\section{induzida experimentalmente em ratos}

Tese apresentada à Faculdade de Odontologia de Bauru da Universidade de São Paulo, como parte dos requisitos para a obtenção do título de Doutor(a) em Odontologia, área de concentração Estomatologia e Biologia Oral.

Orientador: Prof. Dr. Carlos Ferreira dos Santos

Versão corrigida

BAURU - SP 


\begin{tabular}{|c|}
\hline L628s $\begin{array}{c}\text { Lima, Marta da Cunha } \\
\text { O sistema renina-angiotensina na doença periodontal } \\
\text { induzida experimentalmente em ratos. / Marta da Cunha } \\
\text { Lima. - Bauru, } 2011 . \\
129 p . \text { : il. ; } 30 \mathrm{~cm} .\end{array}$ \\
Tese (Doutorado) - Faculdade de Odontologia de Bauru. \\
Universidade de São Paulo. \\
Orientador: Prof. Dr. Carlos Ferreira dos Santos
\end{tabular}

Nota: A versão original desta tese encontra-se disponível no Serviço de Biblioteca e Documentação da Faculdade de Odontologia de Bauru FOB/USP.

Autorizo, exclusivamente para fins acadêmicos e científicos, a reprodução total ou parcial desta tese, por processos fotocopiadores e outros meios eletrônicos.

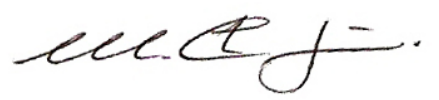

Bauru, 17 de outubro de 2011.

Projeto de Pesquisa aprovado pela Comissão de Ética no Ensino e Pesquisa em Animais da Faculdade de Odontologia de Bauru, Universidade de São Paulo. Proc. $n^{\circ}$ 009/2008. 


\section{Dados Curriculares \\ Marta da Cunha Lima}

20 de junho de 1978

Rio de Janeiro - RJ

2000-2003

2004-2006

2005-2007

2007-2011

2011-presente
Nascimento

Filha de Paulo Corrêa Lima e Maria Auxiliadora da Cunha Lima.

Curso de Graduação em Odontologia pela Faculdade de Odontologia de Bauru Universidade de São Paulo.

Curso de Especialização em Radiologia Odontológica e Imaginologia, pelo Hospital de Reabilitação de Anomalias Craniofaciais - Universidade de São Paulo.

Curso de Pós-Graduação em Estomatologia, nível de Mestrado, pela Faculdade de Odontologia de Bauru Universidade de São Paulo.

Curso de Pós-Graduação em Estomatologia, nível de Doutorado, pela Faculdade de Odontologia de Bauru Universidade de São Paulo, com realização de estágio de doutorado no exterior no Medical College of Wisconsin sob orientação do Dr. Andrew Seth Greene.

Membro do New York Academy of Sciences. 

"0 valor das coisas não está no tempo em que elas duram, mas na intensidade com que acontecem. Por isso, existem momentos inesquecíveis, coisas inexplicáveis e pessoas incomparáveis".

Fernando Pessoa 



\section{Dedicatória}

Dedico

Ao meu marido Bruno,

Por todo o amor, confiança, cumplicidade e incentivo durante todos estes anos. Não existem palavras que consigam expressar todo o meu amor e admiração por ele. A ele todo o meu amor!

À minha mãe Dora,

Pelo exemplo de vida que sempre significou para mim. Seu amor infinito, sua bondade, sua dedicação, seu otimismo, sua força... enfim... suas inúmeras qualidades que sempre a fizeram uma pessoa muito especial. Nunca irei conseguir dizer o valor dela em minha vida e a falta que faz. Obrigada por todo o amor e por todos os seus ensinamentos, eu os levarei por toda a minha vida! À minha mãe querida, todo o meu amor!

Ao meu pai Paulo,

Pai especial, carinhoso e presente. Agradeço por todos os ensinamentos, conselhos, as preocupações e a dedicação à nossa família. Ele me ensinou a ser uma pessoa correta, justa e responsável. Sempre forte e presente em todos os momentos da minha vida. Ao meu pai querido, todo o meu amor!

Ao meu irmão Rafael,

Muito obrigada pelo carinho, companheirismo e paciência ao longo de todos estes anos. 0 amo muito!

Ao meu irmão Vitor,

Por todo o carinho e compreensão. Muito obrigada por trazer um pouco de sua arte para minha vida. 0 amo muito!

À minha irmã Ana,

Por todo seu carinho e amor... seu incentivo constante na minha vida. Por confiar tanto em mim. Além de minha irmã é minha grande amiga. Obrigada por fazer das coisas corriqueiras uma felicidade. A amo muito!

A vocês seis, dedico os resultados de meus esforços, de meus estudos, minhas felicidades e lutas durante todos estes anos. Sem o apoio, carinho, incentivo e compreensão de vocês nada disso seria possível. Meu eterno obrigada! 

A cada dia que vivo, mais me convenço de que o desperdício da vida está no amor que não damos, nas forças que não usamos, na prudência egoísta que nada arrisca, e que, esquivando-se do sofrimento, perdemos também a felicidade." Carlos Drummond de Andrade 



\section{Agradecimentos}

Ao meu querido orientador, Prof. Dr. Carlos Ferreira dos Santos, pela amizade, exemplo, confiança, dedicação, incentivo e ensinamentos durante todos estes anos de convivência. Seus ensinamentos sempre extrapolaram as paredes de uma sala de aula, me ensinando a realidade do ser professor e cientista, contribuindo de maneira muito valiosa para o meu crescimento científico e pessoal. 0 meu muitíssimo obrigada.

Ao meu co-orientador, Prof. Dr. Andrew Seth Greene, pela oportinidade única ao me abrir as portas no Medical College of Wisconsin e possibilitar meu crescimento como pessoa e cientista. Pela confiança em mim depositada, pela sua atenção em qualquer momento, e pelos inúmeros ensinamentos. 0 meu muito obrigada.

Ao Prof. Dr. José Humberto Damante, que fez despertar em mim o interesse pela Estomatologia e me serve de exemplo de competência como clínico e como professor. 0 meu muito obrigada, querido mestre!

Aos meus queridos amigos do doutorado Thais Marchini de Oliveira Valarelli, Bella Luna Colombini Ishikiriama, Bruna Stucchi Centurion, Thiago José Dionísio e Caio Figueiredo, pela paciência, incentivo, conhecimentos transmitidos e pela nossa amizade. Pelo companheirismo, seriedade e nossos inúmeros momentos divertidos, os quais lembrarei para sempre. Muito obrigada meus queridos amigos! Vocês, cada um à sua maneira, participaram e contribuíram em muito para o sucesso deste trabalho. A vocês, a minha eterna amizade e meu eterno muito obrigada!

Aos meus queridos amigos Dan Brozoski e Michelle Williams pela companhia, amizade e acolhida nos EUA. 0 meu muito obrigada!

Aos outros professores do curso de doutorado, Prof. Dr. Flávio Augusto Cardoso de Faria, Prof. Dr. Luiz Eduardo Montenegro Chinellato, Profa. Dra. Ana Lúcia Álvares Capelozza, Profa. Dra. Izabel Regina Fischer Rubira 
de Bullen, Prof. Dr. Eduardo Sant'Ana, Prof. Dr. Osny Ferreira Júnior e Prof. Dr. Paulo Perri, por me ensinarem a ter seriedade no árduo dever de transmitir conhecimento, pelos ensinamentos transmitidos e pela agradável convivência.

Aos funcionários do Departamento de Estomatologia e Ciência Biológicas, Elza Cassalate, Fernanda Cavalari, Josieli Farinha, Luciana Zanon, Marília Gião, Roberto Sales, Roque dos Santos e Vera Lúcia Rufino Rosa, por estarem sempre dispostos a ajudar e contribuir para um convívio agradável nesses anos.

Aos funcionários da biblioteca da FOB / USP Cybelle de Assumpção Fontes, Rita de Cássia Paglione, Valéria Cristina Trindade Ferraz, Vera Regina Casari Boccato, Ademir Padilha, Ana Paula Moço Libel, César Augusto do Amaral Campos, Maria Caetano, Jane Pimentel Nogueira e Maria José dos Santos Formenti, sempre dispostos a ajudar da melhor forma, rompendo a seriedade da pesquisa e deixando a biblioteca cada vez mais acolhedora.

À Diretoria da Faculdade de Odontologia de Bauru, da Universidade de São Paulo pelo trabalho desenvolvido para tornar a Universidade cada vez mais um campo de descobertas, aprendizagem e conhecimento.

À Comissão de Pós-Graduação da Faculdade de Odontologia de Bauru, da Universidade de São Paulo pela competência, dedicação e ousadia na busca de avanços e condições importantes na qualificação dos profissionais.

Aos meus avós, Maria Alacoque Corrêa Lima, Roberto Luiz Fernandes Lima, Maria Vitória Neves da Cunha e Antônio Geraldo Correia da Cunha, que me ensinaram valores importantes que carrego comigo. Sempre estiveram dispostos a ajudar no que fosse preciso. Que me fizeram entender que o conhecimento é algo que se conquista, depende exclusivamente do meu esforço e nunca se perde. E pelo exemplo que me deram me transformaram numa pessoa melhor. Meu sincero obrigada! 
À minha tia Profa. Dra. Maria de Lourdes Corrêa Lima, que me inspirou na minha caminhada rumo à docência, me serve de exemplo pela sua inteligência, esforço e dedicação à área acadêmica. Obrigada pelo brilhante exemplo!

À minha tia-mãe Graça pelo carinho e preocupação de sempre. E ao tio Ralph pela serenidade e exemplo. Obrigada!

À minha querida tia Nanda, por sempre me escutar e apoiar nos meus momentos de estresse, de alegria e de tristeza. Por todo seu carinho e companhia. Obrigada!

Aos tios Ricardo, Tarcísio, João Carlos, Nando, Geraldo e Cinthia, Marcos e Cici, Luiz e Beth, Lídia e Roberto pelo carinho de sempre. Obrigada!

A todos os meus primos Mateus, Gabriel, Tiago, Pedro, Laura, Daniel, Tatiane, Theou, Marcela, Vanessa, Elisa, Rodrigo, Abel, Disrael, Raquel, Ellen, Fernanda, Kátia, Nádia, Luiza, Luiz André, Rodrigo e Ana Clara, pela ótima convivência por todos estes anos. Obrigada!

Aos amigos do Doutorado de Estomatologia, Carla, Etiene, Josiane, Melissa, Renato, Zanda, Flávio, Cássia e Cláudio pela disposição e pelo apoio de sempre.

À minha grande amiga e eterna parceira de clínica Marcela Borgo, por sua valiosa amizade, sua paciência, por nossas longas e divertidas conversas, a minha mais profunda gratidão!

À minha amiga Renata Teixeira, pelas horas e horas de trabalho na FOB... que se não fossem com ela com certeza não aconteceriam. Pessoa de simpatia, cumplicidade e amizade inegáveis. Obrigada pela sua amizade, atenção e preciosa companhia.

Às minhas queridas amigas e "room-mates" Priscila Brenner e Carla Ruffeil Moreira, pela amizade e pelo convívio inigualável.

Às minhas amigas de sempre Renata Karvaly e Paula Barros pela amizade, confiança e incentivo eternos. 
A todos os colegas e alunos de pós-graduação que compartilharam aulas, apresentações, churrascos e que proporcionaram uma convivência sadia, além de aprendizado continuo durante esses anos de amizade.

A todos os pacientes que participaram das clínicas e que, cada um a sua maneira, contribuíram para o meu crescimento científico e humano.

À Capes pelas bolsas de doutorado e estágio de doutorado no exterior a mim concedidas, que possibilitaram o desenvolvimento desta pesquisa.

E, finalmente, a todos que colaboraram, direta ou indiretamente para o desenvolvimento e finalização desta dissertação. Sozinha eu não teria êxito nessa árdua caminhada. E também a todos que tiveram papel importante para a transformação de um desejo em realidade. Muito obrigada! 
"Todo homem, por natureza, quer saber" Aristóteles 

Resumo 



\section{RESUMO}

A doença periodontal (DP) compreende um grupo de lesões que afetam os tecidos periodontais de proteção (gengivite) e suporte (periodontite), envolvendo a participação de células residentes, células estruturais e mediadores inflamatórios. Pesquisa recente do nosso laboratório mostrou a existência de um Sistema ReninaAngiotensina (SRA) local no tecido gengival de ratos e sugeriu que o SRA possa ter participação na DP. Portanto, o objetivo deste trabalho foi avaliar a se o SRA está envolvido na iniciação e na progressão da DP induzida experimentalmente em ratos. Para tanto, foi utilizado modelo de indução da DP por colocação de ligadura, por 7 e 14 dias, ao redor do primeiro molar inferior de ratos e tratamento destes animais com drogas que afetam o SRA [losartan (50 mg/Kg/dia), alisquireno (30 mg/Kg/dia) ou enalapril (10 mg/Kg/dia)]. Foram realizadas técnicas de análise da perda óssea alveolar, reação em cadeia da polimerase (PCR) quantitativa e imunoistoquímica. Após a coleta, os dados foram devidamente analisados por meio de gráficos e tabelas, sendo utilizada ANOVA a 2 e 3 critérios e adotado nível de significância de 5\%. Em nível protéico, houve aumento significativo da maioria dos componentes do SRA $(p<0,05)$ na DP. A renina apresentou aumento nos tratamentos com losartan, alisquireno e enalapril tanto nos animais sham (cirurgia fictícia de indução da DP) quanto nos animais com DP, aos 7 e 14 dias, e não apresentou marcação no grupo controle (água), demonstrando efeito dependente dos tratamentos farmacológicos. Na DP houve aumento dos componentes AT1 (aos 7 e 14 dias), AT2 (aos 7 dias) e enzima conversora da angiotensina (ECA; aos 7 e 14 dias) nos grupos tratados com losartan, alisquireno e enalapril. Também houve aumento de imunomarcação nos animais com DP para AT2 (aos 14 dias) e ECA (aos 14 dias) em animais do grupo controle. Em relação à expressão gênica, houve aumento da expressão de RNA $A_{m}$ nos animais com DP para o receptor AT2 no grupo controle (aos 7 e 14 dias), e nos animais tratados com losartan ou enalapril (aos 7 dias). Houve aumento da expressão de RNA $A_{m}$ para a ECA nos animais com DP tratados com losartan e enalapril (aos 7 dias), e controle (aos 14 dias). O tratamento por 14 dias com as drogas losartan ou alisquireno, mas não com enalapril, foi capaz de diminuir significativamente a perda óssea alveolar $(p<0,05)$. Portanto, pode-se concluir que o SRA está envolvido na iniciação e na progressão da DP induzida experimentalmente em ratos.

Palavras-chave: doença periodontal, sistema renina-angiotensina, inflamação. 

Abstract 



\begin{abstract}
The renin-angiotensin system in experimentally-induced periodontal disease in rats

Periodontal disease (PD) comprises a group of lesions that affect protection (gingivitis) and support periodontal tissues (periodontitis) involving the participation of resident and structural cells as well as inflammatory mediators. Recent research in our laboratory showed the existence of a local gingival renin-angiotensin system (RAS), and suggested that it might participate in PD. Therefore, the aim of this study was to evaluate whether the RAS is involved in the initiation and progression of the experimentallyinduced PD in rats. For this purpose, a model of ligature placement, for 7 and 14 days, around the lower first molar in rats, and the treatment of such animals with drugs that affect the RAS [losartan (50 $\mathrm{mg} / \mathrm{Kg} /$ day), aliskiren (30 $\mathrm{mg} / \mathrm{Kg} /$ day) or enalapril (10 $\mathrm{mg} / \mathrm{Kg} /$ day)] were employed. The following techniques were performed: alveolar bone loss analysis, quantitative real-time polymerase chain reaction and immunohistochemistry. Data were collected, organized in tables and graphs, and submitted to 2 and 3 way ANOVA with significance level established at $5 \%$. In the protein level, there was a significant increase in the majority of the RAS components in PD. Immunolocalization for renin increased when animals were treated with losartan, aliskiren or enalapril, for 7 and 14 days, in both sham (fictitious surgery for PD induction) and PD animals, whereas the control group (water) had no staining, demonstrating a drug-related effect. In animals with PD treated with losartan, aliskiren or enalapril there was an increase in staining for AT1 (at 7 and 14 days), AT2 (at 7 days) and angiotensin-converting enzyme (ACE; at 7 and 14 days). There was also increased staining in PD animals for AT2 (at 14 days) and ACE (at 14 days) in the control group. As far as genic expression, there was an increase in ${ }_{m}$ RNA expression for AT2 in control animals with PD (at 7 and 14 days), and in the animals treated with losartan or enalapril (at 7 days). There was an increase in ${ }_{m} R N A$ for ACE in animals with PD treated with losartan or enalapril (at 7 days) as well as control rats (at 14 days). Treatment for 14 days with losartan or aliskiren, but not enalapril, significantly decreased alveolar bone loss $(p<0.05)$. Therefore, one can conclude that the RAS is involved in the initiation and progression of the experimentally-induced PD in rats.
\end{abstract}

Key words: periodontal disease, renin-angiotensin system, inflammation. 



\section{SUMÁRIO}

\section{RESUMO}

\section{ABSTRACT}

1 INTRODUÇÃO

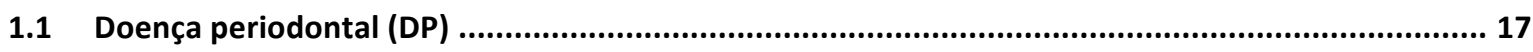

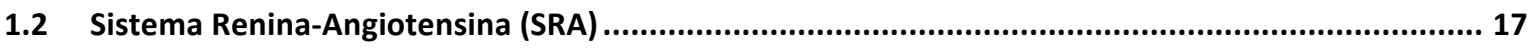

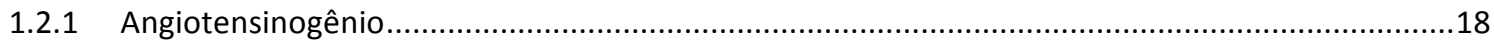

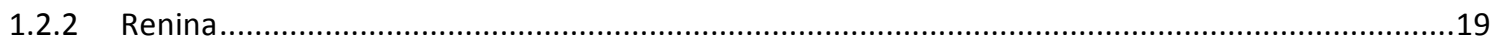

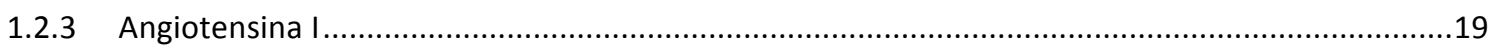

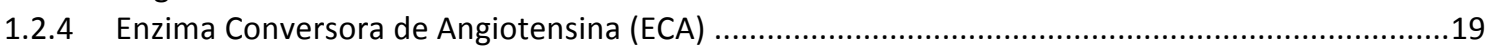

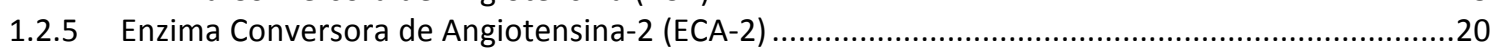

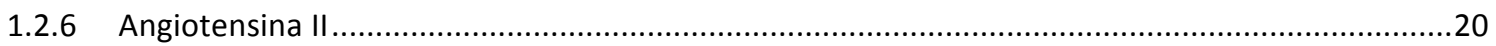

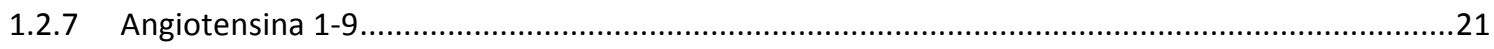

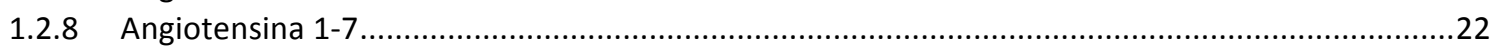

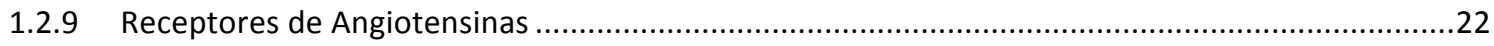

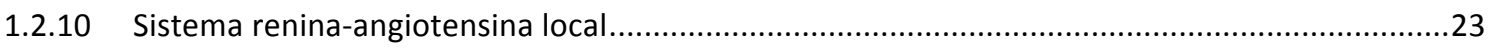

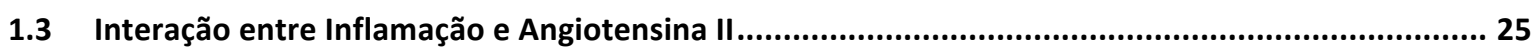

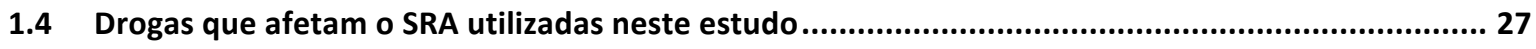

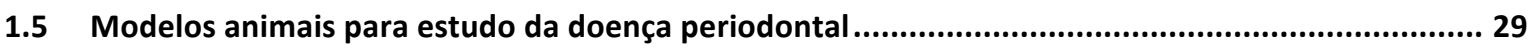

2 PROPOSIÇÃO

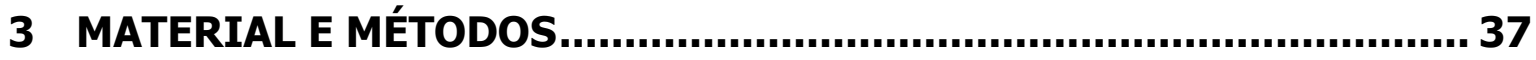

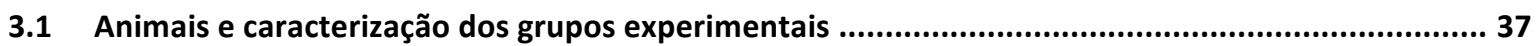

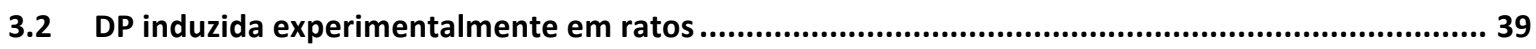

Obtenção de espécimes para os diferentes experimentos.......................................................41

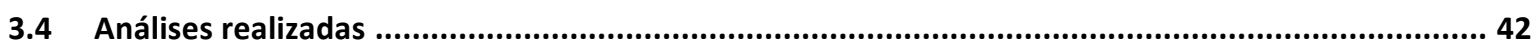

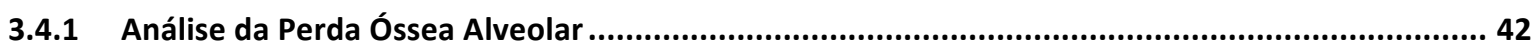

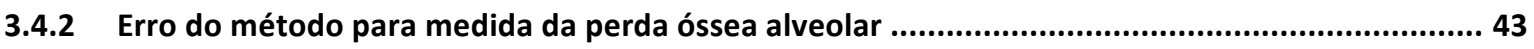

3.4.3 Extração de RNA total das biópsias de tecido gengival ......................................................44

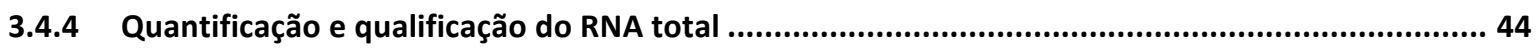

3.4.5 Tratamento do RNA total com DNAse e transcrição reversa............................................. 45

3.4.6 Reação em Cadeia da Polimerase (PCR) quantitativa .......................................................45 


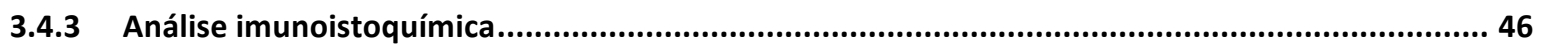

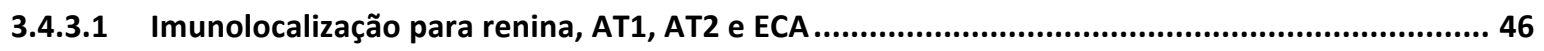

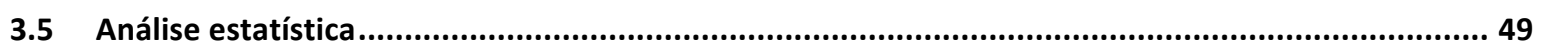

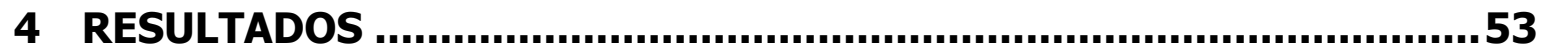

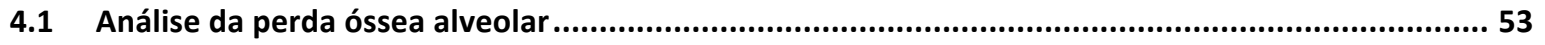

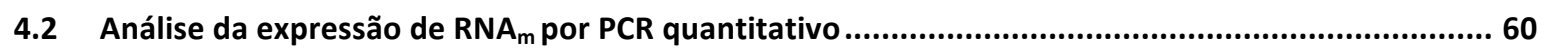

4.2.1 Expressão de $\mathrm{RNA}_{m}$ em animais tratados farmacologicamente ou com água por 7 dias ..............60

4.2.2 Análise da expressão de RNA $m$ por PCR tratados farmacologicamente ou com água por 14 dias .66

4.2.3 Comparação da expressão de RNA $A_{m}$ por PCR tratados farmacologicamente ou com água por $7 \mathrm{e}$

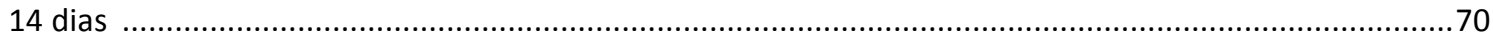

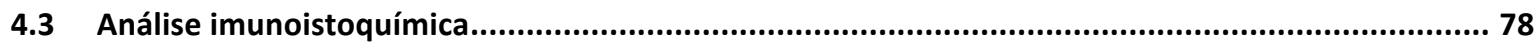

4.3.4 Imunomarcação nos animais tratados farmacologicamente ou com água por 7 dias ...................78

4.3.5 Imunomarcação nos animais tratados farmacologicamente ou com água por 14 dias .................88

4.3.6 Comparação da Imunomarcação nos animais tratados farmacologicamente ou com água por 7 e

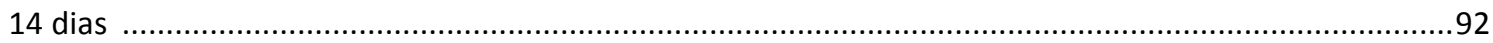

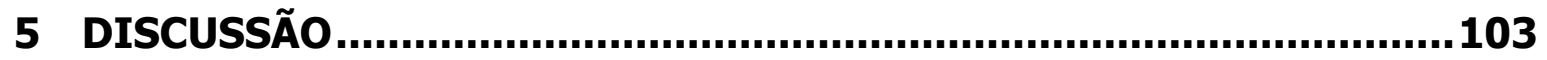

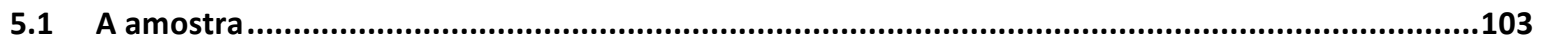

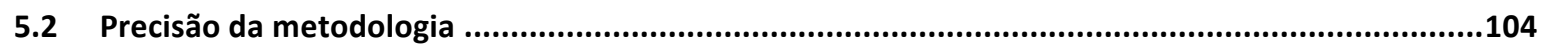

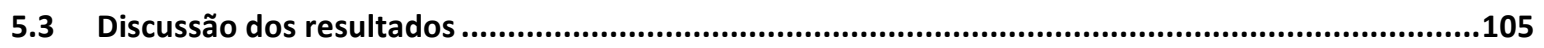

6 CONCLUSÕES ...........................................................................113

REFERÊNCIAS BIBLIOGRÁFICAS

ANEXOS 


\section{Introdução e Síntese Bibliográfica}





\section{INTRODUÇÃO}

\subsection{Doença periodontal (DP)}

Entre os processos patológicos que afetam a dentição humana, as doenças periodontais são das mais comumente observadas. É bem documentado que de $5 \%$ a $15 \%$ de qualquer população sofre de periodontite generalizada, apesar da periodontite moderada afetar a maioria dos adultos (Oliver, 1998; Burt, 2005). Essas doenças compreendem um grupo de lesões que afetam os tecidos periodontais de proteção (gengiva), denominando-se gengivite, e de suporte (cemento, osso alveolar e ligamento periodontal), denominando-se periodontite, a qual pode levar à perda dentária (Flemmig, 1999).

A principal causa da doença periodontal é a placa dentobacteriana que se acumula sobre a superfície dentária, bem como ao nível e abaixo da margem da gengiva. Este acúmulo causa inflamação e fibrose da gengiva, levando à destruição do ligamento periodontal e do osso alveolar. Com a progressão da doença, os tecidos moles separam-se da superfície dentária resultando na lesão característica da periodontite crônica - a bolsa periodontal (Wilson, 1995; Van Dyke e Serhan, 2003).

Interações entre patógenos microbianos e vários sistemas de resposta do hospedeiro desempenham um papel crítico no desenvolvimento e progressão da DP via liberação de vários mediadores inflamatórios e imunológicos (Page, 1991; Ebersole, 2003).

\subsection{Sistema Renina-Angiotensina (SRA)}

O SRA circulante é um sistema endócrino que promove a liberação de Angiotensina (Ang) II, a qual exerce seus efeitos pela interação com receptores específicos (Peach, 1977). A Ang II é gerada pela ação da renina, uma enzima produzida pelos rins, sobre o angiotensinogênio plasmático, produzido pelo fígado, formando o decapeptídeo Ang I (Asp ${ }^{1}-\mathrm{Arg}^{2}-\mathrm{Val}^{3}-\mathrm{Tyr}^{4}-\mathrm{Il}^{5}-\mathrm{His}^{6}-\mathrm{Pro}^{7}-\mathrm{Phe}^{8}$ $\mathrm{His}^{9}-\mathrm{Leu}^{10}$ ), que é clivado na ligação $\mathrm{Phe}^{8}-\mathrm{His}^{9}$ pela enzima conversora de Ang I, 
presente em abundância no endotélio pulmonar, liberando o octapeptídeo ativo Ang II (Asp $\left.{ }^{1}-\mathrm{Arg}^{2}-\mathrm{Val}^{3}-\mathrm{Tyr}^{4}-\mathrm{Ile}^{5}-\mathrm{His}^{6}-\mathrm{Pro}^{7}-\mathrm{Phe}^{8}\right)$. A Figura 1 ilustra o SRA com os componentes descritos acima e outros componentes que serão comentados a seguir.

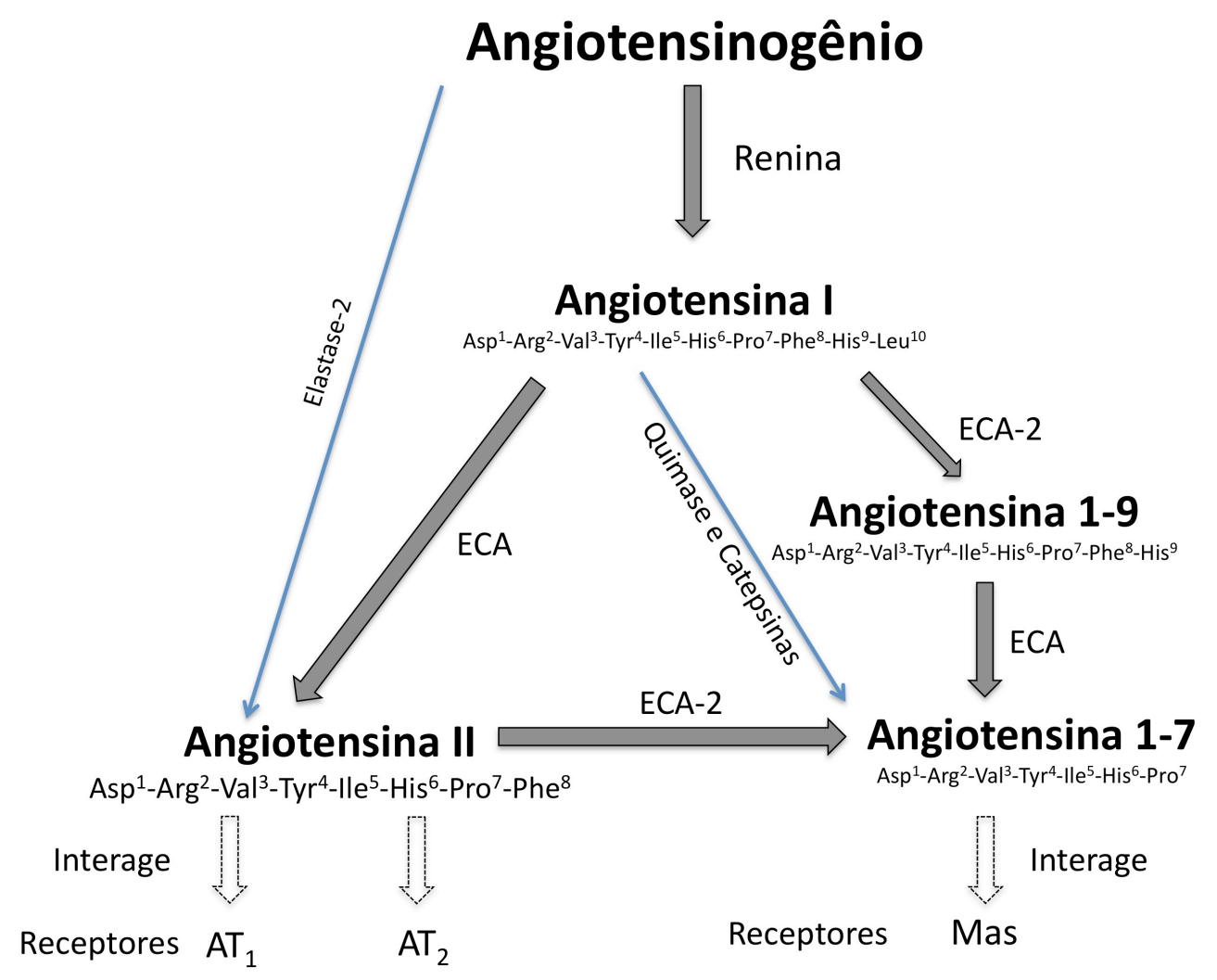

Figura 1 - Principais componentes do sistema renina-angiotensina.

\subsubsection{Angiotensinogênio}

O angiotensinogênio humano, uma alfa 2 globulina de 452 aminoácidos, é sintetizado no fígado. O RNAm que codifica a proteína também é abundante no tecido gorduroso, determinadas regiões do sistema nervoso central (SNC) e rins (Campbell, Habener 1986; Cassis, Save, Peach 1988). Vários hormônios como glicocorticóides, hormônio tireoidiano e a própria Ang II (Bem-Ari, Garrison 1988) estimulam a síntese de angiotensinogênio. 


\subsubsection{Renina}

A enzima renina é uma glicoproteína de 340 aminoácidos, sendo sintetizada e armazenada sob a forma inativa, denominada pró-renina nas células justaglomerulares dos rins, que são células musculares lisas modificadas localizadas nas paredes das arteríolas aferentes dos glomérulos (Oliveira et al., 1999).

Com a queda de pressão arterial, reações intrínsecas nos próprios rins fazem com que muitas moléculas de pró-renina sejam clivadas e assim liberando a renina. A secreção da renina é controlada por 3 mecanismos: 2 agem predominantemente nos rins (mecanismo de mácula densa e mecanismo barorreceptor infra-renal) e o terceiro que age por meio do SNC (mecanismo do receptor $\beta$-adrenérgico). O mecanismo denominado de feedback negativo de alça curta consiste no fato de que elevações da secreção de renina aumentam a formação de Ang II que, interagindo com seus receptores renais, inibe a liberação de renina nas células justaglomerulares. O mecanismo de feedback negativo de alça longa consiste na inibição da liberação da renina devido a aumentos da pressão arterial induzidos pela Ang II (Jackson, Garrison 1995).

\subsubsection{Angiotensina I}

A Ang I é um peptídeo de 10 aminoácidos (Asp ${ }^{1}-\mathrm{Arg}^{2}-\mathrm{Val}^{3}-\mathrm{Tyr}^{4}-\mathrm{Ile}^{5}-\mathrm{His}^{6}-$ $\mathrm{Pro}^{7}-\mathrm{Phe}^{8}-\mathrm{His}^{9}-\mathrm{Leu}^{10}$ ) desprovido de propriedades vasoconstritoras para produzir alterações funcionais significativas na função circulatória; serve como substrato para vias enzimáticas formadoras de Ang II (Paul, Mehr, Kreutz 2006).

\subsubsection{Enzima Conversora de Angiotensina (ECA)}

A ECA humana, uma metaloprotease de ligação de membrana, contém 1.278 resíduos de aminoácidos e possui 2 domínios homólogos, cada um com um 
local catalítico e com uma região de ligação do zinco (Soubrier et al., 1988; Berstein et al., 1989). A ECA é encontrada abundantemente no endotélio dos vasos pulmonares (Ryan et al., 1975, 1976) e também no plasma e em diversos tecidos orgânicos como: endotélio vascular (Caldwell et al., 1976; Ryan et al., 1976), cérebro, placenta, intestino e nos túbulos renais (Hall et al., 1976; Erdös, Skidgel 1986; Schulz et al., 1988).

\subsubsection{Enzima Conversora de Angiotensina-2 (ECA-2)}

A ECA-2 tem sido descrita como uma metaloprotease dependente de zinco com atividade de carboxipeptidase. A ECA-2 está envolvida na geração de peptídeos de angiotensina alternativos, em particular pela conversão de Ang II em Ang 1-7, sendo esta considerada sua principal função, e Ang I em Ang 1-9. A expressão de genes da ECA-2 é descrita no sistema cardiovascular, no córtex renal e medula, em alguns tecidos do trato gastrintestinal e nos testículos (Raizada, Ferreira 2007). A ECA-2 está presente em macrófagos, células endoteliais e musculares lisas (Kramkowski, Mogielnicki, Buczko 2006) e tem sido sugerida como um importante regulador das funções cardíacas e do desenvolvimento (Paul, Mehr, Kreutz 2006).

\subsubsection{Angiotensina II}

Pela ação da ECA, há a liberação do último dipeptídeo da Ang I (His ${ }^{9}$ $\mathrm{Leu}^{10}$ ), formando a Ang II, um octapeptídeo (Asp ${ }^{1}-\mathrm{Arg}^{2}-\mathrm{Val}^{3}-\mathrm{Tyr}^{4}-\| \mathrm{e}^{5}-\mathrm{His}^{6}-\mathrm{Pro}^{7}$ $\mathrm{Phe}^{8}$ ). A Ang II é considerada o principal peptídeo efetor do SRA (Paul, Mehr, Kreutz 2006).

Além do seu efeito vasoconstritor e estimulatório sobre a secreção de aldosterona, a Ang II tem ações inotrópica e cronotrópica positivas sobre o coração (Peach, 1977). Em adição aos seus efeitos no sistema cardiovascular, tem-se demonstrado que a Ang II está envolvida em outras funções, tais como 
mitogênese de fibroblastos da pele, síntese de DNA por células do ligamento periodontal e regulação da formação óssea, crescimento celular, apoptose, geração de espécies reativas ao oxigênio, secreção hormonal, ações prófibrogenéticas, tônus vascular e indução da liberação de prostaglandina $E_{2}\left(P_{G} E_{2}\right)$ em fibroblastos gengivais humanos (Nickenig et al., 1997; Lundergan et al., 1999; Hiruma et al., 1997; Hagiwara et al., 1998; Lamparter et al., 1998; Leung, 2004; Segawa et al., 2003; Paul, Mehr, Kreutz 2006).

Vários estudos têm mostrado a participação de outras enzimas, além da ECA, na geração de Ang II. Cerca de $40 \%$ da Ang I é clivada em Ang II por vias alternativas à via da ECA (Ram 2007), podendo ocorrer via quimases e catepsinas (Schmieder 2007) ou via elastase-2 (Paula et al., 1998; Santos et al., 2002a; Santos et al., 2002b; Santos et al., 2003; Santos et al., 2004).

\subsubsection{Angiotensina 1-9}

A angiotensina 1-9 (Asp $\left.{ }^{1}-\mathrm{Arg}^{2}-\mathrm{Val}^{3}-\mathrm{Tyr}^{4}-\| \mathrm{e}^{5}-\mathrm{His}^{6}-\mathrm{Pro}^{7}-\mathrm{Phe}^{8}-\mathrm{His}^{9}\right) \quad$ é conhecida como um peptídeo com pouca atividade biológica (Kramkowski, Mogielnicki, Buczko 2006). Acredita-se que seja inativa até que a ECA a clive e libere Ang 1-7. Subseqüentemente, Ang 1-7 é inativada pela liberação do dipeptídeo C-terminal para formar Ang 1-5 (Asp $\left.{ }^{1}-\mathrm{Arg}^{2}-\mathrm{Val}^{3}-\mathrm{Tyr}^{4}-\| \mathrm{e}^{5}\right)($ Chen et al., 2005). Por ser provavelmente o principal produto do metabolismo de Ang I em plaquetas, a Ang 1-9 pode estar envolvida na regulação da função plaquetária (Kramkowski, Mogielnicki, Buczko 2006). Em concentrações micromolares, Ang 19 inibe a ECA (Snyder, Wintroub 1986; Marcic et al., 1999) e potencializa a ação da bradicinina em seu receptor B2 (Marcic et al., 1999). Em coração humano, a catepsina A (CATA) gera derivados Ang 1-9 e Ang 1-7 a partir de Ang I (Jackman et al., 2002). 


\subsubsection{Angiotensina 1-7}

A angiotensina 1-7 é um componente bioativo do SRA, sendo um heptapeptídeo (Asp ${ }^{1}-\mathrm{Arg}^{2}-\mathrm{Val}^{3}-\mathrm{Tyr}^{4}-\| \mathrm{e}^{5}-\mathrm{His}^{6}-\mathrm{Pro}^{7}$ ) formado a partir da Ang I por ação de endopeptidases neutras, ou seja, por uma via independente da ECA (Santos et al., 1988; Santos, Compagnole-Santos 1994). Algumas destas enzimas, como a neprilisina, estão envolvidas no metabolismo do fator natriurético atrial e bradicinina. A ECA também tem sido envolvida no metabolismo e quebra da Ang 1-7, sugerindo uma interação entre diferentes sistemas de peptídeos cardiovasculares (Paul, Mehr, Kreutz 2006). A Ang 1-7 tem ações contraregulatórias às da Ang II, como a proliferação celular estimulada pela Ang II e ações anti-proliferativas da Ang 1-7. Enquanto a Ang II tem efeitos vasoconstritores, a Ang 1-7 tem efeitos vasodilatadores. A Ang 1-7 pode regular a pressão sangüínea, a função cardíaca e o crescimento celular, sendo talvez importante futuramente no tratamento de doenças cardíacas, câncer, doença renal e pré-eclampsia (Trask, Ferrario 2007).

\subsubsection{Receptores de Angiotensinas}

A Ang II possui interações com diferentes tipos de receptores, conhecidos como $A T_{1}$ e $A T_{2}$. No músculo liso vascular, o receptor $A T_{1}$, membro da família de receptores ligados à proteína $\mathrm{G}$, possui 7 regiões transmembrânicas com 359 aminoácidos, é mediador da angiogênese e possui propriedades vasoconstritoras, enquanto que o receptor $A T_{2}$ tem 363 aminoácidos, possuindo propriedades vasodilatadoras e inibindo a angiogênese. Os subtipos de receptores $A T_{1}$ e $A T_{2}$ apresentam estruturas genômicas e localizações diferentes, e também expressão e regulação específicas para cada tecido. Em quimiorreceptores do corpo da carótida, o receptor $\mathrm{AT}_{1}$ pode mediar a liberação de cálcio intracelular. As funções da Ang II, tais como constrição vascular, proliferação celular e liberação da aldosterona são conhecidas por serem mediadas via receptores $A T_{1}$. Em ratos e camundongos, dois subtipos de receptores $\mathrm{AT}_{1}$ foram clonados e caracterizados: $A T_{1 a}$ e $A T_{1 b}$ (Linderman, Greene 2001; Paul, Mehr, Kreutz 2006; Lam, Leung 
2002; Hirasawa et al., 2002; Inagami et al., 1994; De Gasparo, Siragy 1999; De Gasparo et al., 2000; Speth, Thompson, Johns 1995; Wright, Yamamoto, Harding 2008) .

Há evidências de um receptor de angiotensina adicional denominado $A_{4}$, que interage com um peptídeo de Ang truncado, a Ang IV ou Ang 3-8 (Val ${ }^{3}$-Tyr ${ }^{4}$ $\| e^{5}-\mathrm{His}^{6}-\mathrm{Pro}^{7}-\mathrm{Phe}^{8}$ ). $\mathrm{AT}_{4}$ foi originalmente definido como específico com local de ligação de alta afinidade para Ang IV (Paul, Mehr, Kreutz 2006) e parece estar relacionado à consolidação da memória, fluxo sangüíneo, reabsorção tubular renal e proliferação celular (Wright, Yamamoto, Harding 2008).

O protooncogene Mas é sugerido como um receptor funcional de angiotensinas (Jackson et al., 1988). O Mas é caracterizado como um receptor acoplado à proteína $\mathrm{G}$, originalmente descrito como um fator envolvido na gênese de tumores. Os efeitos do receptor Mas podem ser mediados por Ang 1-7 ou outros peptídeos de angiotensina, o que sugere alguma relevância funcional in vivo (Paul, Mehr, Kreutz 2006).

Esse conceito clássico do SRA circulante está sendo modificado em função de evidências que mostram a participação de diferentes tecidos na formação de Ang II. Um número crescente de estudos mostra a existência de sistemas locais capazes de gerar angiotensinas de forma independente do SRA circulante em vários tecidos, tais como cérebro, coração, rim, gônadas, ovários, osso, músculo esquelético, tecido adiposo, pâncreas, corpo da carótida, cordão umbilical, polpa dental e tecido gengival (Campbell, 1987; Phillips, Speakman, Kimura 1993; Obermüller et al., 2004; Leung 2004, Goker et al., 2005; Souza et al., 2007; Santos et al. 2009).

\subsubsection{Sistema renina-angiotensina local}

Há muitas evidências acerca da existência de alguns componentes do SRA no tecido gengival e em fibroblastos gengivais de diferentes espécies (Ohuchi et al., 2002; Segawa et al., 2003; Berggreen e Heyeraas, 2003; Ohuchi et al., 2004; Santos et al., 2009). 
Ohuchi et al. (2002) sugeriram, por meio da utilização de drogas antagonistas de receptores de Ang II, que a proliferação de fibroblastos gengivais de cobaios estimulada pela fenitoína e nifedipina é mediada indiretamente por receptores $\mathrm{AT}_{1}$ presentes em fibroblastos gengivais em cultura. Os autores também sugeriram que Ang II é sintetizada localmente nestas células.

Segawa et al. (2003) investigaram o efeito da Ang II sobre a produção de $\mathrm{PGE}_{2}$ em fibroblastos gengivais humanos. Um antagonista de receptores $A T_{1}$, mas não um antagonista de receptores $A T_{2}$, foi capaz de inibir a produção de $\mathrm{PGE}_{2}$ estimulada pela Ang II administrada.

Berggreen e Heyeraas (2003) sugeriram, com a utilização de drogas antagonistas de receptores $\mathrm{AT}_{1}$, a existência destes receptores na polpa dentária e no tecido gengival de furão quando estudaram o efeito da Ang II sobre o fluxo sangüíneo em tecidos orais destes animais.

Ohuchi et al. (2004) demonstraram que a Ang II induziu a proliferação de fibroblastos gengivais de coelhos de maneira concentração-dependente. Esta proliferação foi inibida por um antagonista de receptores $A T_{1}$, porém não foi alterada por um antagonista de receptores $\mathrm{AT}_{2}$, sugerindo, portanto, que a proliferação de fibroblastos gengivais de coelho induzida pela Ang II nestas células em cultura ocorre via receptores $A T_{1}$. Adicionalmente, em complemento aos achados farmacológicos, os autores demonstraram a presença dos receptores $A T_{1}$ e $A T_{2}$ nestas células com auxílio da técnica de Western blot.

Os receptores $A T_{1}$ e $A T_{2}$ foram encontrados na polpa dental por Souza et al. (2007), demonstrando a participação destes receptores de Ang II na pulpite pelo envolvimento tanto no estabelecimento como na modulação das alterações pulpares.

Estudos recentes do nosso laboratório demostram a existência de um SRA local no tecido gengival de ratos. Experimentos mostraram que neste tecido existe a expressão de RNA $_{m}$ para todos os principais componentes do SRA (angiotensinogênio, renina, ECA e receptores $A T_{1 a}, A_{1 b}$ e $A T_{2}$; Santos et al., 2009). 


\subsection{Interação entre Inflamação e Angiotensina II}

Na doença periodontal, a inflamação e a destruição tecidual são eventos iniciais e constantes durante o processo mediado pelo hospedeiro em resposta à infecção bacteriana (Listgarten, 1987; Delima e Van Dyke, 2003; Van Dyke e Serhan, 2003).

A inflamação é um processo complexo que pode ocorrer nos tecidos em resposta a estímulos patológicos e usualmente leva à recuperação da integridade tecidual, mas se o reparo não é perfeitamente controlado o processo inflamatório pode resultar em dano tecidual permanente (Marchesi et al. 2008). Independente da etiologia do estímulo primário e do tecido envolvido, a inflamação classicamente segue três estágios: aumento na permeabilidade vascular (mudanças no calibre/fluxo vascular e incremento na permeabilidade vascular); recrutamento de leucócitos (rolamento/adesão/transmigração e quimiotaxia) e ativação dos processos para reparo tecidual. A Ang II está envolvida em todos estes três estágios da resposta inflamatória (Suzuki et al., 2003; Marchesi et al., 2008; Figura 2).

A Ang II, o principal peptídeo ativo do SRA, além de ser um mediador fisiológico do sistema circulatório, é reconhecida como um fator de crescimento que regula o crescimento celular e fibrose. Um grande número de estudos tem demonstrado que a Ang II está envolvida em eventos-chave da inflamação. Nesse processo, as células inflamatórias são equipadas com todos os componentes do sistema renina-angiotensina (SRA), podendo produzir angiotensina (Ang) II (Gomez et al., 1993; Owen e Campbell, 1998).

A Ang II é capaz de induzir dano vascular independente dos efeitos hemodinâmicos de indução da remodelação vascular e disfunção endotelial e aumento nos níveis de pressão arterial (Schiffrin, 2002) e isso pode ser explicado pelo menos parcialmente pelos efeitos pró-inflamatórios da Ang II.

A Ang II exerce seus efeitos pró-inflamatórios na vasculatura por meio da indução de integrinas, moléculas de adesão, citocinas e mediadores profibróticos 
e de crescimento pela ativação de fatores de transcrição e vias envolvendo espécies oxigênio reativas (Marchesi et al 2008).

Um estudo feito por de Cavanagh et al (2010), em ratos, concluiu que a inibição do SRA com bloqueadores dos receptores AT1 e com inbibidores da ECA, além da diminuição da pressão arterial e proteção contra as ações profibróticas e proliferativas da Ang II, reduziram o estresse oxidativo principalmente pela prevenção da formação de espécies oxigênio reativas derivadas da ativação da enzima nicotinamida adenina dinucleotídeo fosfato $(\mathrm{NAD}(\mathrm{P}) \mathrm{H})$ oxidase induzida pela Ang II.

Outro estudo feito por Borges Jr et al (2007) sobre marcadores próinflamatórios e estresse oxidativo na doença periodontal comprovou uma importante correlação entre marcadores de estresse oxidativo e a doença periodontal.

Somando-se as informações de que a Ang II está presente em todas as fases da inflamação (Marchesi et al 2008), que a inibição do SRA diminui o estresse oxidativo pela inibição da via Ang II de ativação da NAD(P)H oxidase (de Cavanagh et al 2010) e que a doença periodontal e o estresse oxidativo têm importante correlação (Borges $\mathrm{Jr}$ et al 2007) sugere-se que a inibição do SRA diminua os danos da doença periodontal durante sua progressão por meio da diminuição do estresse oxidativo pela inibição da via Ang II-enzima $N A D(P) H$ oxidase. 


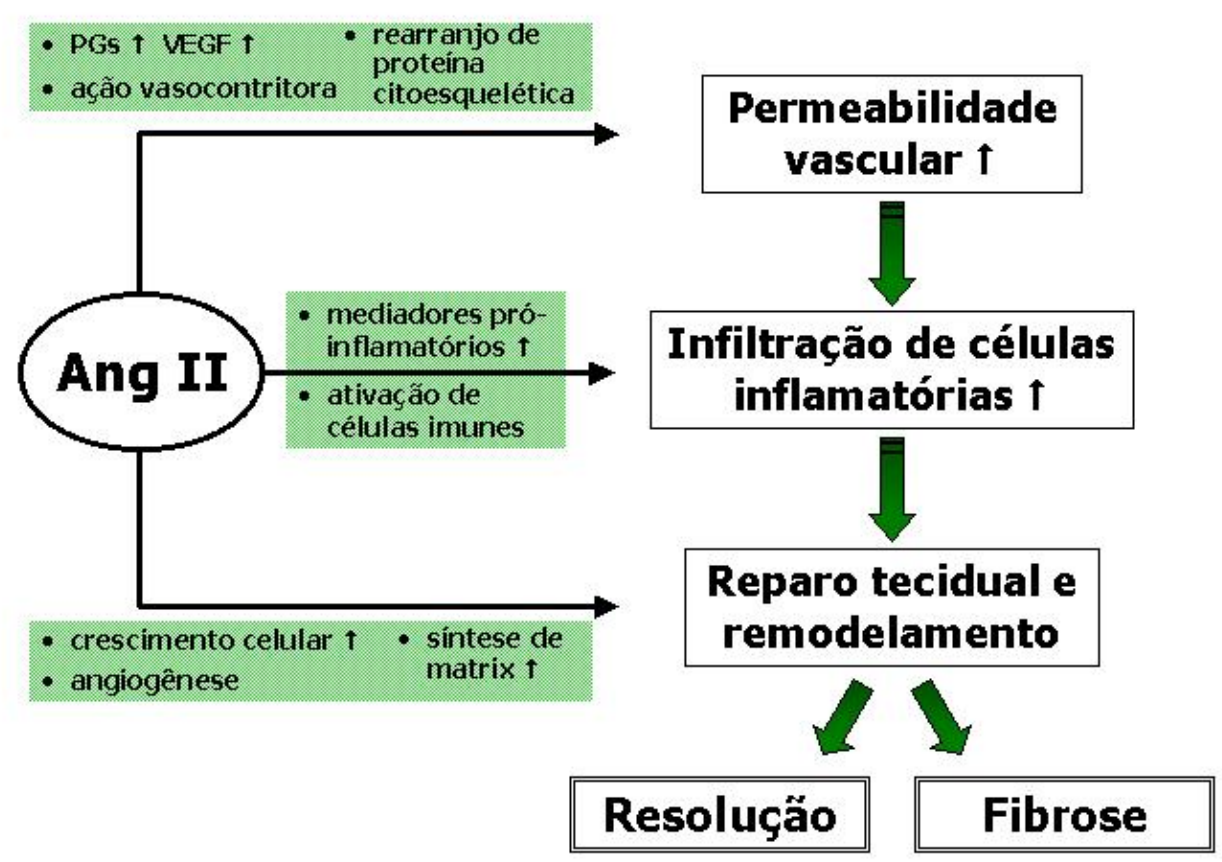

Figura 2: Ang II participa em importantes eventos da resposta inflamatória (modificado de Suzuki et al., 2003). PG - prostaglandinas; VEGF - fator de crescimento endotelial vascular.

\subsection{Drogas que afetam o SRA utilizadas neste estudo}

A alteração da atividade do SRA é alvo constante para o tratamento da hipertensão e falência cardíaca. Várias drogas são empregadas com este intuito, incluindo inibidores da ECA, antagonistas/bloqueadores dos receptores da Ang II e inibidores de renina (Nussberger 2008).

O losartan foi o primeiro antagonista do receptor de angiotensina sem propriedades agonistas. Após administração via oral, é rapidamente absorvido, atingindo a máxima concentração após 1 a 2 horas. É administrado como uma pró-droga que é convertida em seu metabólito ativo E3174, o qual tem uma meiavida de várias horas sofrendo principalmente clearance renal. O losartan é efetivo na redução da pressão arterial e útil na diminuição da progressão da nefropatia devida ao diabetes e à doença renal avançada (Sica 2005).

Alisquireno é um inibidor da renina potente e seletivo que se liga ao sítio ativo da renina impedindo que esta exerça a sua função catalítica, inibindo assim a conversão do angiotensinogênio em Ang I, como conseqüência reduzindo as concentrações de Ang II (O’Brien 2007). O pico plasmático ocorre de 1 a 3 horas 
após a ingestão da droga, que é principalmente eliminada pelo trato hepatobiliar como droga não metabolizada (Waldmeier 2007).

O enalapril (maleato de enalapril) é uma pró-droga que é hidrolisada por esterases no fígado, produzindo sua forma ativa: o enalaprilato, que é um inibidor altamente potente da ECA. O pico de concentração plasmática da droga (forma ativa) acontece cerca de três a quatro horas após a ingestão. Em virtude de sua forte ligação à ECA tem meia-vida plasmática de cerca de 11 horas, sendo excretado na forma de enalapril inalterado ou enalaprilato pelos rins. (Goodman e Gilman, 2007).

A figura 3 ilustra em que pontos da cascata do SRA atuam as drogas utilizadas neste estudo.

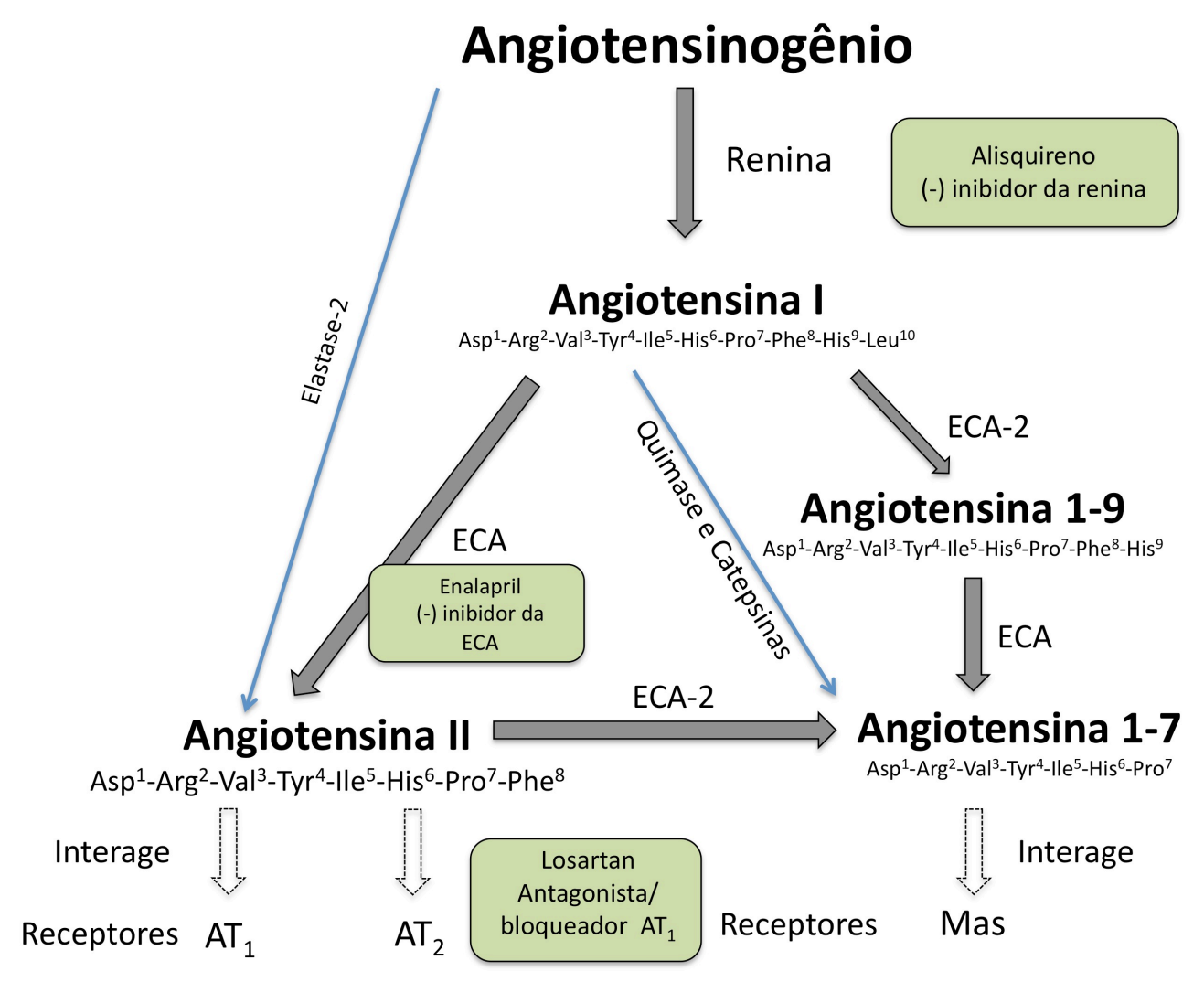

Figura 3 - Principais componentes do sistema renina-angiotensina com os pontos de atuação das drogas utilizadas neste estudo (alisquireno, losartan e enalapril). 


\subsection{Modelos animais para estudo da doença periodontal}

A pesquisa da doença periodontal requer o uso de animais de laboratório para o teste de agentes terapêuticos e para a avaliação da segurança e eficácia de técnicas, drogas e ferramentas. Pelo fato da maior parte das doenças periodontais resultarem em destruição irreversível do tecido conjuntivo e do osso alveolar, a indução da periodontite em humanos não representa um procedimento ético. Portanto, os modelos animais, nos quais a doença periodontal é induzida experimentalmente, continuarão indispensáveis para o estudo desta doença. A facilidade de manejo, o custo relativamente baixo e o curto período de tempo de estudo fazem do rato um instrumento versátil para estudo da doença periodontal (Madden e Caton, 1994). Neste projeto utilizou-se um modelo animal de indução de doença periodontal em ratos, conforme publicações recentes de nosso grupo (Rodini et al., 2008; Oliveira et al., 2008; Santos et al., 2009). 



\section{Proposição}





\section{PROPOSIÇÃO}

Com o intuito de trazer contribuições para um melhor entendimento da DP, os objetivos desta tese foram:

1) avaliar se drogas que afetam o SRA alteram a progressão da DP induzida experimentalmente em ratos;

2) avaliar se há um aumento da expressão dos componentes do SRA na DP induzida experimentalmente em ratos. 

Material e Métodos 



\section{Material e Métodos}

\subsection{Animais e caracterização dos grupos experimentais}

Foram utilizados 160 ratos Wistar, machos, com peso entre 200 e $250 \mathrm{~g}$ (aproximadamente 60 dias), provenientes do Biotério Central da Faculdade de Odontologia de Bauru, Universidade de São Paulo (FOB/USP), divididos em quatro grupos de 40 animais cada:

GRUPO 1 (controle-água) - Metade dos animais (20) deste grupo foi submetida à indução da DP por ligadura e a outra metade foi submetida à indução fictícia da DP (sham operados). Os animais deste deste grupo não receberam tratamento farmacológico, foram tratados apenas com o veículo usado para dissolver as outras drogas (água);

GRUPO 2 (losartan) - Metade dos animais (20) deste grupo foi submetida à indução da DP por ligadura e a outra metade foi submetida à indução fictícia da DP (sham operados). Os animais desse grupo foram tratados com antagonista de receptores $A T_{1}$ losartan (50 mg/kg/dia, via gavagem) (Amaral et al., 2001);

GRUPO 3 (alisquireno) - Metade dos animais (20) deste grupo foi submetida à indução DP por ligadura, a outra metade foi submetida à indução fictícia da DP (sham operados). Os animais desse grupo foram tratados com o inibidor da renina alisquireno (30 mg/Kg/dia, via gavagem) (Singh et al., 2008);

GRUPO 4 (enalapril)- Metade dos animais (20) deste grupo foi submetida à indução da DP por ligadura e a outra metade foi submetida à indução fictícia da DP (sham operados). Os animais desse grupo foram tratados com o inibidor da ECA enalapril (10 mg/kg/dia, via gavagem) (Broulik et al. 2001).

As figuras 4, 5, 6 e 7 ilustram a distribuição das amostras dos diferentes grupos de acordo com o tempo de indução da DP, tratamento e análises realizadas nesta tese. 


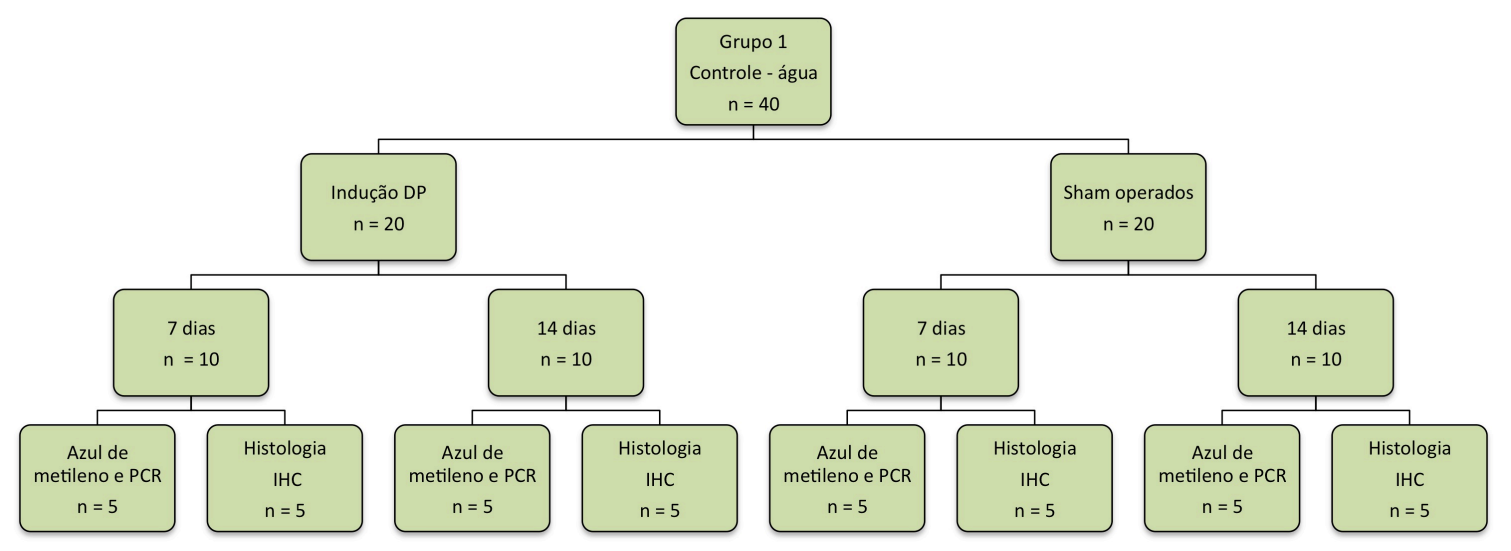

Figura 4 - Grupo 1 (controle - água).

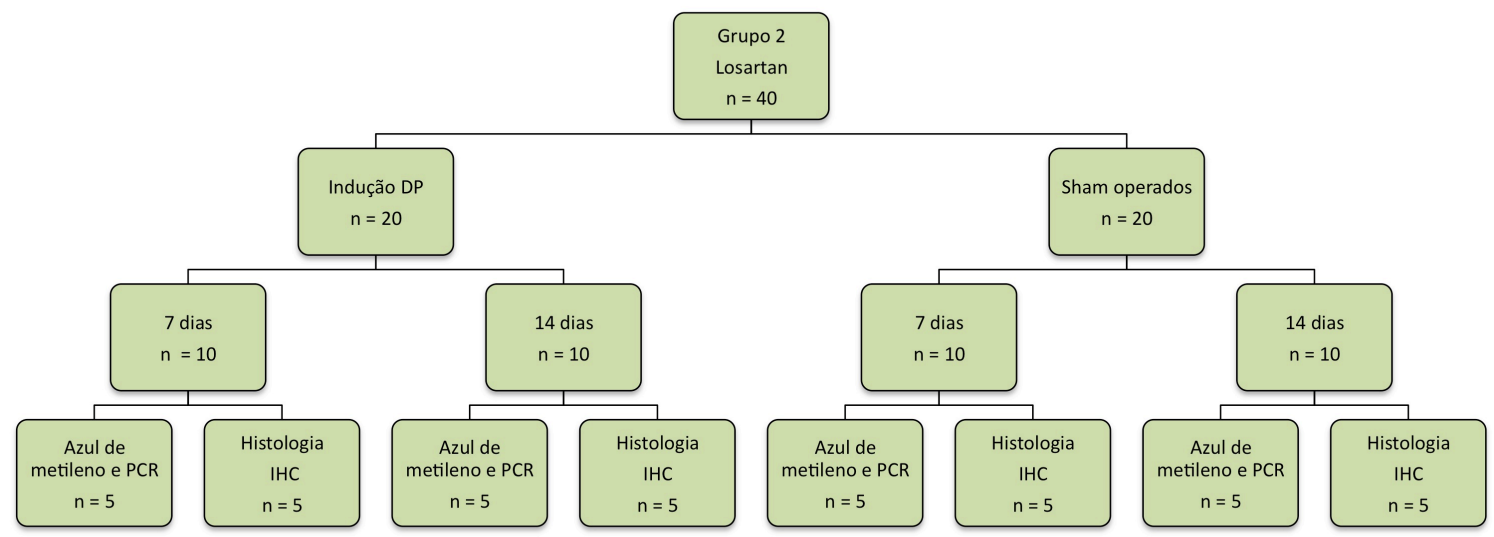

Figura 5 - Grupo 2 - tratados com losartan.

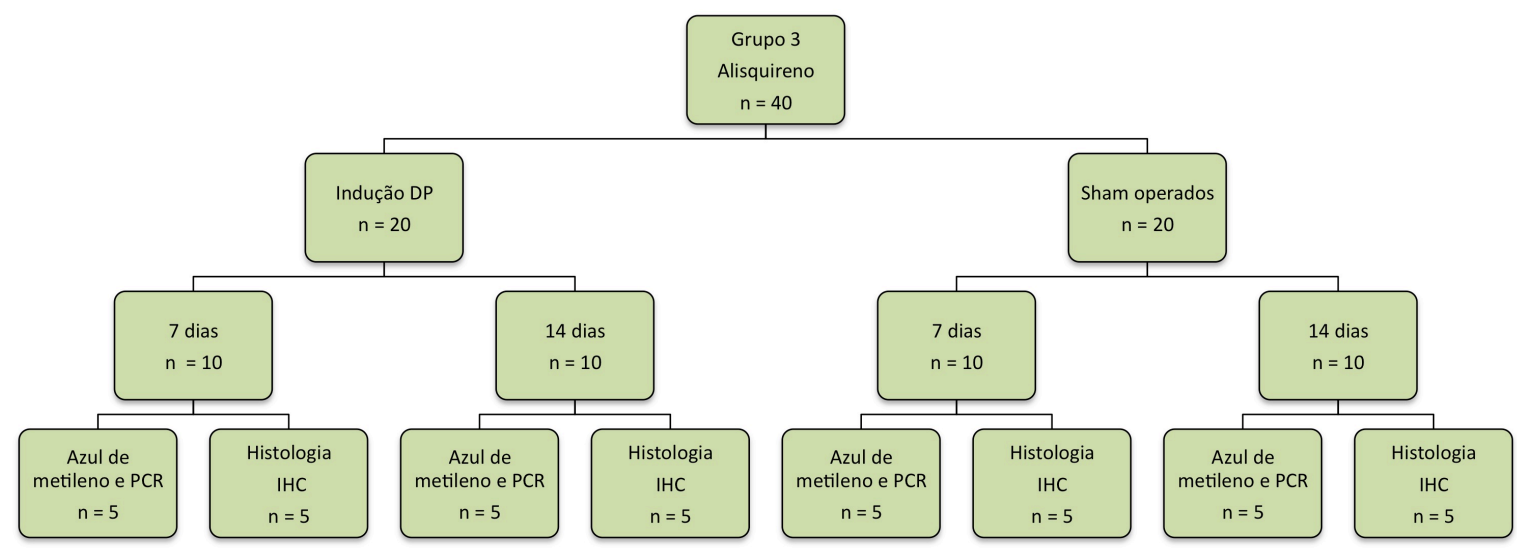

Figura 6 - Grupo 3 - tratados com alisquireno. 


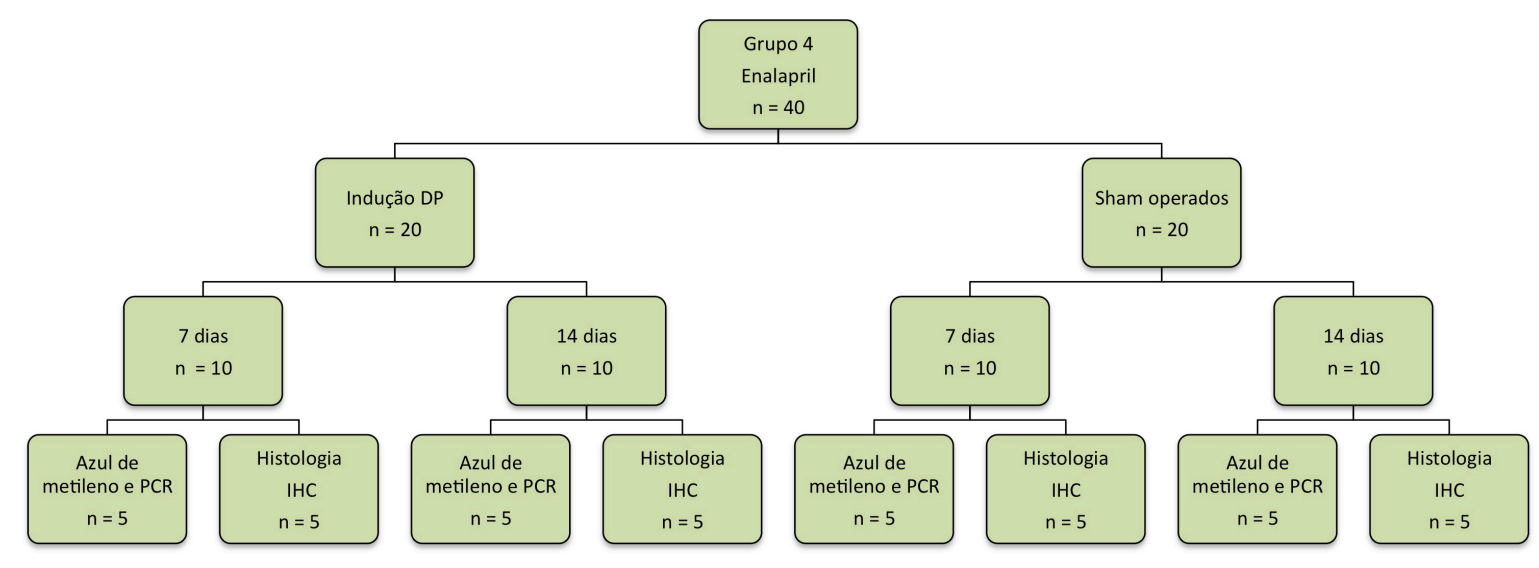

Figura 7 - Grupo 4 - tratados com enalapril

\subsection{DP induzida experimentalmente em ratos}

A manipulação animal seguiu o protocolo aprovado pela Comissão de Ética no Ensino e Pesquisa em Animais da FOB/USP (Processo $n^{\circ}$ 009/2008). Os animais foram anestesiados com Cloridrato de Ketamina e Cloridrato de xilazina (Dopalen® - 0,4 mL/kg e Anasedan $®$ - 0,02 mL/kg, via intramuscular; de Almeida et al., 2007).

A ligadura constituiu-se de fio de seda preta 3-0 estéril e foi colocada na região cervical do primeiro molar inferior direito, tomando-se o cuidado de penetrar o fio no sulco gengival, portanto em íntima proximidade aos tecidos gengivais, ficando o nó na região mesial (Györfi et al., 1994; Lohinai et al., 1998) (Figura 8). Os ratos de todos os grupos foram mantidos no Biotério Central da Faculdade de Odontologia de Bauru/ Universidade de São Paulo (FOB/USP) e alimentados com ração normal e água ad libitum, e medicados via gavagem (Figura 9). 

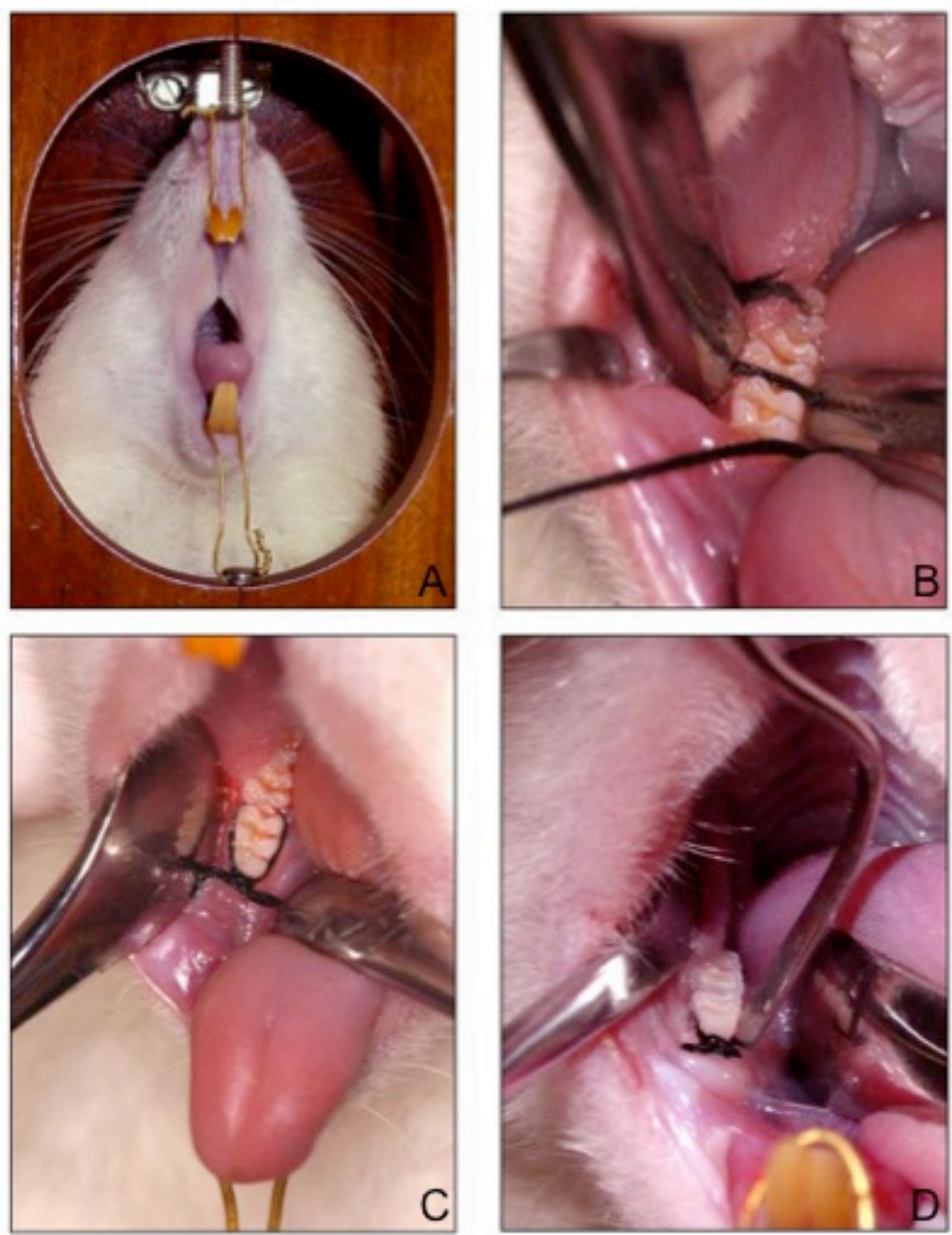

Figura 8 - A e B) Seqüência da colocação da ligadura na região cervical do primeiro molar inferior. C) O nó foi mantido na região mesial e D) o fio inserido em todas as faces do dente (fotos cedidas pela Profa. Dra. Thais Marchini de Oliveira Valarelli da Disciplina de Odontopediatria da FOB/USP). 

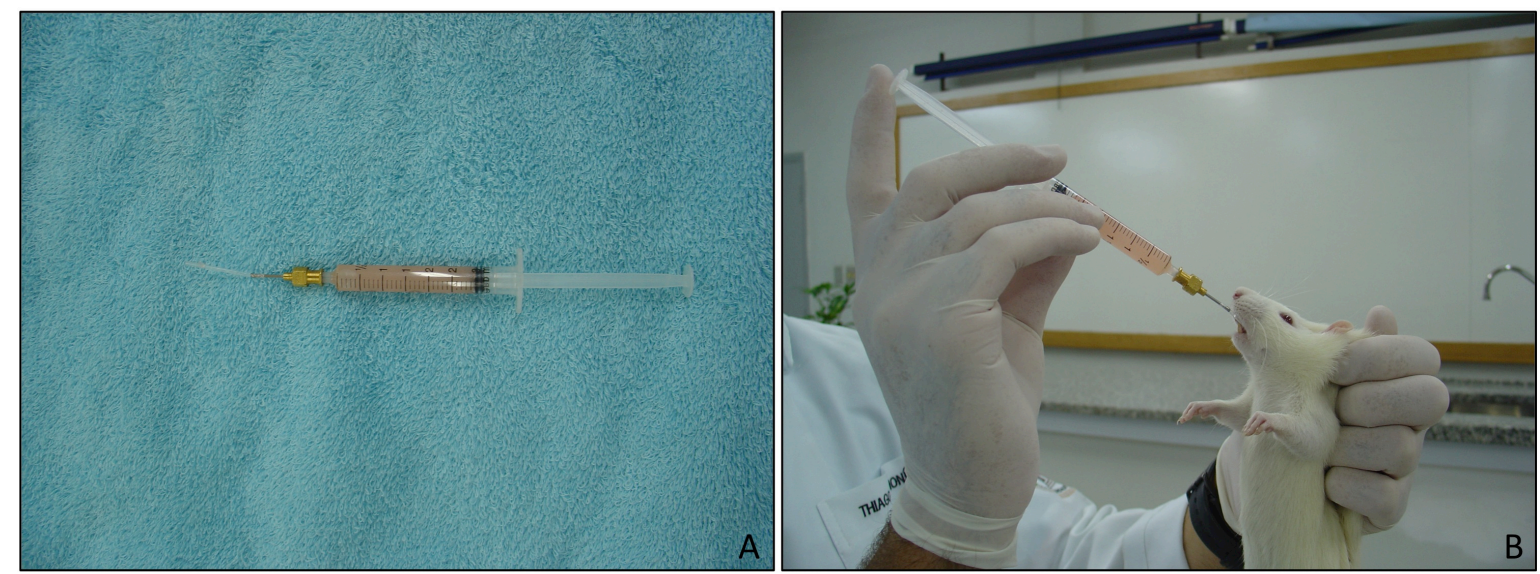

Figura 9 - A) Seringa com a cânula acoplada e B) medicação do animal via gavagem.

\subsection{Obtenção de espécimes para os diferentes experimentos}

Os animais foram mortos com dose excessiva de anestésico nos tempos de 7 e 14 dias após a colocação da ligadura e tratamento com as drogas, durante os tempos citados, procedendo-se à obtenção de espécimes para os diferentes experimentos, que envolveram as seguintes análises durante a progressão da DP:

a) perda óssea alveolar;

b) Reação da cadeia da polimerase (PCR) quantitativa;

c) imunolocalização de proteínas do SRA.

Imediatamente após a morte dos animais a mandíbula foi removida, sendo, então, separada em duas hemimandíbulas. O material destinado à análise da perda óssea alveolar teve o tecido mole cuidadosamente descolado e congelado a $-80^{\circ} \mathrm{C}$ para análises por PCR e teve o tecido ósseo tratado com peróxido de hidrogênio 30 volumes $50 \%$, comforme detalhado a seguir.

O material destinado às análises histológica e imunohistoquímica foi fixado em Formol 10\% por 7 dias, desmineralizado em solução de EDTA 4,13\% (com trocas semanais) por 7 semanas e posteriormente incluído em parafina em blocos de aproximadamente $8 \times 10 \times 6 \mathrm{~mm}$ (contendo o primeiro molar inferior). 


\subsection{Análises realizadas}

\subsubsection{Análise da Perda Óssea Alveolar}

Para avaliação da perda óssea alveolar, as hemimandíbulas foram tratadas com solução de peróxido de hidrogênio 30 volumes $50 \%$ em água, por 24 horas, para remoção do restante do tecido mole aderido ao tecido ósseo, lavadas em seguida com solução salina tamponada em fosfato (PBS) 1x e deixadas para secar em temperatura ambiente. O material foi então imerso em azul de metileno $0,1 \%$, por 5 minutos, para que se pudesse diferenciar o osso do dente. Em seguida, as imagens foram capturadas com auxílio de uma câmera de vídeo (Sony CCD-IRIS/RGB), acoplada a um microscópico (MC80Dx, Carl Zeiss), com aumento de $4 \mathrm{x}$, com a face oclusal dos molares posicionada perpendicularmente ao microscópico. As imagens foram armazenadas em arquivos com extensão TIFF com resolução de 300 dpi, recebendo então um código aleatório, de modo que quando fosse realizada a medição o examinador não soubesse a que grupo ou tempo de tratamento a amostra fazia parte. Com o auxílio de um programa de análise de imagens (K 300 - 3.0, Carl Zeiss) foi realizada então a medição da área compreendida entre a junção amelo-cementária (JAC) e as cristas ósseas alveolares mesial e distal, em $\mu^{2}$, e transformada em $\mathrm{mm}^{2}$ correspondentes aos pixels contidos na área selecionada (Figura 10). Para cada amostra, a perda óssea foi definida como a área total entre a JAC e as cristas ósseas alveolares mesial e distal da face vestibular do primeiro molar inferior direito. 


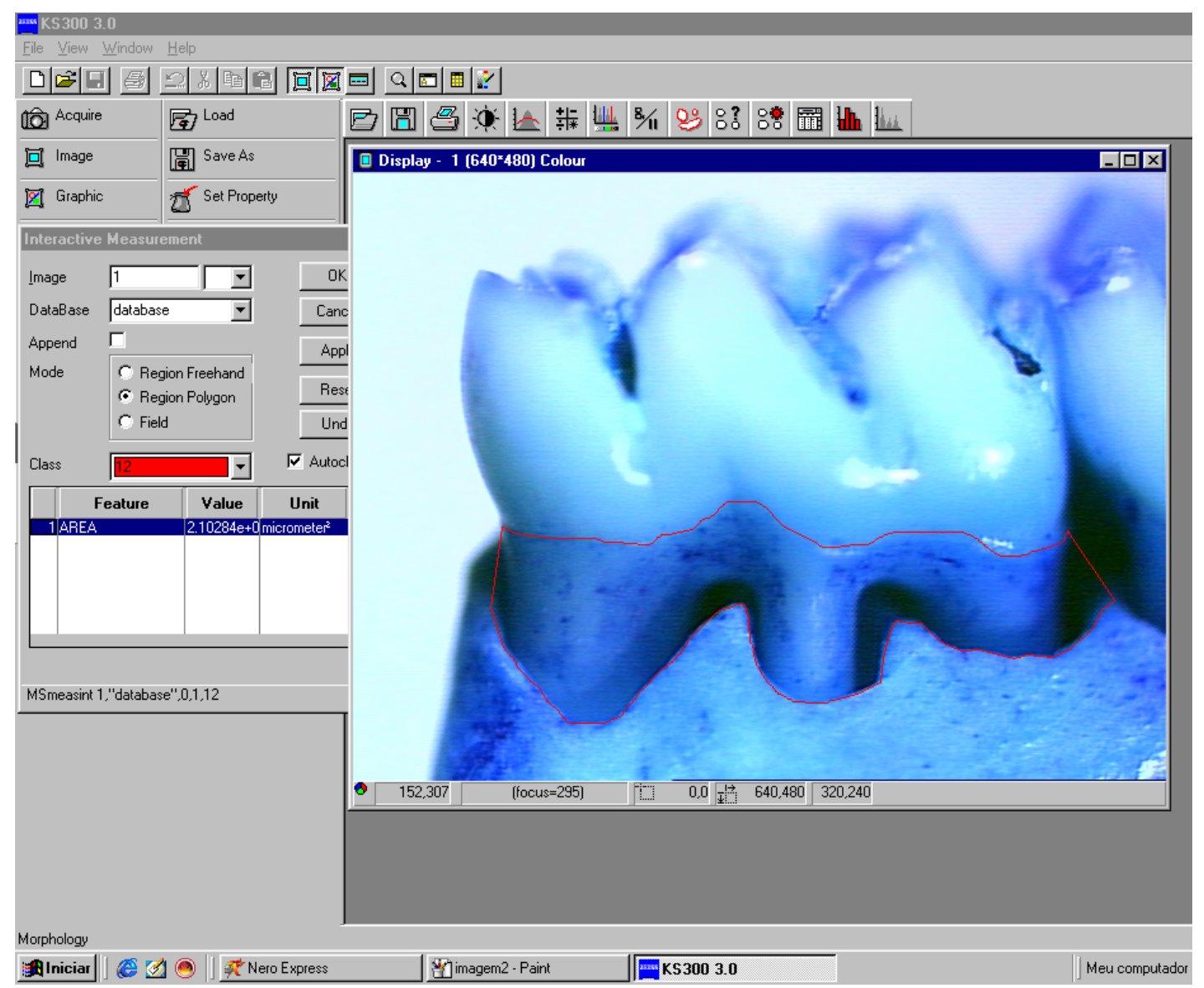

Figura 10 - Delimitação da área analisada (traçado em linha vermelha), compreendida entre a junção amelo-cementária e as cristas ósseas alveolares mesial e distal.

\subsubsection{Erro do método para medida da perda óssea alveolar}

Para estimar o valor do erro sistemático inter e intra-examinador a perda óssea alveolar foi analisada por 2 examinadores distintos e após 30 dias da análise inicial um terço da amostra foi novamente estudada. $O$ teste t pareado foi utilizado para cálculo do erro inter-examinador sistemático do método, obtido por 2 examinadores e o teste t pareado para avaliar o erro intra-examinador, obtido em duas análises distintas com intervalo de 30 dias. Valores de $p>0,05$ foram considerados para estimar a viabilidade de utilização do método proposto. 


\subsubsection{Extração de RNA total das biópsias de tecido gengival}

Para a realização destes experimentos, seguimos as descrições realizadas em publicações do nosso laboratório (Santos et al., 2002b; Santos et al., 2003; Oliveira et al., 2008; Rodini et al., 2008; Santos et al., 2009). Logo após a remoção, os tecidos gengivais foram imediatamente colocados em tubos de centrífuga contendo TRIzol (Invitrogen Life Technologies, Estados Unidos) $(0,1 \mathrm{~g}$ de tecido/1,0 mL de TRIzol) e congelados a -80oC até o momento da extração de RNA total pelo método guanidino-isotiocianato-fenol-clorofórmio. No momento oportuno, os tubos foram descongelados e os tecidos homogenizados utilizandose um homogenizador de tecidos. Em seguida, os tubos foram incubados por 5 min a $4^{\circ} \mathrm{C}$ e então foi adicionado um volume de $20 \%$ de clorofórmio. Os tubos foram vigorosamente agitados e deixados em repouso a $4^{\circ} \mathrm{C}$ por $5 \mathrm{~min}$, sendo em seguida centrifugados a $13.000 \mathrm{~g}$ por $15 \mathrm{~min}$. A camada superior (fase aquosa) foi recuperada em alíquotas de $400 \mu \mathrm{L}$ que foram colocadas em tubos de microcentrífuga de $1,5 \mathrm{~mL}$ contendo $400 \mu \mathrm{L}$ de isopropanol. Os tubos foram agitados vigorosamente e deixados em repouso a $4^{\circ} \mathrm{C}$ por $15 \mathrm{~min}$. Após centrifugação a $13.000 \mathrm{~g}$ por $10 \mathrm{~min}$ a $4^{\circ} \mathrm{C}$, foi descartado o sobrenadante e foi adicionado $1 \mathrm{~mL}$ de etanol 70\% [em água com dietil pirocarbonato (DEPC) 0,1\%], agitando-se vigorosamente. Foi realizada centrifugação a $8.000 \mathrm{~g}$ por $5 \min$ a $4^{\circ} \mathrm{C}$, descartando-se o sobrenadante e repetindo-se outra centrifugação com $1 \mathrm{~mL}$ de etanol $70 \%$ a $8.000 \mathrm{~g}$ por $5 \mathrm{~min}$ a $4^{\circ} \mathrm{C}$. Para permitir a secagem das amostras, o sobrenadante foi descartado e os tubos foram deixados abertos em temperatura ambiente por 5 min dentro de uma capela de fluxo laminar vertical (para impedir a contaminação das amostras). O precipitado de RNA foi ressuspenso em um volume de $30 \mu \mathrm{L}$ de água livre de DNAase e RNAase tratada com DEPC 0,1\%.

\subsubsection{Quantificação e qualificação do RNA total}

Para a quantificação do RNA total das amostras foi utilizado o espectofotômetro Nanodrop 1000 Thermo Scientific (USA). Foram utilizados $2 \mu \mathrm{L}$ de cada amostra para obtenção das leituras nos comprimentos de onda de 260 $\mathrm{nm}$ (A260) e $280 \mathrm{~nm}$ (A280), os quais forneceram informações sobre a quantidade 
e qualidade do RNA. Amostras com valores entre 1,9 e 2,1 na relação A260/A280 foram transcritas.

\subsubsection{Tratamento do RNA total com DNAse e transcrição reversa}

Para evitar a possibilidade de contaminação do RNA total extraído de diferentes tecidos e células por DNA genômico, procedeu-se o tratamento de todas as amostras com DNase (gDNA wipeout - Qiagen, Alemanha) durante 2 minutos a $42^{\circ} \mathrm{C}$ sendo este procedimento realizado segundo as orientações do fabricante. As amostras com $1 \mu \mathrm{g}$ de RNA total cada foram tratadas com DNAse e imediatamente submetidas ao processo de transcrição reversa com o kit Quantitect ${ }^{\circledR}$ Reverse Transcription (Qiagen).

Neste RNA tratado com DNAse foi adicionado uma mistura $1 \mu \mathrm{L}$ dos primers randômicos e oligo $\mathrm{dT}, 1 \mu \mathrm{L}$ da trancriptase reversa e $4 \mu \mathrm{L}$ do tampão Quantscript RT. Esta mistura foi incubada à $42^{\circ} \mathrm{C}$ por 30 minutos, seguido de outra incubação a $95^{\circ} \mathrm{C}$ por 3 minutos.

\subsubsection{Reação em Cadeia da Polimerase (PCR) quantitativa}

O protocolo para PCR quantitativa foi realizado conforme padronização estabelecida por trabalhos prévios (Garlet et al., 2004; Garlet et al., 2006). A expressão quantitativa dos componentes do SRA foi analisada por meio de reações de PCR em tempo real, utilizando-se o sistema Taqman (Applied Biosystems, Foster City, USA) em um aparelho Viia 7 (Applied Biosystems, Foster City, USA). Os primers utilizados (Applied Biosystems, Foster City, USA) para tais reações são apresentados na Figura 11. Esse sistema realiza as reações de amplificação e detecção e quantifica as amostras (Viia 7 Software versão 1.1) por meio de nucleases fluorogênicas utilizadas na reação, sendo tal expressão normalizada com base em controles. A expressão foi normalizada pelo RNAm de RPL13A. O DNA complementar sintetizado a partir do RNA mensageiro foi utilizado juntamente com reagentes Taqman, como determinado pelo fabricante. A reação compreende 2 min a $50^{\circ} \mathrm{C}, 10$ minutos a $95^{\circ} \mathrm{C}, 50$ ciclos de $15 \mathrm{~s}$ a $95^{\circ} \mathrm{C}$ e $1 \mathrm{~min}$ a $60^{\circ} \mathrm{C}$. 


\begin{tabular}{|cc|}
\hline $\begin{array}{c}\text { Alvo } \\
\text { ratRPL13A }\end{array}$ & $\begin{array}{c}\text { Número de catálogo } \\
\text { Rn00821258_g1 }\end{array}$ \\
\hline AT1 $\mathbf{a}$ & Rn00578456_m1 \\
\hline AT1 & Rn02132799_s1 \\
\hline AT2 & Rn00560677_s1 \\
\hline ECA & Rn00561094_m1 \\
\hline Elastase-2 & Rn00561147_m1 \\
\hline
\end{tabular}

Figura 11 - Número de catálogo dos kits de PCR inventoriados (Applied Biosystems) utilizados nesta pesquisa.

\subsubsection{Análise imunoistoquímica}

Os blocos de parafina tiveram seus cortes histológicos obtidos com $5 \mu \mathrm{m}$ de espessura, em micrótomo rotatório, de acordo com a rotina do Laboratório de Histologia da FOB/USP, como utilizada em outros trabalhos (Rodini et al., 2008; Oliveira et al., 2008), resultando em cortes mésio-distais, sendo aderidos às lâminas de vidro comuns para microscopia (Corning ${ }^{\circledR}$ ), e então corados com hematoxicilina e eosina, e às lâminas silanizadas (DaKo® $S$ 3003) para imunoistoquímica.

\subsubsection{Imunolocalização para renina, AT1, AT2 e ECA}

Os cortes histológicos para a realização da análise imunoistoquímica aderidos às lâminas silanizadas (cola à base de poli-D-lisina) tiveram seu protocolo validado no Medical College of Wisconsin durante o programa de Estágio de Doutorado no Exterior com bolsa concedida pela CAPES (processo 2435/09-9). Os cortes foram colocados na estufa a $65^{\circ} \mathrm{C}$ por $2 \mathrm{~h}$ para o início da desparafinização e adesão à lâmina. Em seguida, as lâminas foram acomodadas 
em cubas de Coopler com ranhuras e passaram por dois banhos de xilol, de 5 min cada, e banhos de etanol 95\%, 80\%, 70\%, 60\% e 30\% de 2 min cada. Por último foram deixadas em banho de água destilada.

As lâminas foram transferidas para bandejas e permaneceram em agitador onde passaram então por bloqueador da proteína avidina (por $30 \mathrm{~min}$ ) e lavagem cuidadosa com solução salina tamponada em tris (TBS) e então por bloqueador de biotina, também por $30 \mathrm{~min}$. Em seguida foram gotejados os bloqueadores de proteínas livres, soro de cavalo ou cabra dependendo da espécie em que o anticorpo secundário foi desenvolvido, diluídos $10 \%$ em TBS, por $30 \mathrm{~min}$. Os anticorpos primários disponíveis comercialmente (Figura 12) para os alvos estudados, devidamente diluídos em TBS pH 7,3, foram então pingados sobre as lâminas ficando em câmara úmida por $1 \mathrm{~h}$ em temperatura ambiente. Os cortes foram cuidadosamente lavados com TBS para receber peróxido de hidrogênio 1,5\% (diluído em metanol) por 30 min e novamente lavados com TBS para em seguida receber o anticorpo secundário biotinilado, ficando por $1 \mathrm{~h}$ em temperatura ambiente. Em seguida os cortes foram lavados com TBS e incubados na solução de estreptavidina-peroxidase por $30 \mathrm{~min}$. Para controle negativo, um dos cortes de cada alvo foi incubado com soro normal de cavalo ou cabra ( $2 \%$ em TBS) em substituição ao anticorpo primário. Após a exposição à solução de estreptavidina-peroxidase, as lâminas foram lavadas com TBS e o excesso aspirado. Gotejou-se a solução diaminobenzidina (DAB), a qual permaneceu em contato com o corte histológico por $3 \mathrm{~min}$. Na seqüência as lâminas foram lavadas com água destilada por 5 min e transferidas para as cubas de Coopler, contracoradas com hematoxilina de Gill por 2,5 min. Depois passaram rapidamente por 10 imersões em ácido acético 2\%, 10 imersões em água destilada, incubadas por 1 min em hidróxido de amônio $\left(\mathrm{NH}_{4} \mathrm{OH}\right)$ e mais 10 imersões em água destilada. Em seguida as lâminas foram lavadas em água destilada e com ranhura e passadas rapidamente por 3 vezes em álcool etílico absoluto e 3 vezes em xilol. A montagem das lâminas feita com resina sintética ENTELAN ${ }^{\circledR}$ (Merck, Darmstadt, Alemanha). A imunomarcação para renina, AT1, AT2 e ECA possibilitou a localização de tais proteínas no tecido analisado e foi atribuído um escore que variou de 0 (sem marcação) a 4 (marcação forte) a cada amostra (Tan et al., 2005). 
Os resultados foram submetidos à Análise de Variância a 2 e 3 critérios (ANOVA), sendo adotado nível de significância de 5\%. Estas proteínas foram expressas em regiões distintas do tecido periodontal e identificadas conforme a proteína-alvo como descrito a seguir.

\begin{tabular}{|c|c|c|c|}
\hline $\begin{array}{l}\text { Proteína } \\
\text { alvo }\end{array}$ & $\begin{array}{l}\text { Bloqueadores de } \\
\text { proteínas livres }\end{array}$ & $\begin{array}{l}\text { Anticorpo primário } \\
\text { (Santacruz) }\end{array}$ & $\begin{array}{c}\text { Anticorpo } \\
\text { secundário } \\
\text { (Vectorlabs) }\end{array}$ \\
\hline Renina & Soro de cavalo & $\begin{array}{c}\text { Renin (E-17) } \\
1: 50\end{array}$ & $\begin{array}{c}\text { Anti-cabra } \\
1: 500\end{array}$ \\
\hline AT1 & Soro de cabra & $\begin{array}{c}\text { AT1 }(\mathrm{N}-10) \\
1: 50\end{array}$ & $\begin{array}{l}\text { Anti-coelho } \\
1: 100\end{array}$ \\
\hline AT2 & Soro de cabra & $\begin{array}{c}\text { AT2 }(\mathrm{H}-143) \\
1: 50\end{array}$ & $\begin{array}{c}\text { Anti-coelho } \\
1: 100\end{array}$ \\
\hline ECA & Soro de cavalo & $\begin{array}{c}\text { ACE }(C-20) \\
1: 500\end{array}$ & $\begin{array}{c}\text { Anti-cabra } \\
1: 100\end{array}$ \\
\hline
\end{tabular}

Figura 12 - Anticorpos primários e secundários utilizados para a marcação imunoistoquímica.

\section{Imunomarcação para renina}

Para controle positivo da imunomarcação para renina foi utilizado o rim. A utilização do anticorpo primário para renina neste tecido marcou as células justaglomerulares da arteríola aferente glomerular, que é a região responsável pela produção de renina (Bader, 2010).

\section{Imunomarcação para AT1}

Para controle positivo da imunomarcação para o receptor AT1 foi utilizada a glândula adrenal. A utilização do anticorpo primário para o receptor AT1 neste tecido marcou a região medular (Sanchez-Lemus, 2008).

\section{Imunomarcação para AT2}

Para controle positivo da imunomarcação para o receptor AT2 foi utilizada a glândula adrenal. A utilização do anticorpo primário para o receptor AT2 neste tecido marcou a região cortical (Nora et al., 1998; Sanchez-Lemus, 2008).

\section{Imunomarcação para ECA}

Para controle positivo da imunomarcação para ECA foi utilizado o rim. A utilização do anticorpo primário para ECA neste tecido marcou a região tubular renal (Komlosi et al., 2003). 


\subsection{Análise estatística}

Após a coleta, os dados foram devidamente analisados por meio de gráficos, sendo utilizada ANOVA a 2 e 3 critérios. Todos os testes foram realizados com o programa SIGMASTAT 2.0 (SPSS,Chicago, IL, USA), sendo adotado nível de significância de $5 \%$ para que as diferenças fossem consideradas estatisticamente significativas. 

Resultados 



\section{RESULTADOS}

\subsection{Análise da perda óssea alveolar}

Como dito anteriormente, a análise da perda óssea alveolar foi feita por dois examinadores. Assim, observou-se que erros na verificação da precisão desta metodologia foram admissíveis para erro sistemático intra-examinadores: $p=0,462$ (DP - examinador 1); $p=0,405$ (sham - examinador 1); $p=0,276$ (DP examinador 2); $p=0,117$ (sham - examinador 2) e para erro sistemático interexaminadores: $p=0,399$ (DP -examinador 1 e 2); $p=0,249$ (sham - examinador 1 e 2), promovendo resultados transparentes e fidedignos. Os resultados da perda óssea alveolar foram submetidos à Análise de Variância (ANOVA) a 2 e 3 critérios, sendo adotado nível de significância de $5 \%$.

A análise revelou maior perda óssea nos sítios com doença periodontal quando comparados aos sítios sham operados do grupo 1 controle - água somente no período de 14 dias $(p<0,05)$. (Figura 13).

\section{7 dias}
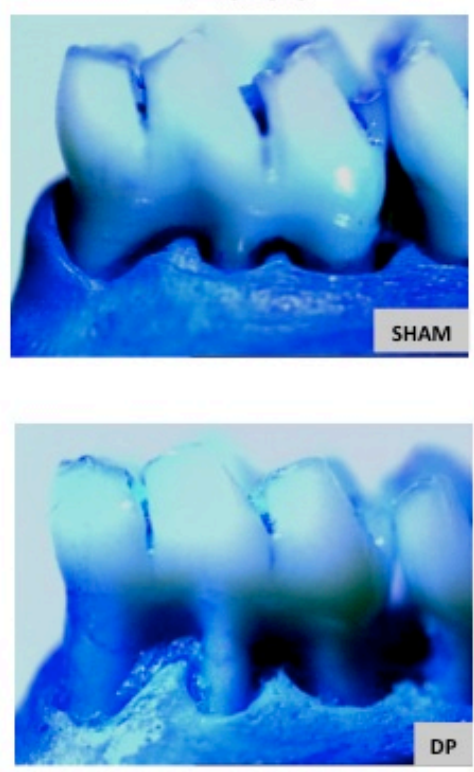

\section{4 dias}
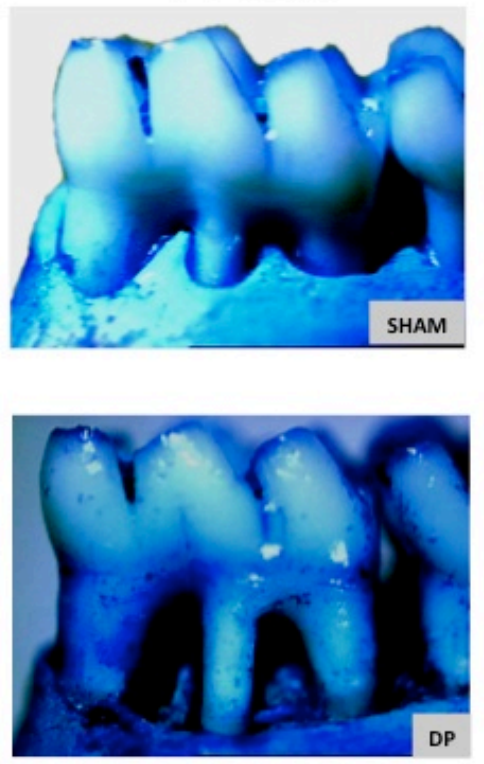

Figura 13 - Progressão da perda óssea alveolar no grupo 1 (controle - água). SHAM: operação fictícia para indução da doença periodontal. DP: doença periodontal induzida experimentalmente. 
O grupo 1 (controle - água) não revelou diferença estatisticamente significativa entre os animais Sham e DP tratados por 7 dias. Quando a indução atingiu 14 dias os animais com doença periodontal (DP) apresentaram maior perda óssea em comparação aos animas DP com apenas 7 dias de indução $(p<0,05)$. Esta maior perda óssea também foi constatada quando comparados os animais sham operados e DP aos 14 dias $(p<0,05)$ (Figura 14).

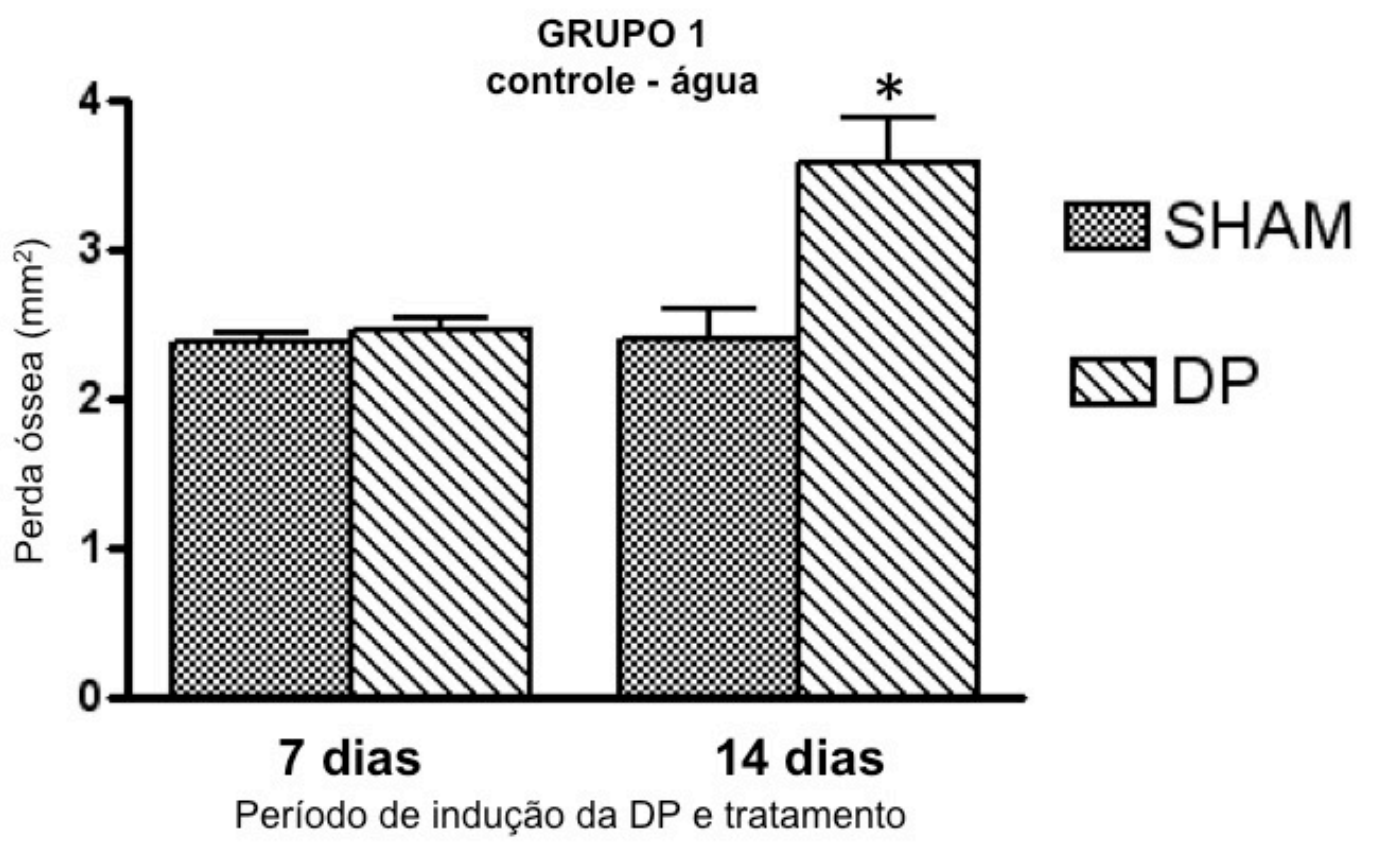

Figura 14 - Representação gráfica da perda óssea alveolar em ratos com tecidos afetados pela doença periodontal e sham ( $\mathrm{n}=5$ em todos os períodos), sem tratamento farmacológico.

SHAM: operação fictícia para indução da doença periodontal. DP: doença periodontal induzida experimentalmente.

$\left.{ }^{*}\right)$ diferença estatisticamente significativa entre sham $\times$ DP- 14 dias $(p<0,05)$; e diferença estatisticamente significativa entre DP - 7dias x DP - 14 dias $(p<0,05)$. 
No grupo tratado com losartan, quando se avaliou a perda óssea não foram observadas diferenças estatisticamente significativas entre os animais sham e DP nos períodos de 7 e 14 dias, comprovando a eficácia do tratamento farmacológico com esta droga (Figura 15).

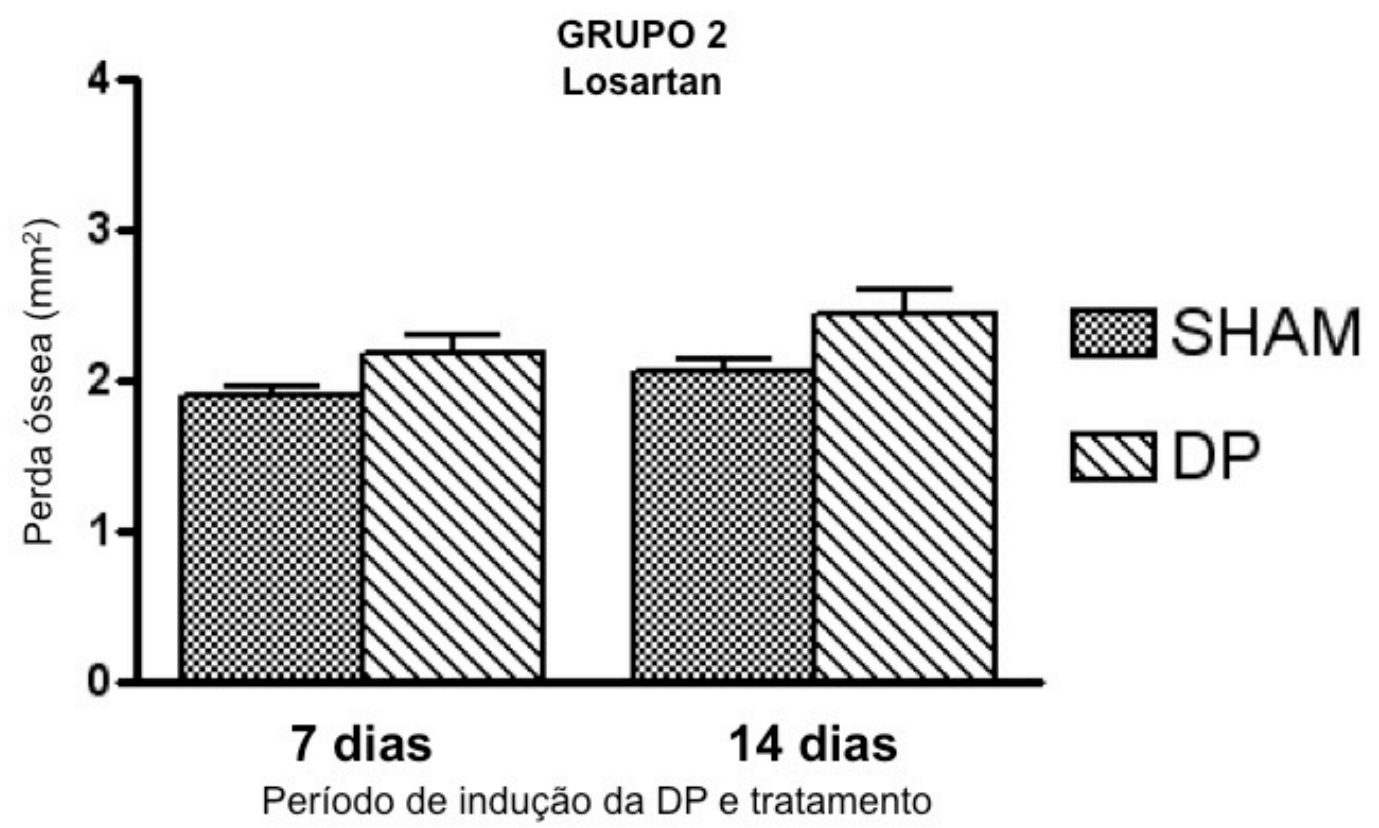

Figura 15 - Representação gráfica da perda óssea alveolar em ratos com tecidos afetados pela doença periodontal e sham ( $\mathrm{n}=5$ em todos os períodos), tratados com losartan $(50 \mathrm{mg} / \mathrm{Kg} / \mathrm{dia}$ via gavagem). SHAM: operação fictícia para indução da doença periodontal. DP: doença periodontal induzida experimentalmente. 
No grupo tratado com alisquireno, quando se avaliou a perda óssea não foram observadas diferenças estatisticamente significativas entre os animais sham e doença periodontal nos períodos de 7 e 14 dias, também comprovando a eficácia do tratamento farmacológico com esta droga (Figura 16).

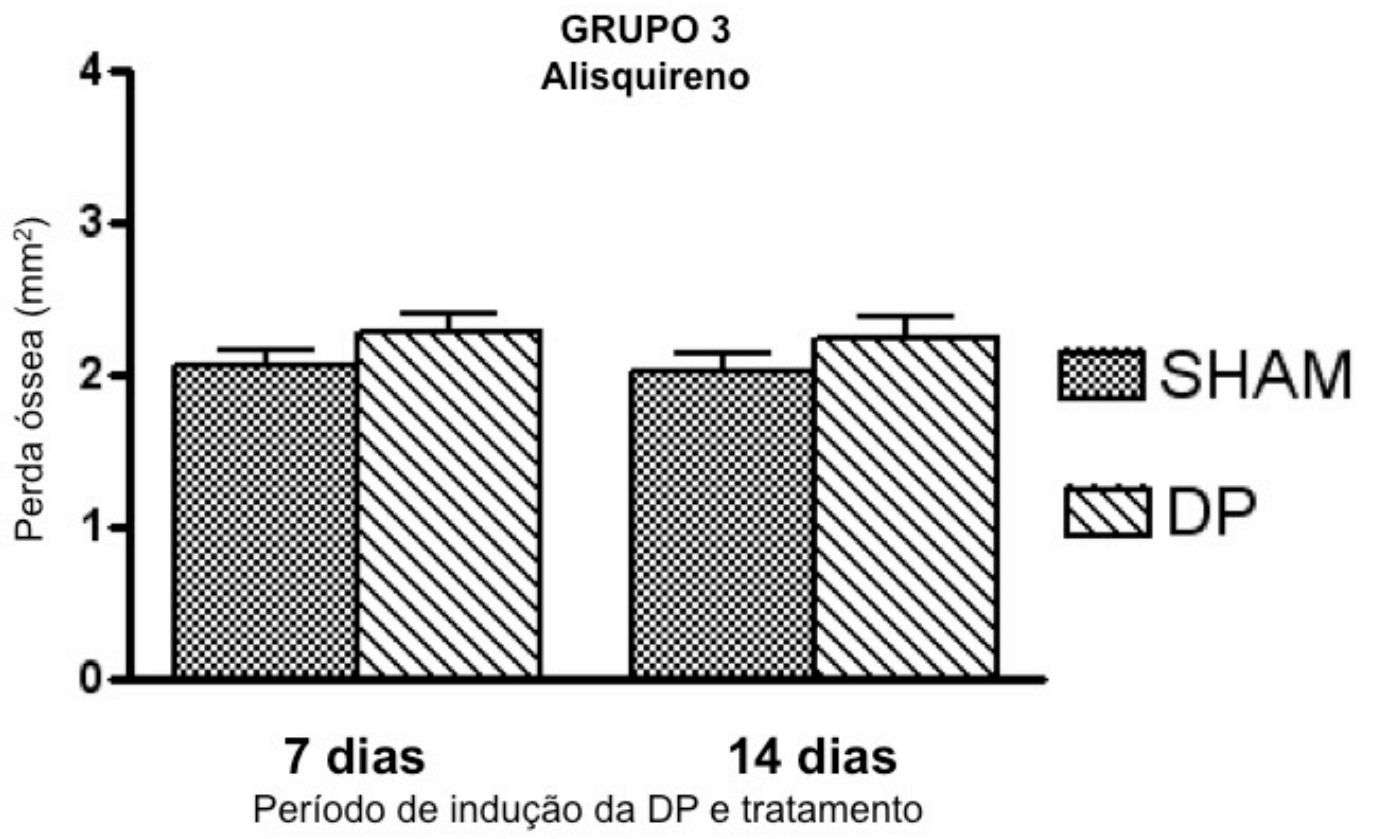

Figura 16 - Representação gráfica da perda óssea alveolar em ratos com tecidos afetados pela doença periodontal e sham ( $\mathrm{n}=5 \mathrm{em}$ todos os períodos), tratados com alisquireno $(30 \mathrm{mg} / \mathrm{Kg} / \mathrm{dia}$ via gavagem). SHAM: operação fictícia para indução da doença periodontal. DP: doença periodontal induzida experimentalmente. 
O grupo tratado com enalaprll somente revelou maior perda óssea nas amostras dos animais com DP no período de 14 dias quando comparados às amostras dos sham operados, mostrando a ineficácia do tratamento farmacológico com esta droga $(p<0,05)$ (Figura 17).

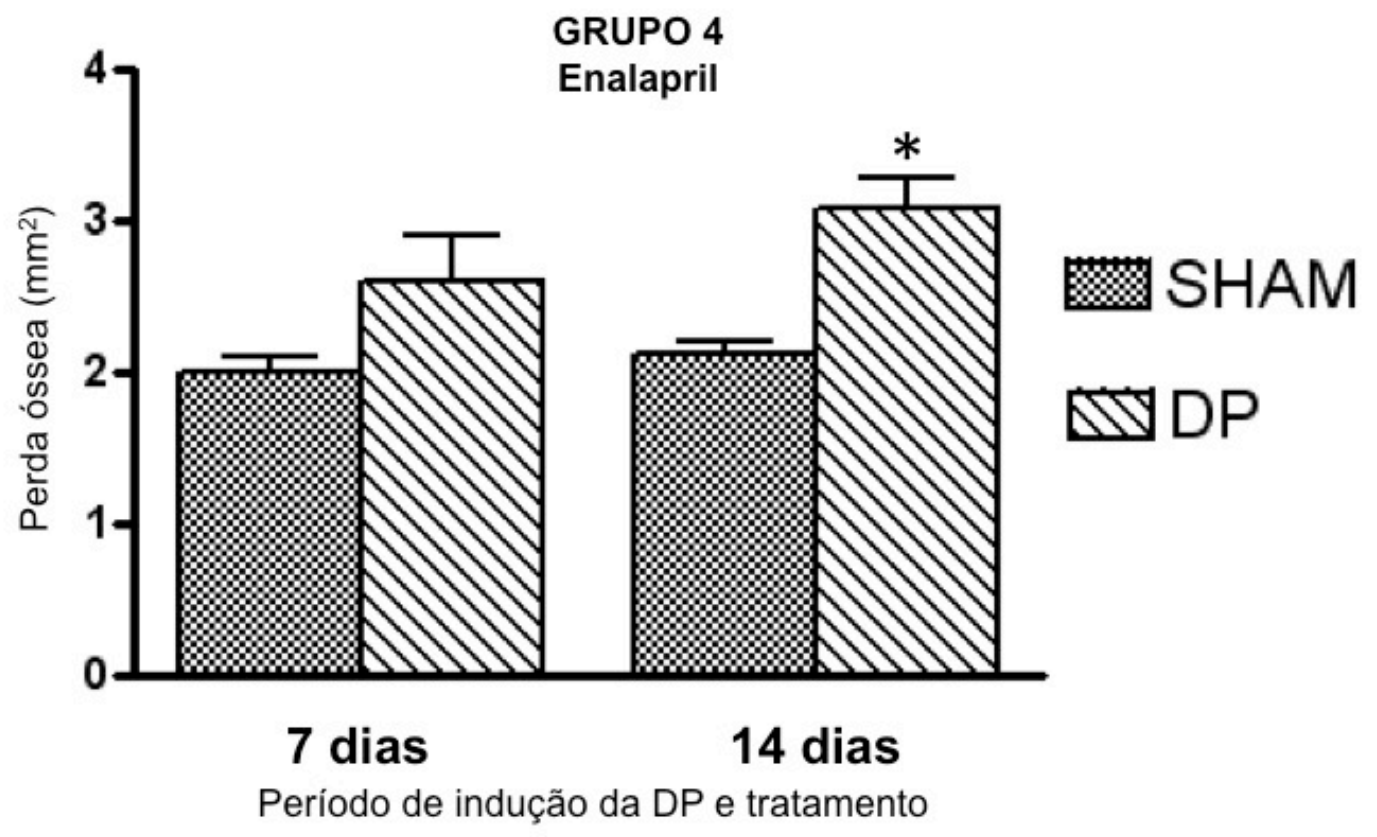

Figura 17 - Representação gráfica da perda óssea alveolar em ratos com tecidos afetados pela doença periodontal e no grupo sham ( $\mathrm{n}=5 \mathrm{em}$ todos os períodos), tratados com enalapril (10 $\mathrm{mg} / \mathrm{Kg} / \mathrm{dia}$ via gavagem). SHAM: operação fictícia para indução da doença periodontal. DP: doença periodontal induzida experimentalmente.

$\left(^{*}\right)$ diferença estatisticamente significativa entre sham x DP - 14 dias $(p<0,05)$. 
Ao se comparar o tempo de indução de 7 e 14 dias para o grupo 1 (controle - água) pode-se observar diferença estatisticamente significativa na progressão da doença periodontal. Esta diferença não foi observada nos grupos 2 (losartan), 3 (alisquireno) e 4 (enalapril). No entanto quando comparados os períodos de 14 dias dos grupos 2 (losartan) e 3 (alisquireno) com grupo 1 (controle - água) 14 dias, foi possível observar diferença estatisticamente significantiva (Figura 18). Esta diferença não ocorreu na comparação do grupo 1 (controle - água) com o grupo 4 (enalapril).
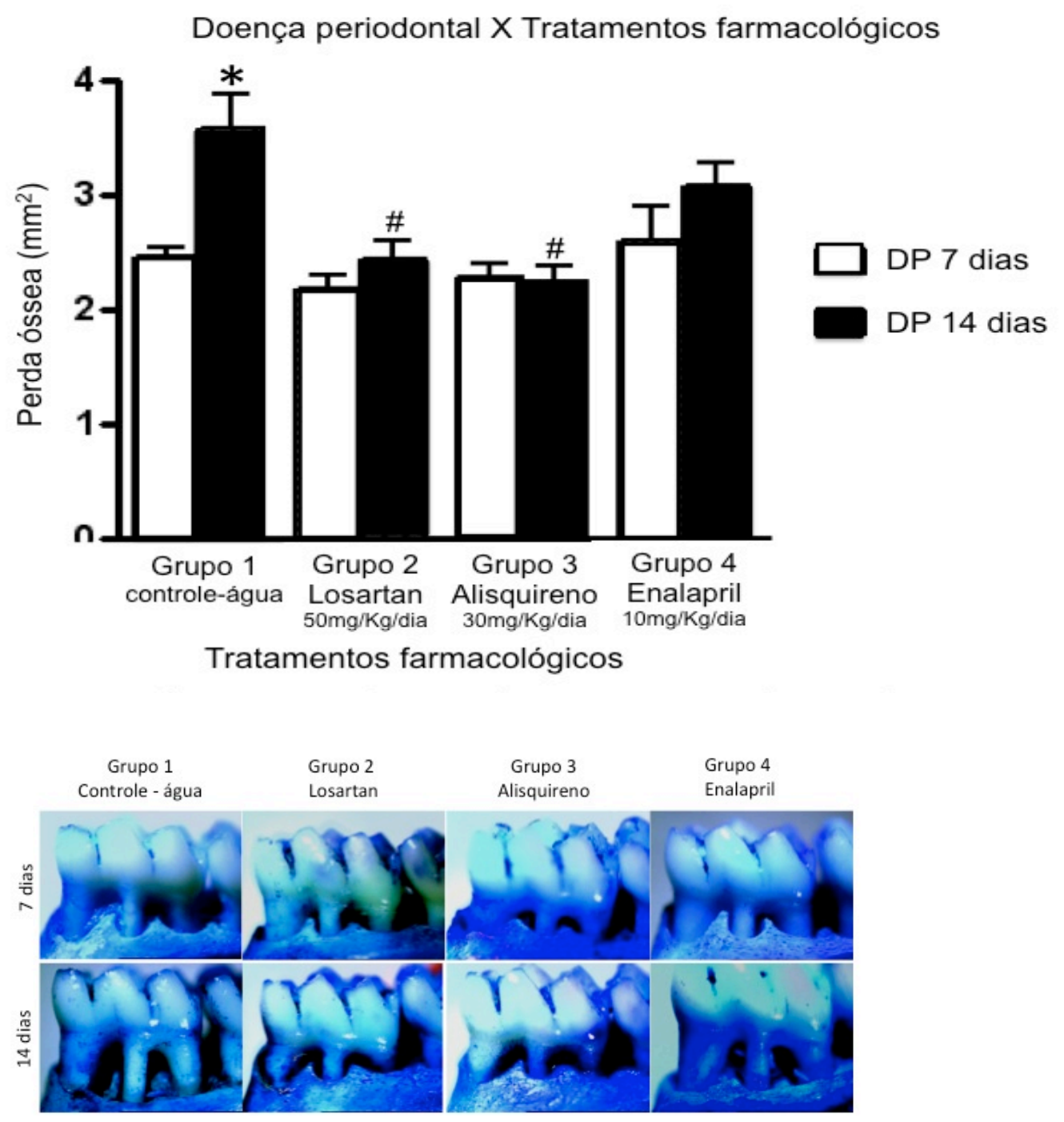

Figura 18 - Representação gráfica (painel superior) e ilustrativa (painel inferior) da perda óssea alveolar em amostras de animais com tecidos afetados pela doença periodontal induzida experimentalmente por 7 e 14 dias ( $n=5$ em todos os períodos), nos diferentes tratamentos farmacológicos. DP: doença periodontal induzida experimentalmente.

$\left({ }^{*}\right)$ diferença estatisticamente significativa entre 7 dias $\times 14$ dias na progressão da doença periodontal no grupo 1 (controle - água) $(p<0,05)$.

(\#) diferença estatisticamente significativa em comparação com o grupo 1 (controle - água) aos 14 dias $(p<0,05)$. 
O método de indução experimental da DP apenas mostrou perda óssea alveolar significativa aos 14 dias, e não aos 7 dias, em comparação com os animais sham operados do grupo 1 , controle - água ( $p<0,05$; Figura 18). A seguir são ilustrados somente os resultados do período de 14 dias (Figura 19).

SHAM E DP 14 DIAS
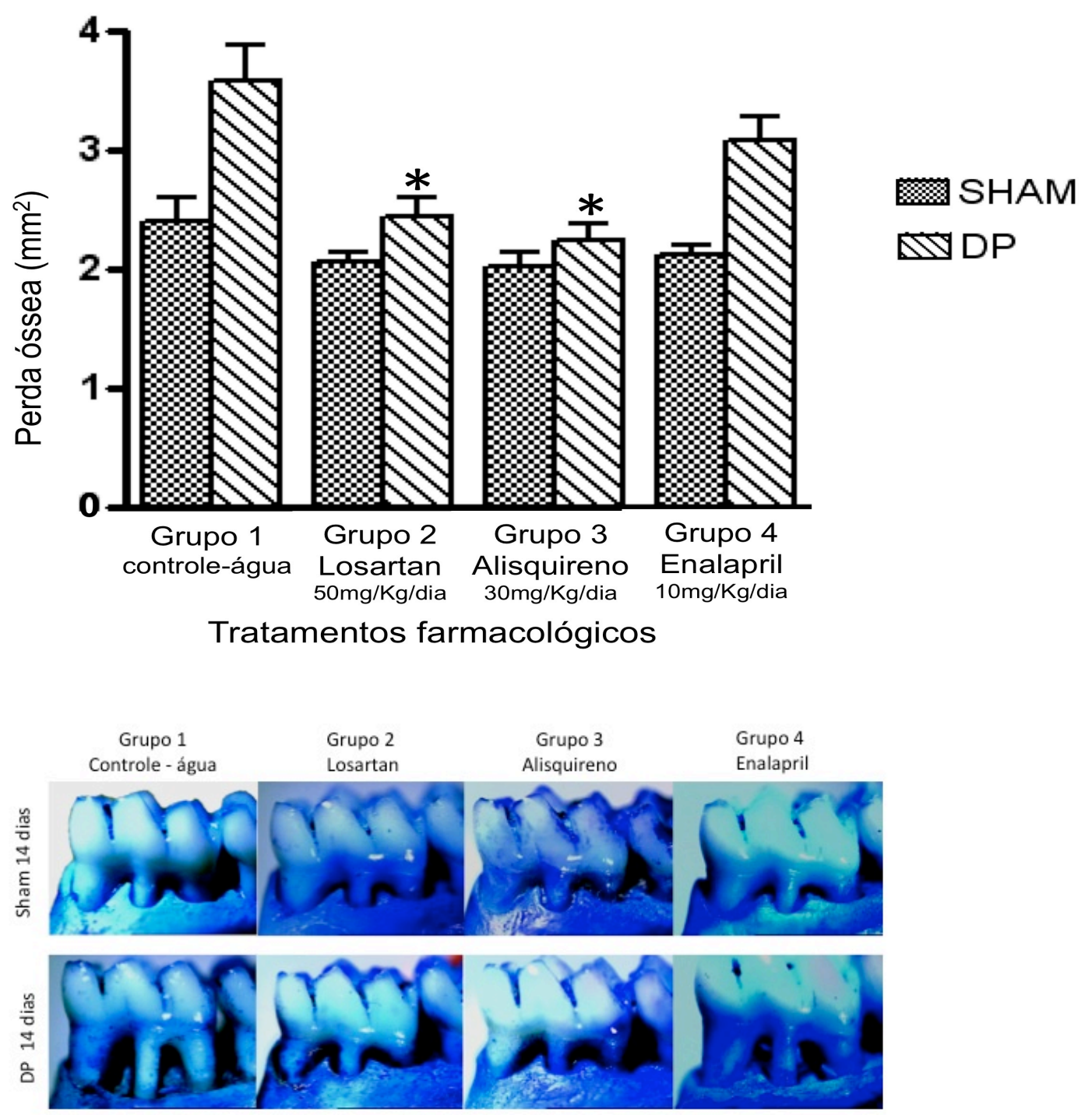

Figura 19 - Representação gráfica (painel superior) e ilustrativa (painel inferior) da perda óssea alveolar em amostras de ratos sham operados e com tecidos afetados pela doença periodontal induzida experimentalmente por 14 dias ( $n=5$ em todos os períodos), nos diferentes tratamentos farmacológicos, em comparação com o grupo 1 (controle - água). SHAM: operação fictícia para indução da doença periodontal. DP: doença periodontal induzida experimentalmente.

$\left(^{*}\right)$ diferença estatisticamente significativa quando comparado ao grupo 1 (controle - água) $(p<0,05)$. 


\subsection{Análise da expressão de RNA}

Os resultados foram analisados com base no valor de Ct (cicle threshold ou ciclo limiar), sendo este o ponto correspondente ao número de ciclos a partir do qual a amplificação atinge um dado limiar que permite a análise quantitativa da expressão do fator avaliado. O limiar para positividade da PCR quantitativa foi determinado com base em controle negativo ou controle água. Os cálculos para a determinação do nível relativo de expressão gênica foram realizados pelo programa Viia 7 versão 1.1 da Applied Biosystems. As médias dos valores de $\mathrm{Ct}$ de medidas em duplicata foram utilizadas para calcular a expressão do gene alvo, com normalização a um controle interno RPL13A, e então comparados utilizando a fórmula (1+eficiência) ${ }^{-\Delta \Delta C t}$, onde a eficiência é de 1 , ou seja $100 \%$, garantida pelo fabricante dos primers utilizados (Applied Biosystems, Foster City, USA).

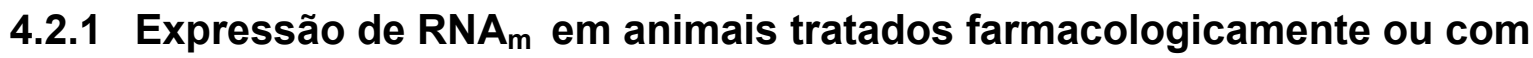 água por 7 dias}

\subsubsection{Expressão de RNA $_{m}$ para Elastase-2 em relação ao RPL13A aos 7 dias}

Os resultados do PCR revelaram a presença de $\mathrm{RNA}_{m}$ para Elastase-2 no tecido gingival, que embora inconsistente não deixam dúvidas a respeito da presença desta enzima no tecido (Figuras 20 e 21). 


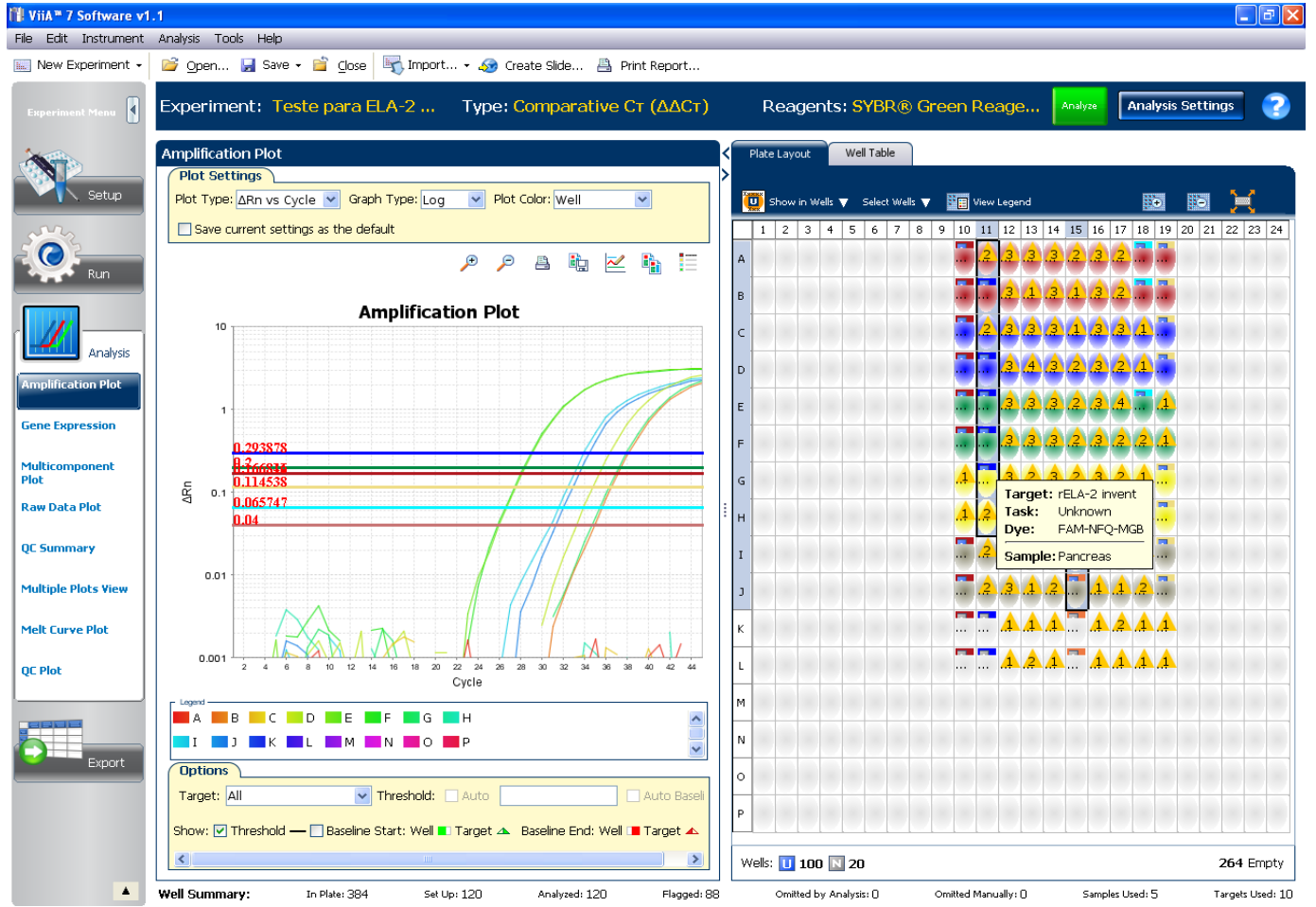

Figura 20 - Representação ilustrativa da amplificação de Elastase-2 nos diversos tecidos: Vermelho = Gengiva; Bege = Fígado; Verde = Pâncreas; Azul = Pulmão .

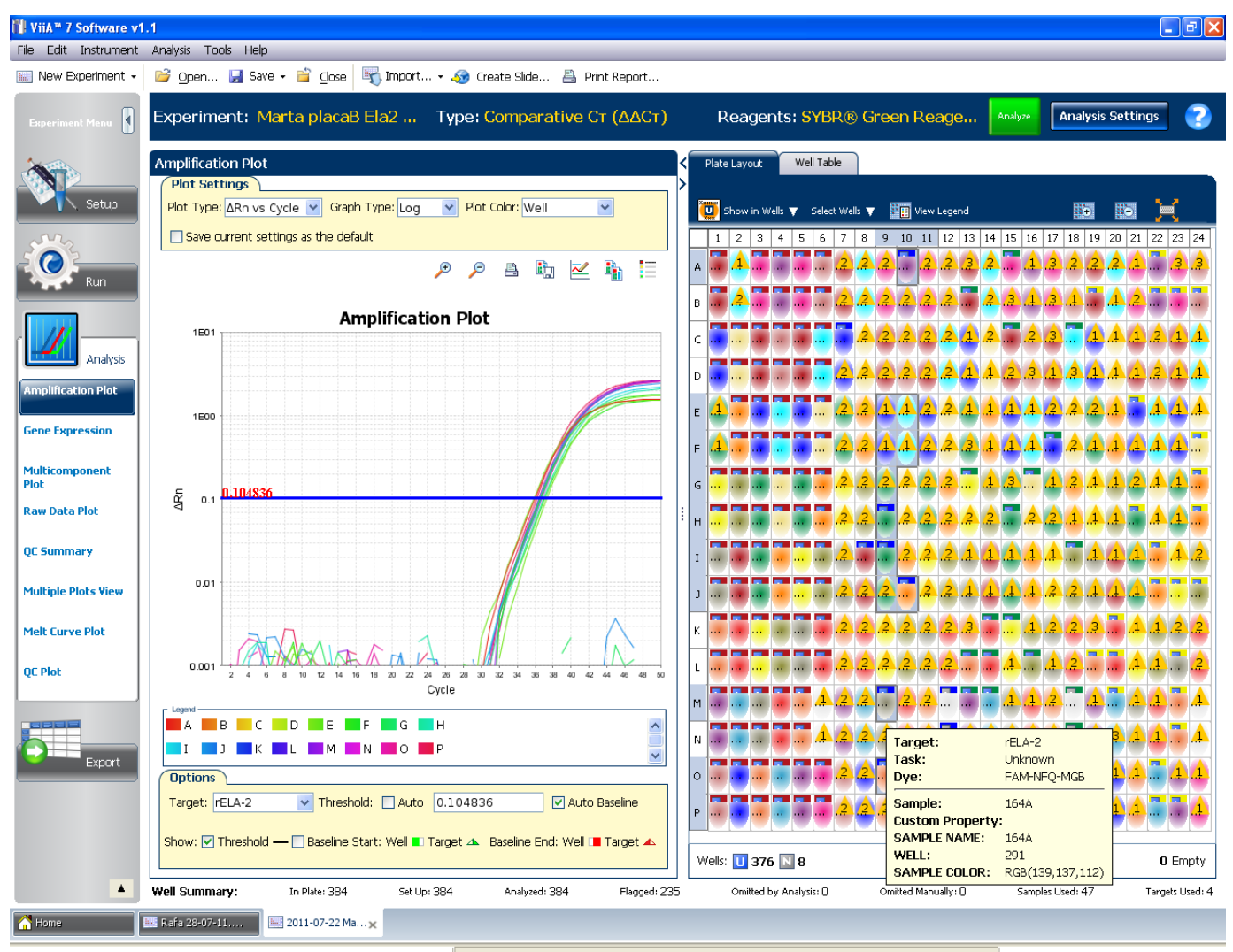

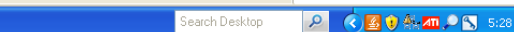

Figura 21 - Representação ilustrativa da amplificação de Elastase-2 na gengiva. 


\subsubsection{Expressão de $\mathrm{RNA}_{\mathrm{m}}$ para $\mathrm{AT}_{1 \mathrm{a}}$ em relação ao $\mathrm{RPL13A}$ aos 7 dias}

Com relação à expressão de $\mathrm{RNA}_{m}$ para $A T_{1 a}$ revelou-se uma maior expressão desse receptor nos animais tratados com losartan (grupo 2) e uma menor expressão desse receptor no grupo tratado com alisquireno (grupo 3) em relação ao grupo 1 (controle-água) aos 7 dias (Figura 22).

$$
\mathrm{AT}_{1 \mathrm{a}} 7 \text { dias - Sham } \times \text { DP }
$$

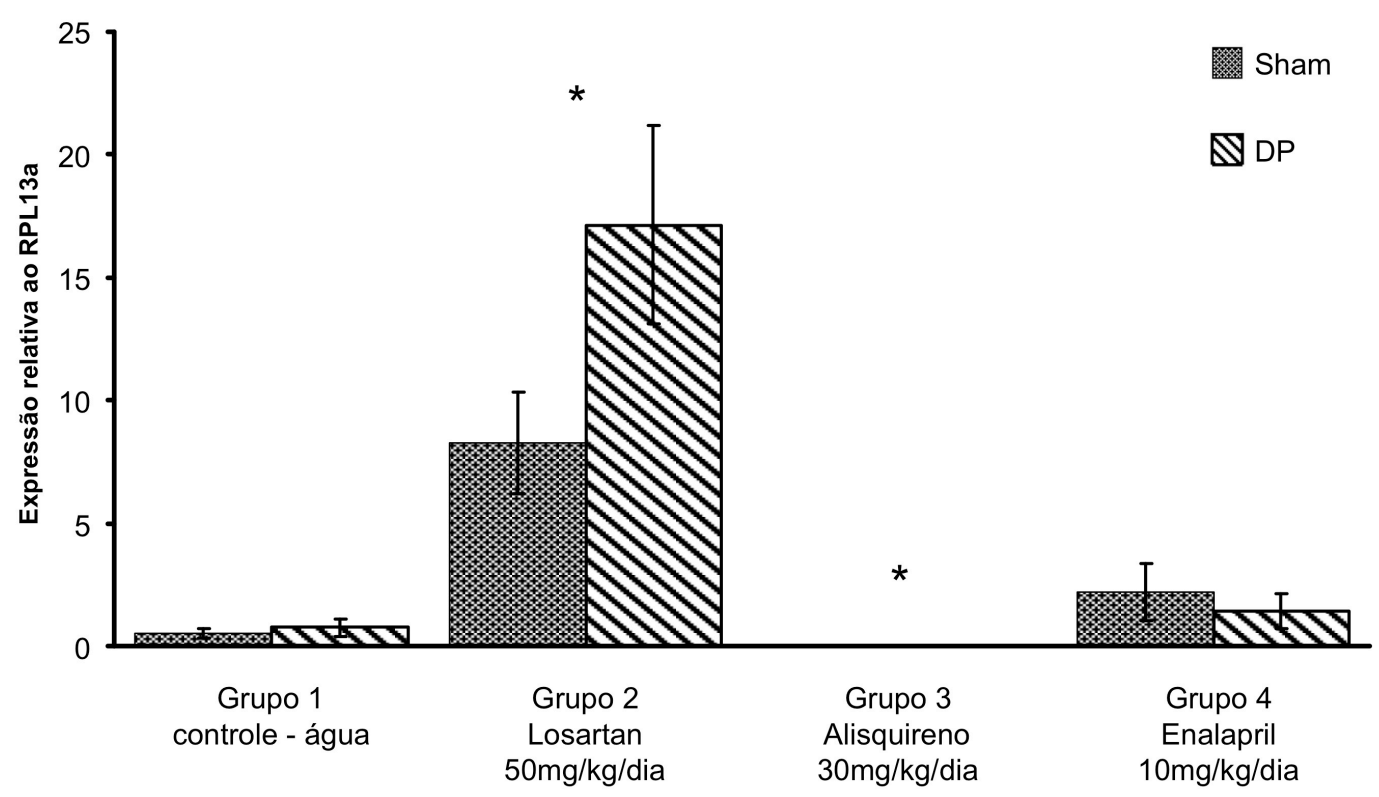

Figura 22 - Representação gráfica da expressão do receptor $A T_{1 a}$ em relação ao RPL13A em amostras de animais sham operados e com tecidos afetados pela doença periodontal induzida experimentalmente por 7 dias ( $n=5$ em todos os períodos), nos diferentes tratamentos farmacológicos.SHAM: operação fictícia para indução da doença periodontal. DP: doença periodontal induzida experimentalmente.

$\left(^{*}\right)$ diferença estatisticamente significativa $(p<0,05)$ em relação ao grupo 1 (controle - água) tanto para animais sham e animais com DP. 


\subsubsection{Expressão de $\mathrm{RNA}_{m}$ para $\mathrm{AT}_{1 \mathrm{~b}}$ em relação ao RPL13A aos 7 dias}

Ao analisar a expressão do receptor $A T_{1 b}$ em relação ao RPL13A não houve diferença estatisticamente significativa quando comparados os animais sham provenientes dos vários tratamentos e nem quando comparadas as condições sham e DP (Figura 23).

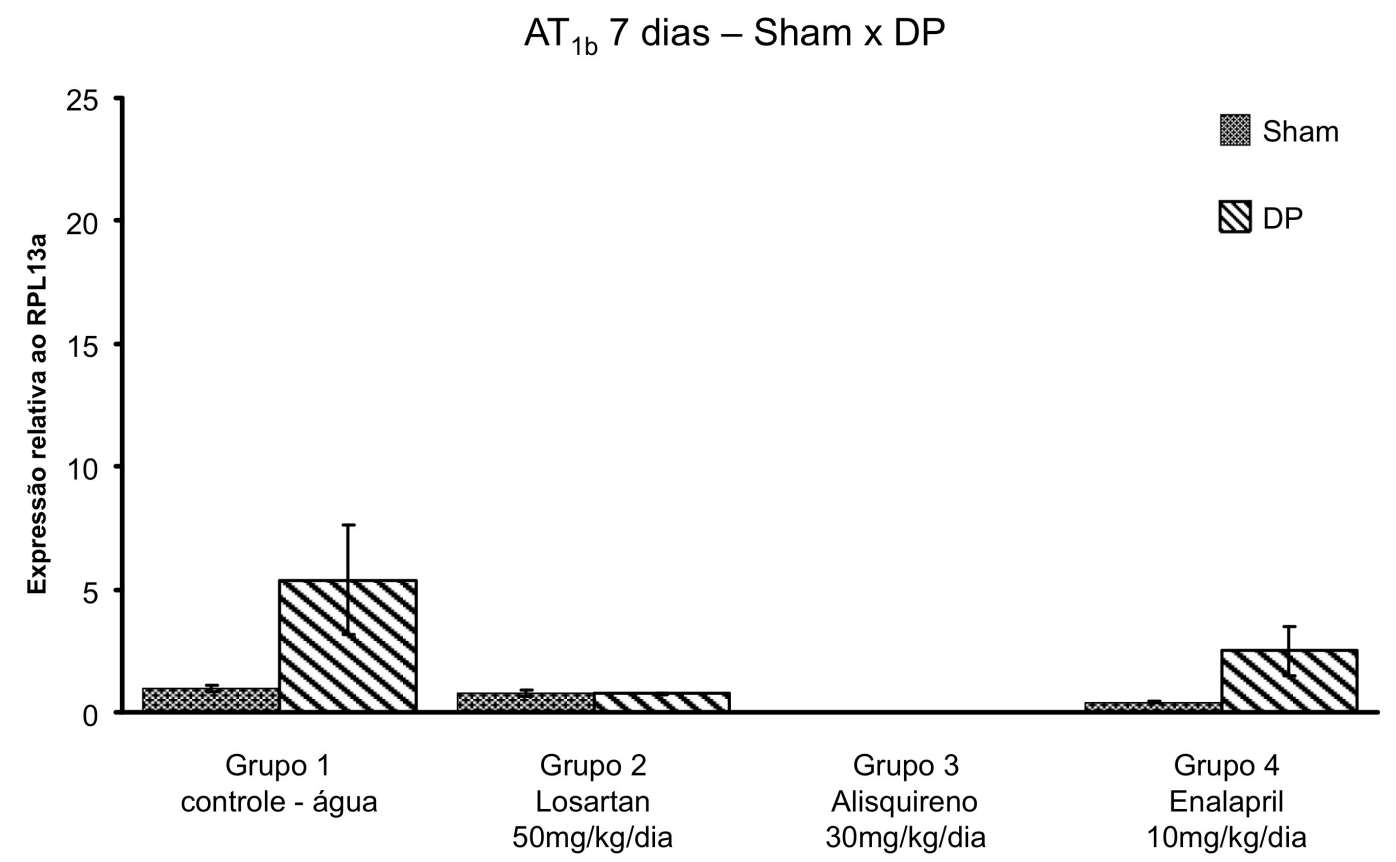

Figura 23 - Representação gráfica da expressão do receptor $A T_{1 b}$ em relação ao RPL13A em amostras de animais sham operados e com tecidos afetados pela doença periodontal induzida experimentalmente por 7 dias ( $\mathrm{n}=5 \mathrm{em}$ todos os períodos), nos diferentes tratamentos farmacológicos.SHAM: operação fictícia para indução da doença periodontal. DP: doença periodontal induzida experimentalmente. 


\subsubsection{Expressão de $R_{N A}$ para $A T_{2}$ em relação ao $R P L 13 A$ aos 7 dias}

Com relação à expressão de RNA $m$ para AT2 houve uma menor expressão desse receptor nos animais sham do grupo 3 (alisquireno) e do grupo 4 (enalapril), aos 7 dias, em relação ao sham do grupo 1 (controle-água).

Já nos animais com DP do grupo 1 (controle-água) e do grupo 2 (losartan), aos 7 dias, houve uma maior expressão do RNA ${ }_{m}$ para AT2 em relação ao seu respectivo sham. (Figura 24).

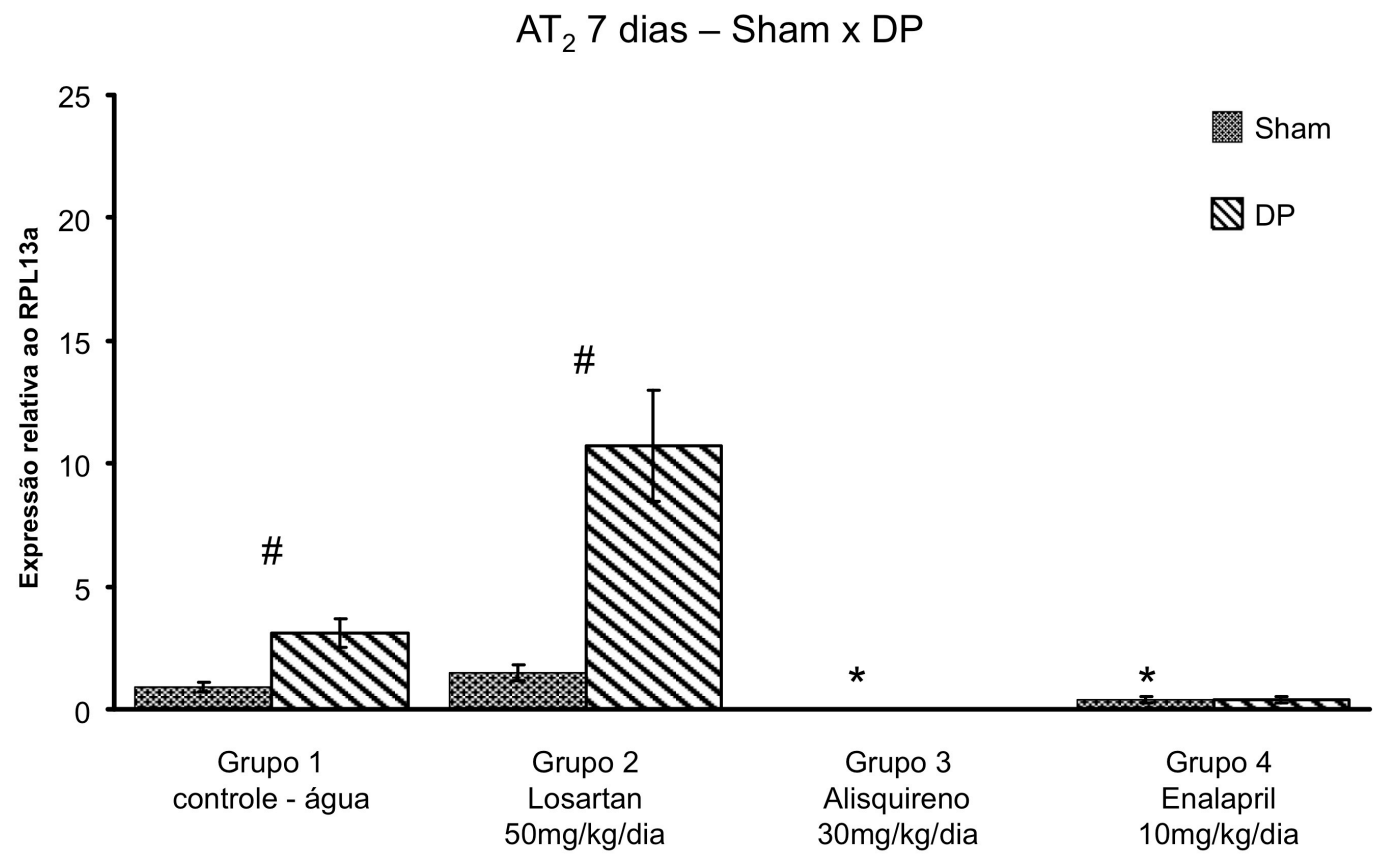

Figura 24 - Representação gráfica da expressão do receptor $A T_{2}$ em relação ao RPL13A em amostras de animais sham operados e com tecidos afetados pela doença periodontal induzida experimentalmente por 7 dias ( $\mathrm{n}=5 \mathrm{em}$ todos os períodos), nos diferentes tratamentos farmacológicos.SHAM: operação fictícia para indução da doença periodontal. DP: doença periodontal induzida experimentalmente.

$\left({ }^{*}\right)$ diferença estatisticamente significativa $(p<0,05)$ em relação ao grupo 1 (controle - água) para animais sham.

(\#) diferença estatisticamente significativa $(p<0,05)$ em relação ao animais do mesmo grupo (tratamento farmacológico) entre animais sham e DP. 


\subsubsection{Expressão de RNA $_{m}$ para ECA em relação ao RPL13A aos 7 dias}

Com relação à expressão de RNA $m$ para ECA houve uma menor expressão desse receptor nos animais sham do grupo 3 (alisquireno) e do grupo 4 (enalapril), aos 7 dias, em relação ao sham do grupo 1 (controle-água).

Já nos animais com DP do grupo 2 (losartan), aos 7 dias, houve uma maior expressão do RNA $\mathrm{m}_{m}$ para ECA em relação ao seu respectivo sham (Figura 25).

ECA 7 dias - Sham $\times$ DP

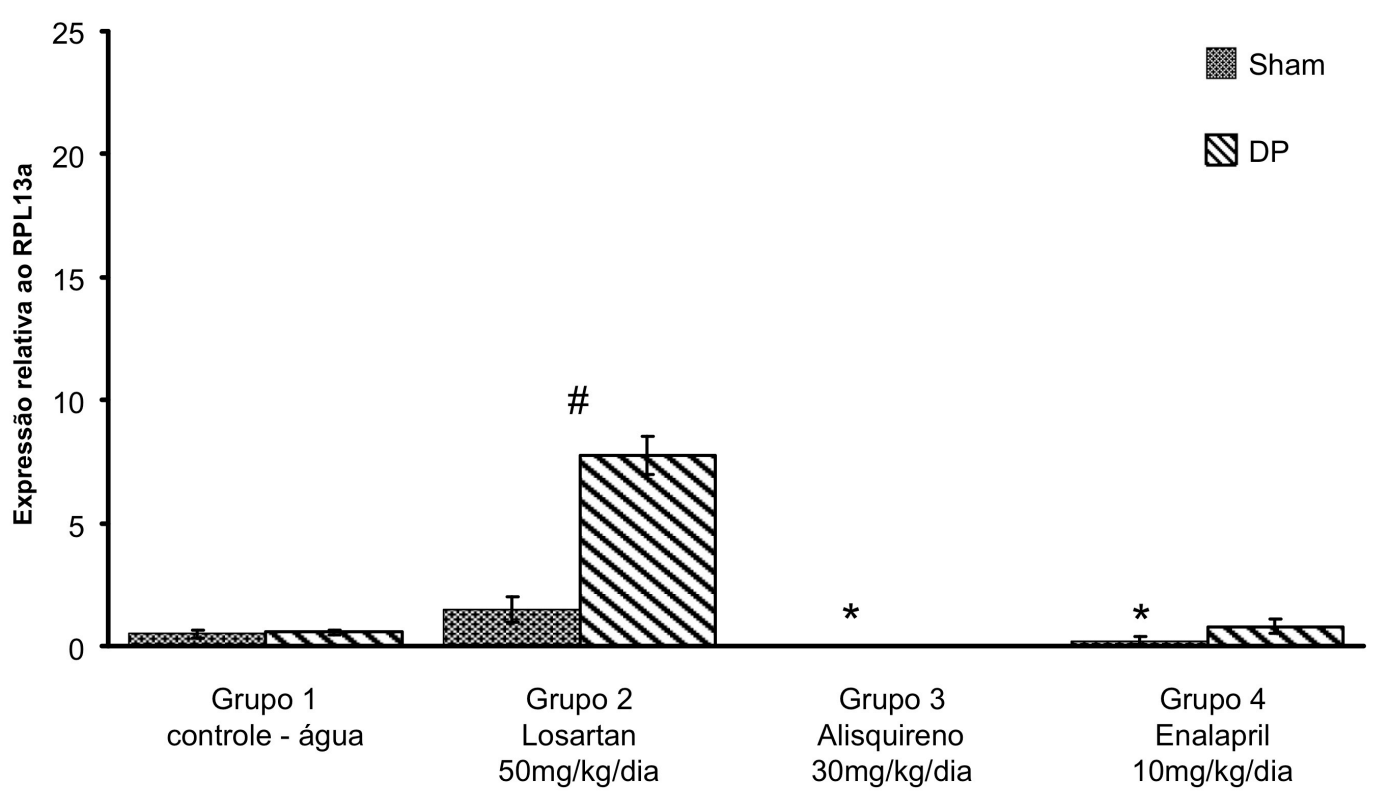

Figura 25 - Representação gráfica da expressão do receptor ECA em relação ao RPL13A em amostras de animais sham operados e com tecidos afetados pela doença periodontal induzida experimentalmente por 7 dias ( $n=5$ em todos os períodos), nos diferentes tratamentos farmacológicos.SHAM: operação fictícia para indução da doença periodontal. DP: doença periodontal induzida experimentalmente.

$\left({ }^{*}\right)$ diferença estatisticamente significativa $(p<0,05)$ em relação ao grupo 1 (controle - água) para animais sham.

(\#) diferença estatisticamente significativa $(p<0,05)$ em relação ao animais do mesmo grupo (tratamento farmacológico) entre animais sham e DP. 


\subsubsection{Análise da expressão de $R^{2} A_{m}$ por $P C R$ tratados farmacologicamente ou com água por 14 dias}

\subsubsection{Expressão de $\operatorname{RNA}_{m}$ para $A T_{1 a}$ em relação ao $R P L 13 A$ aos 14 dias}

A expressão de $R N A_{m}$ para $A T_{1 a}$ teve aumento nos animais sham do grupo 2 (losartan), aos 14 dias, em relação ao sham do grupo 1 (controle-água) (Figura 26).

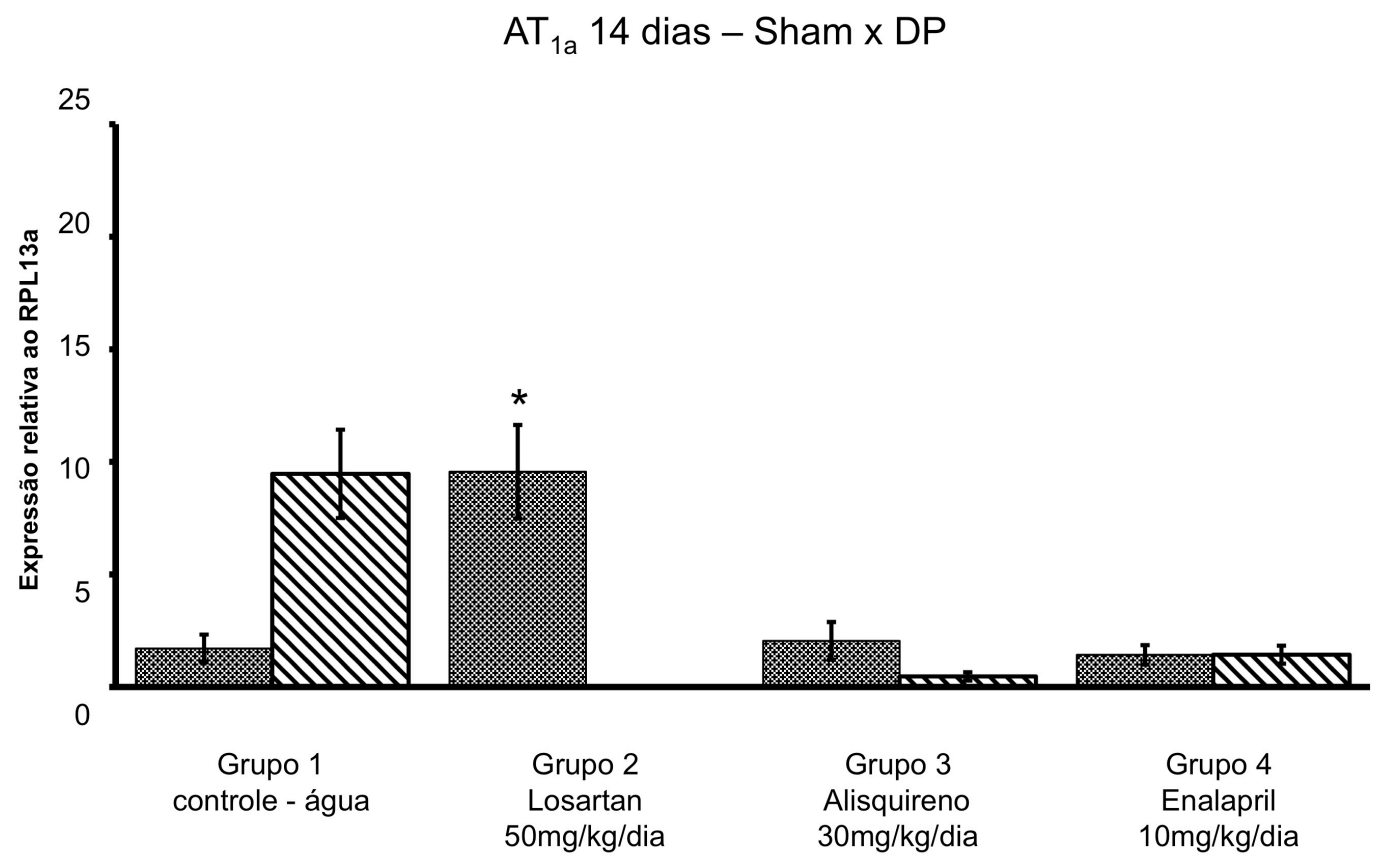

Figura 26 - Representação gráfica da expressão do receptor $A T_{1 a}$ em relação ao RPL13A em amostras de animais sham operados e com tecidos afetados pela doença periodontal induzida experimentalmente por 14 dias ( $\mathrm{n}=5 \mathrm{em}$ todos os períodos), nos diferentes tratamentos farmacológicos.SHAM: operação fictícia para indução da doença periodontal. DP: doença periodontal induzida experimentalmente.

$\left.{ }^{*}\right)$ diferença estatisticamente significativa $(p<0,05)$ em relação ao grupo 1 (controle - água) para animais sham. 


\subsubsection{Expressão de RNA $_{m}$ para $\mathrm{AT}_{1 \mathrm{~b}}$ em relação ao RPL13A aos 14 dias}

Ao analisar a expressão do receptor $A T_{1 b}$ em relação ao RPL13A não houve diferença estatisticamente significativa quando comparados os animais sham provenientes dos vários tratamentos e nem quando comparadas as condições sham e DP (Figura 27).

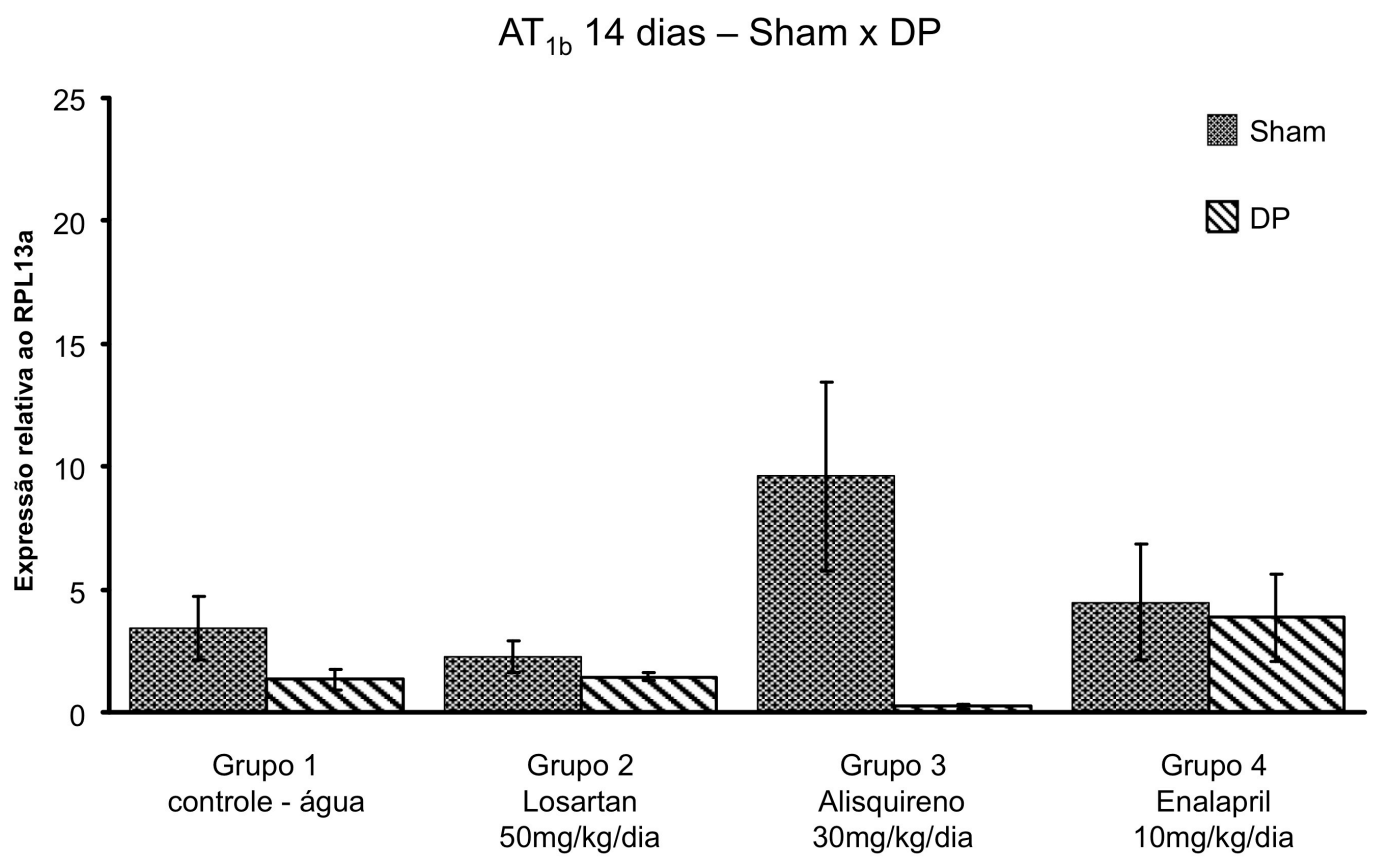

Figura 27 - Representação gráfica da expressão do receptor $A T_{1 b}$ em relação ao RPL13A em amostras de animais sham operados e com tecidos afetados pela doença periodontal induzida experimentalmente por 14 dias ( $\mathrm{n}=5 \mathrm{em}$ todos os períodos), nos diferentes tratamentos farmacológicos.SHAM: operação fictícia para indução da doença periodontal. DP: doença periodontal induzida experimentalmente. 


\subsubsection{Expressão de $R_{N A}$ para $A T_{2}$ em relação ao $R P L 13 A$ aos 14 dias}

Com relação à expressão de $\mathrm{RNA}_{m}$ para AT2 revelou-se uma menor expressão desse receptor nos animais sham do grupo 2 (losartan) e 4 (enalapril) em relação ao sham do grupo 1 (controle-água) aos 14 dias.

Houve aumento da expressão de RNA $\mathrm{m}_{m}$ para AT2 nos animais com DP dos grupos 1 (controle-água) e 2 (losartan) quando comparados com os seus respectivos sham.

E ainda os animais com DP tratados com alisquireno (grupo3) tiveram menor expressão de RNA $m$ para AT2 em relação aos animais com DP do grupo 1 (controle-água) (Figura 28).

$\mathrm{AT}_{2} 14$ dias - Sham x DP

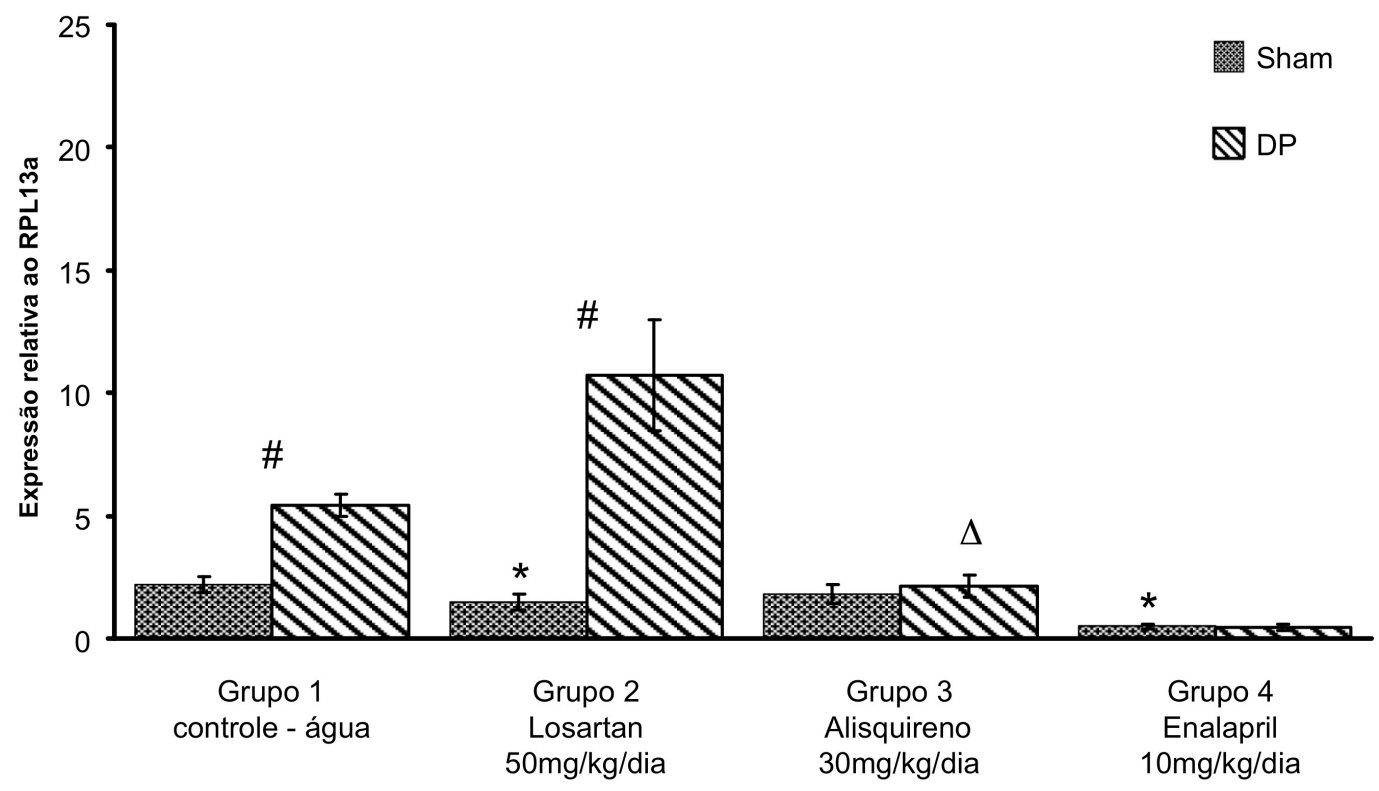

Figura 28 - Representação gráfica da expressão do receptor $A T_{2}$ em relação ao RPL13A em amostras de animais sham operados e com tecidos afetados pela doença periodontal induzida experimentalmente por 14 dias ( $\mathrm{n}=5 \mathrm{em}$ todos os períodos), nos diferentes tratamentos farmacológicos.SHAM: operação fictícia para indução da doença periodontal. DP: doença periodontal induzida experimentalmente.

$\left({ }^{*}\right)$ diferença estatisticamente significativa $(p<0,05)$ em relação ao grupo 1 (controle - água) para animais sham.

(\#) diferença estatisticamente significativa $(p<0,05)$ em relação ao animais do mesmo grupo (tratamento farmacológico) entre animais sham e DP.

$(\Delta)$ diferença estatisticamente significativa $(p<0,05)$ em relação grupo 1 (controle - água) para animais com DP. 


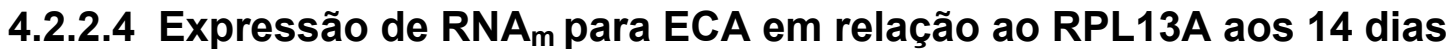

Houve um aumento considerável da expressão de RNA $A_{m}$ para ECA no grupo 1 (controle - água), aos 14 dias de experimento, nos animais com DP. Os animais tratados com losartan (grupo 2) apresentaram maior expressão de RNA para ECA nos animais sham quando comparados aos animais DP dentro do mesmo tratamento farmacológico (Figura 29).

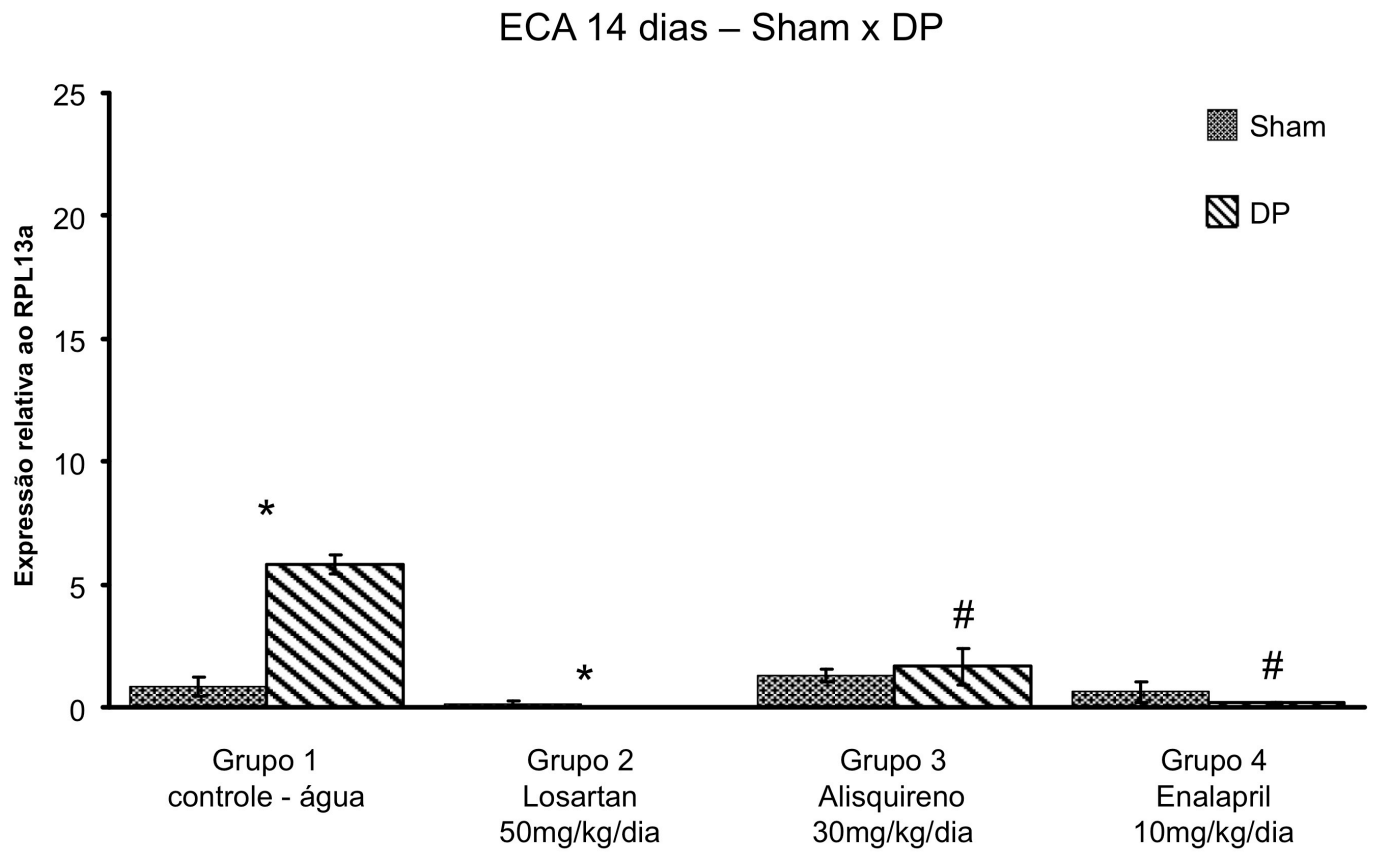

Figura 29 - Representação gráfica da expressão do receptor ECA em relação ao RPL13A em amostras de animais sham operados e com tecidos afetados pela doença periodontal induzida experimentalmente por 14 dias $(n=5$ em todos os períodos), nos diferentes tratamentos farmacológicos.SHAM: operação fictícia para indução da doença periodontal. DP: doença periodontal induzida experimentalmente.

$\left(^{*}\right)$ diferença estatisticamente significativa $(p<0,05)$ em relação aos animais do mesmo grupo (tratamento farmacológico) entre animais sham e DP.

(\#) diferença estatisticamente significativa $(p<0,05)$ em relação ao grupo 1 (controle - água) para animais DP. 


\subsubsection{Comparação da expressão de $R^{2 N A}$ por PCR tratados farmacologicamente ou com água por 7 e 14 dias}

\subsubsection{Expressão de $\mathrm{RNA}_{m}$ para $\mathrm{AT}_{1 \mathrm{a}}$ em relação ao RPL13A nos animais sham aos 7 e 14 dias}

Ao analisar a expressão do receptor $A T_{1 a}$ em relação ao RPL13A não houve diferença estatisticamente significativa quando comparados os animais sham 7 e 14 dias (Figura 30 ).

$\mathrm{AT}_{1 \mathrm{a}}$ Sham $-7 \times 14$ dias

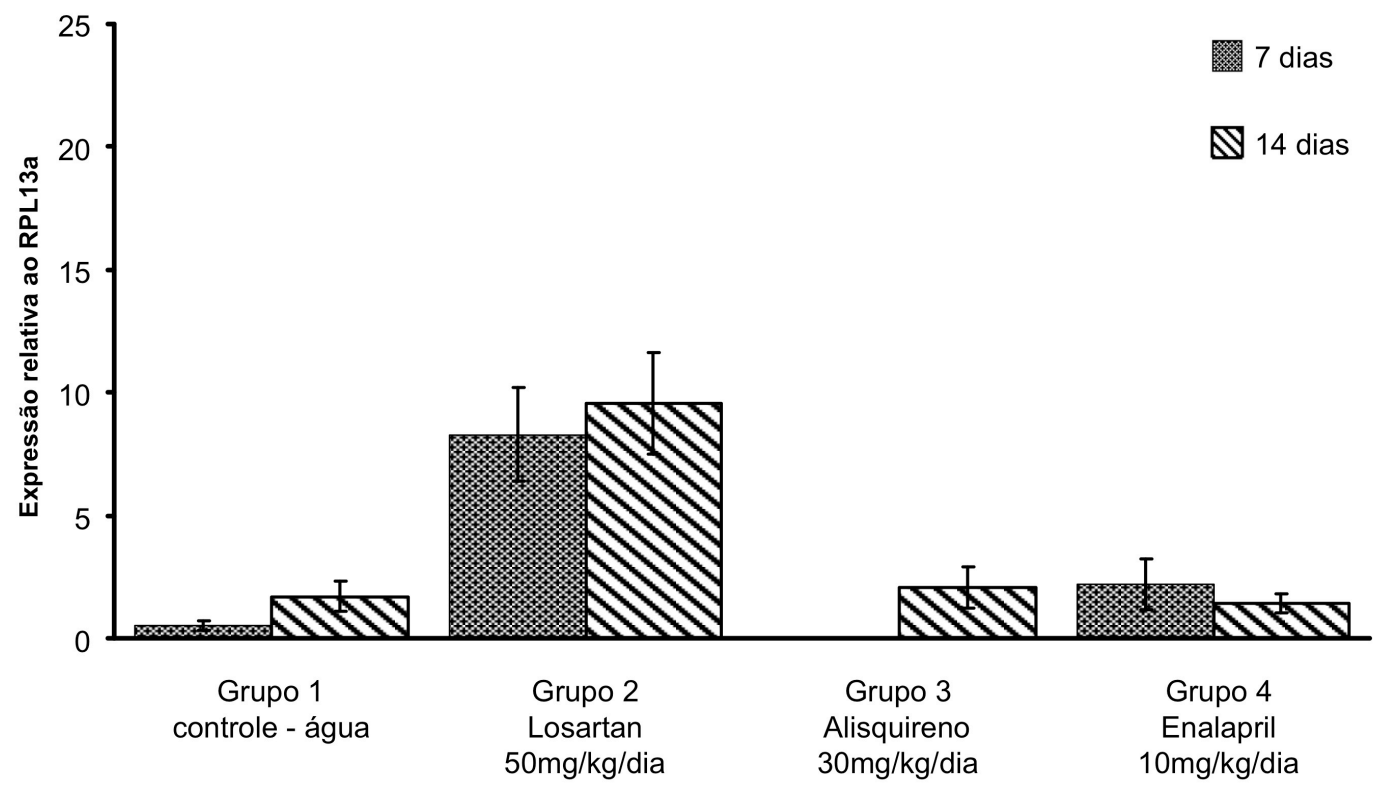

Figura 30 - Representação gráfica da expressão do receptor $A T_{1 a}$ em relação ao RPL13A em amostras de animais sham operados e com tecidos afetados pela doença periodontal induzida experimentalmente por 7 e 14 dias ( $n=5$ em todos os períodos), nos diferentes tratamentos farmacológicos.SHAM: operação fictícia para indução da doença periodontal. 


\subsubsection{Expressão de RNA $_{m}$ para $\mathrm{AT}_{1 \mathrm{~b}}$ em relação ao RPL13A nos animais sham aos 7 e aos 14 dias}

Ao analisar a expressão do receptor $A T_{1 b}$ em relação ao RPL13A não houve diferença estatisticamente significativa quando comparados os animais sham 7 e 14 dias (Figura 31).

$\mathrm{AT}_{1 \mathrm{~b}}$ Sham - $7 \times 14$ dias

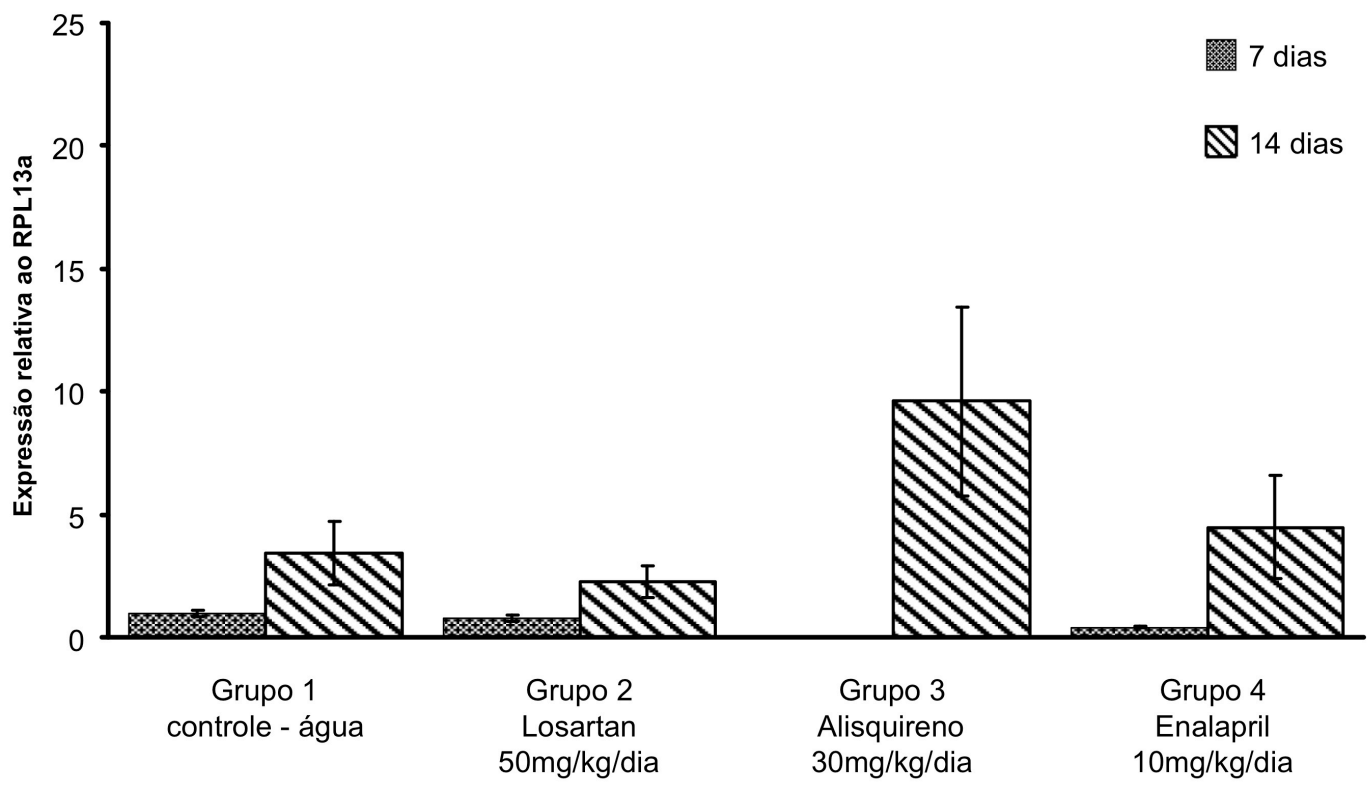

Figura 31 - Representação gráfica da expressão do receptor $A T_{1 b}$ em relação ao RPL13A em amostras de animais sham operados e com tecidos afetados pela doença periodontal induzida experimentalmente por 7 e 14 dias ( $n=5$ em todos os períodos), nos diferentes tratamentos farmacológicos.SHAM: operação fictícia para indução da doença periodontal. 


\subsubsection{Expressão de $\mathrm{RNA}_{m}$ para $A T_{2}$ em relação ao RPL13A nos animais sham aos 7 e aos 14 dias}

Com relação à expressão de $\mathrm{RNA}_{\mathrm{m}}$ para $\mathrm{AT}_{2}$ revelou-se uma maior expressão desse receptor nos animais sham aos 14 dias em comparação com os 7 dias no grupo 1 (controle-água), grupo 3 (alisquireno) e 4 (enalapril). No grupo 2 (losartan) aconteceu o inverso, houve maior expressão de $\mathrm{RNA}_{\mathrm{m}}$ para $\mathrm{AT}_{2}$ aos 7 dias em relação aos 14 dias (Figura 32).

$\mathrm{AT}_{2}$ Sham - $7 \times 14$ dias

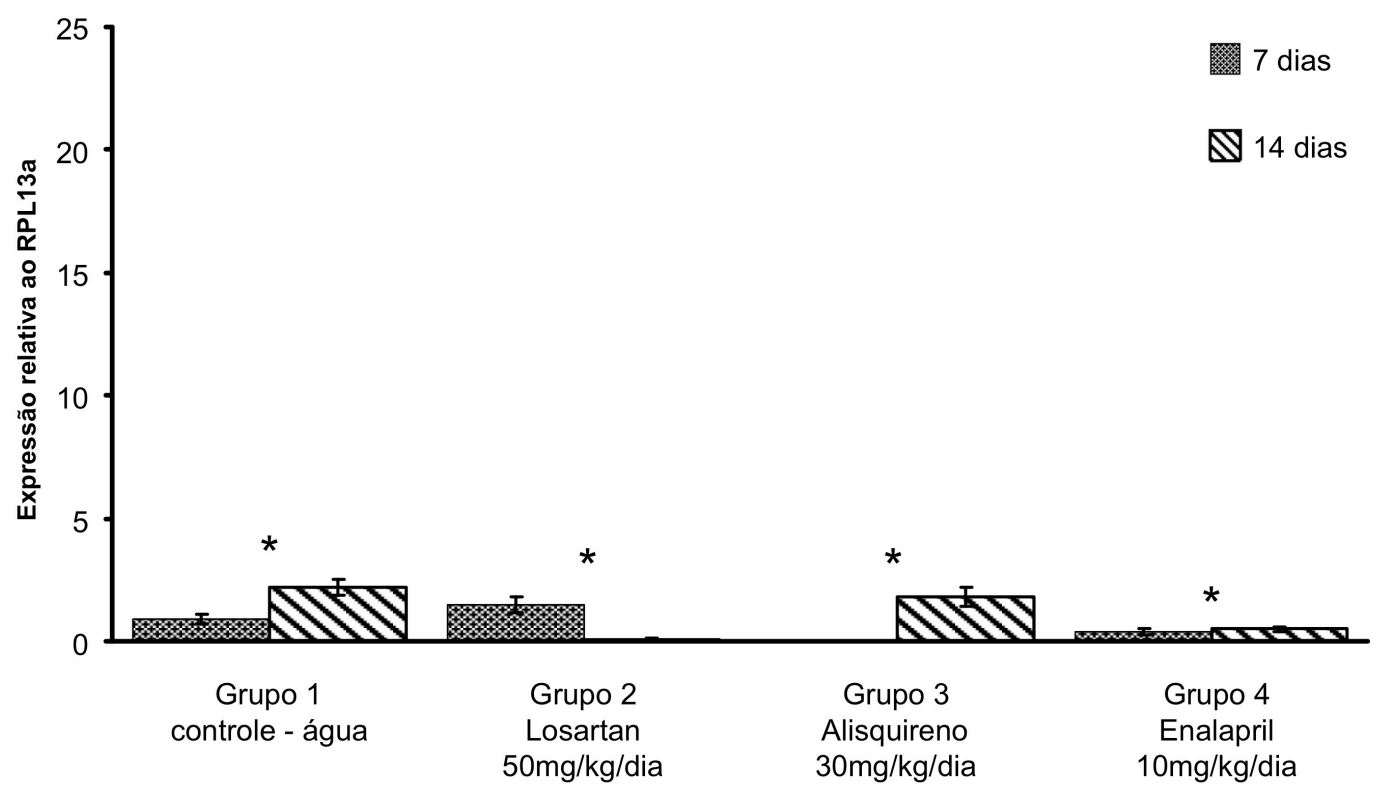

Figura 32 - Representação gráfica da expressão do receptor $A T_{2}$ em relação ao RPL13A em amostras de animais sham operados e com tecidos afetados pela doença periodontal induzida experimentalmente por 7 e 14 dias ( $n=5$ em todos os períodos), nos diferentes tratamentos farmacológicos.SHAM: operação fictícia para indução da doença periodontal.

${ }^{*}$ ) diferença estatisticamente significativa $(p<0,05)$ em relação aos animais do mesmo grupo (tratamento farmacológico) entre animais sham 7 e 14 dias. 


\subsubsection{Expressão de RNA $_{m}$ para ECA em relação ao RPL13A nos animais sham aos 7 e aos 14 dias}

Com relação à expressão de RNA $_{m}$ para ECA foi observada uma maior expressão dessa enzima nos animais tratados com alisquireno (grupo 3) aos 14 dias em comparação com 7 dias de tratamento (Figura 33).

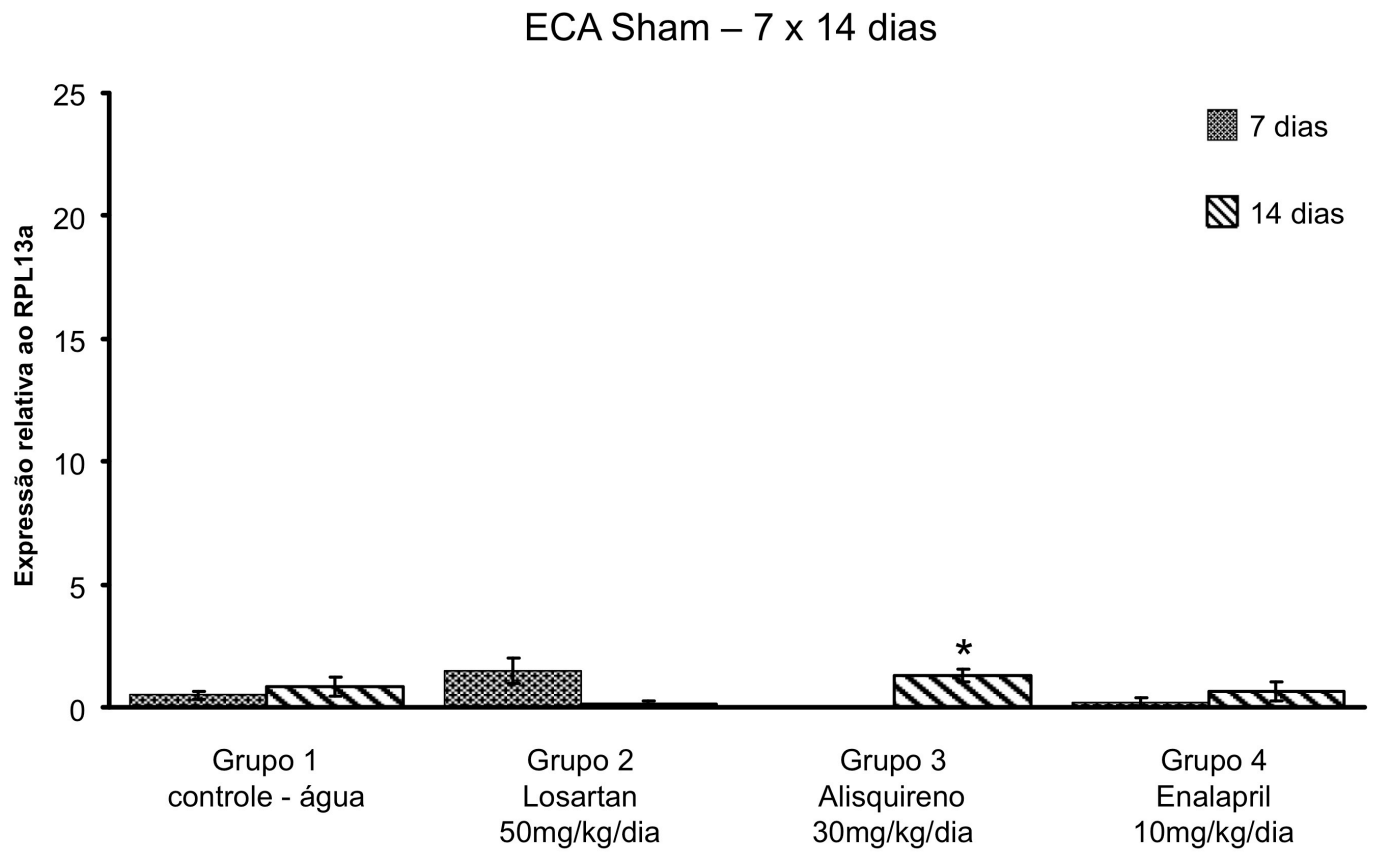

Figura 33 - Representação gráfica da expressão do receptor ECA em relação ao RPL13A em amostras de animais sham operados e com tecidos afetados pela doença periodontal induzida experimentalmente por 7 e 14 dias ( $n=5$ em todos os períodos), nos diferentes tratamentos farmacológicos.SHAM: operação fictícia para indução da doença periodontal.

$\left(^{*}\right)$ diferença estatisticamente significativa $(p<0,05)$ em relação aos animais do mesmo grupo (tratamento farmacológico) entre animais sham 7 e 14 dias. 


\subsubsection{Expressão de $\mathrm{RNA}_{\mathrm{m}}$ para $\mathrm{AT}_{1 \mathrm{a}}$ em relação ao $\mathrm{RPL13A}$ nos animais DP aos 7 e 14 dias}

Com relação à expressão de $\mathrm{RNA}_{m}$ para $A T 1_{a}$ (análogo ao AT1) foi observada uma maior expressão desses receptores nos animais com DP tratados com losartan (grupo 2) aos 7 dias em comparação com 14 dias de tratamento, e nos animais do grupo 3 (alisquireno) aos 14 dias em comparação com 7 dias de tratamento (Figura 34).

$\mathrm{AT}_{1 \mathrm{a}} \mathrm{DP}-7 \times 14$ dias

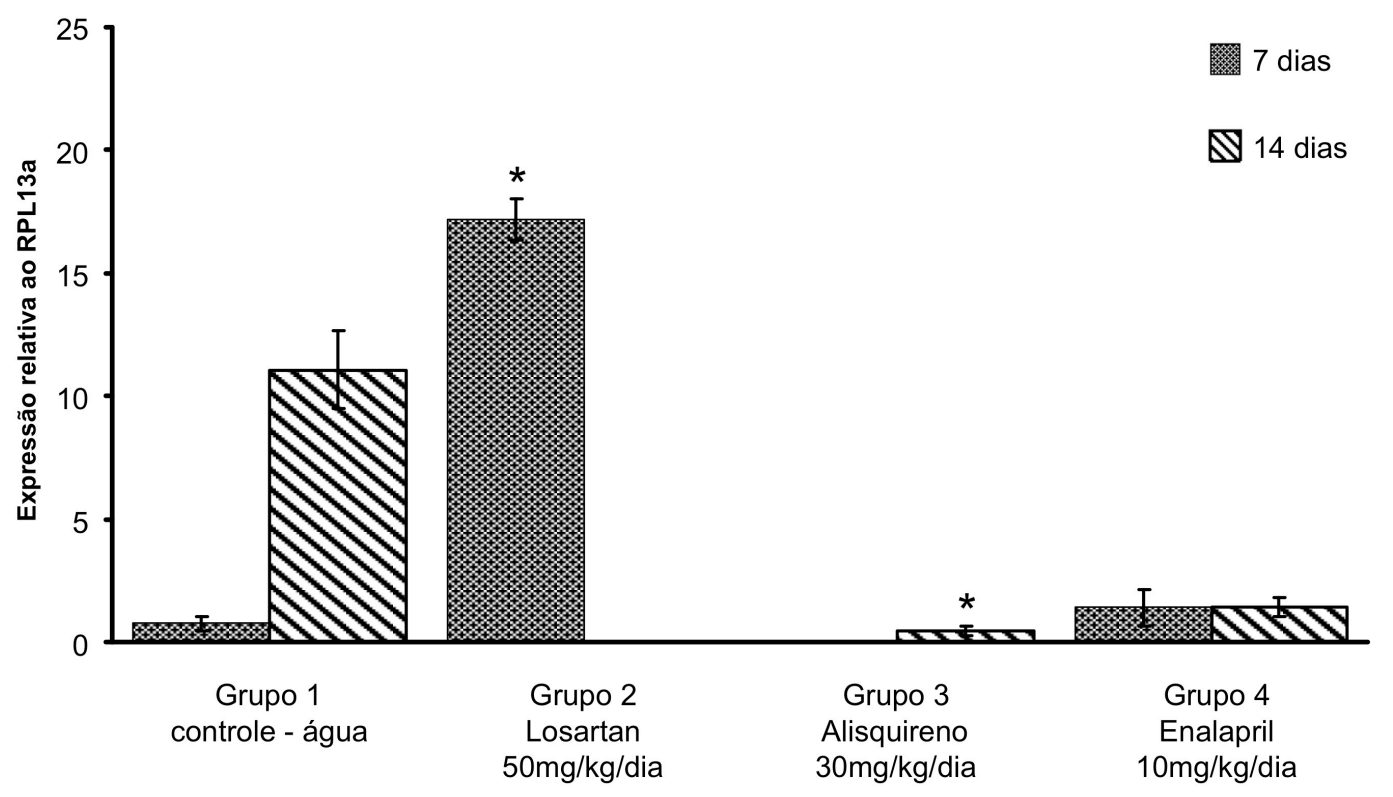

Figura 34 - Representação gráfica da expressão do receptor $A T_{1 a}$ em relação ao RPL13A em amostras de animais sham operados e com tecidos afetados pela doença periodontal induzida experimentalmente por 7 e 14 dias ( $n=5$ em todos os períodos), nos diferentes tratamentos farmacológicos. DP: doença periodontal induzida experimentalmente.

$\left({ }^{*}\right)$ diferença estatisticamente significativa $(p<0,05)$ em relação aos animais do mesmo grupo (tratamento farmacológico) entre animais com DP 7 e 14 dias. 


\subsubsection{Expressão de RNA para $\mathrm{AT}_{1 \mathrm{~b}}$ em relação ao RPL13A nos animais DP aos 7 e aos 14 dias}

Com relação à expressão de $\mathrm{RNA}_{\mathrm{m}}$ para $A T_{1 \mathrm{~b}}$ foi observada uma maior expressão desses receptores nos animais com DP tratados com losartan (grupo 2) aos 14 dias em comparação com 7 dias de tratamento, e nos animais do grupo 3 (alisquireno) aos 7 dias em comparação com 14 dias de tratamento (Figura 35).

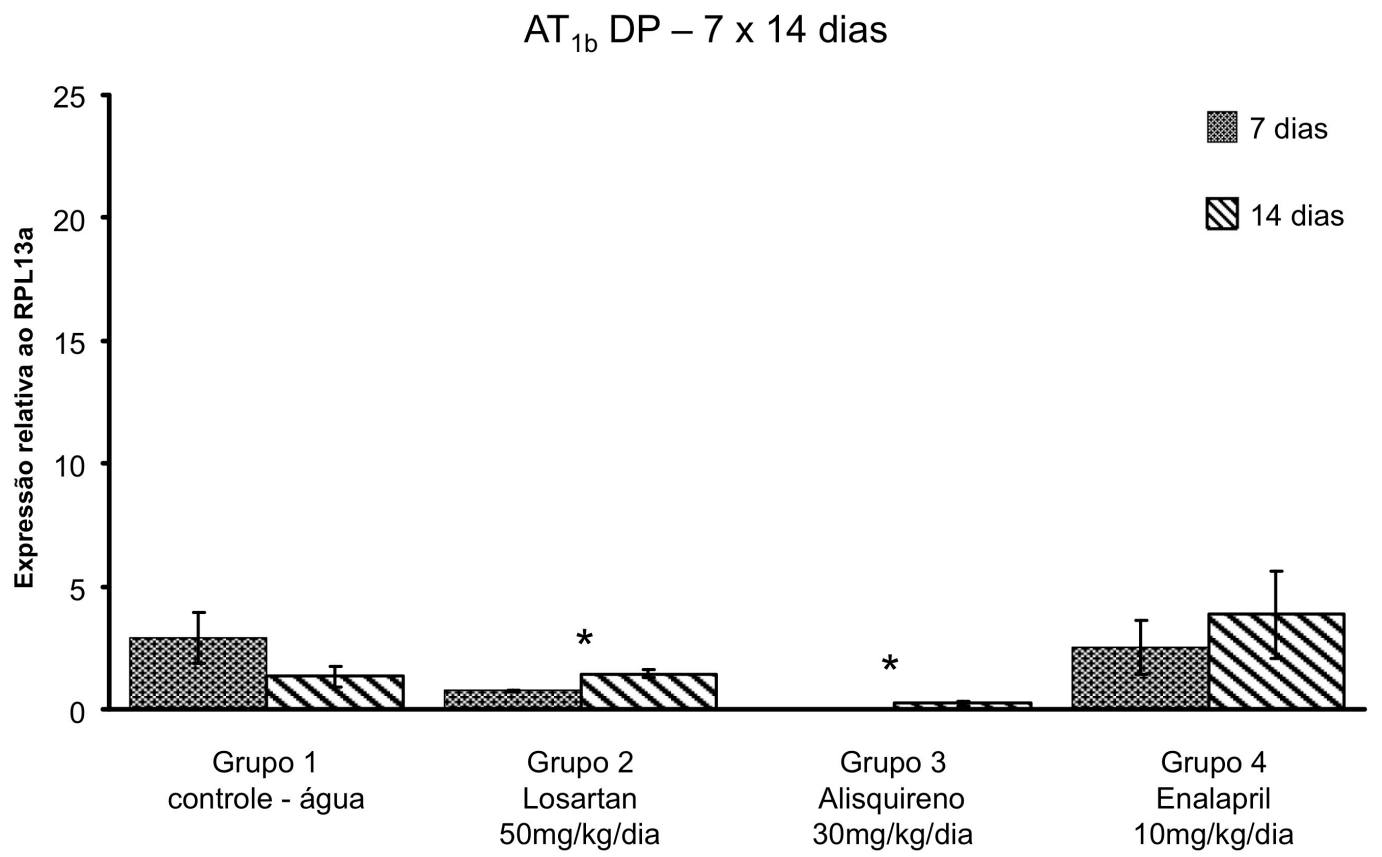

Figura 35 - Representação gráfica da expressão do receptor $A T_{1 b}$ em relação ao RPL13A em amostras de animais sham operados e com tecidos afetados pela doença periodontal induzida experimentalmente por 7 e 14 dias ( $n=5$ em todos os períodos), nos diferentes tratamentos farmacológicos. DP: doença periodontal induzida experimentalmente.

$\left(^{*}\right)$ diferença estatisticamente significativa $(p<0,05)$ em relação aos animais do mesmo grupo (tratamento farmacológico) entre animais com DP 7 e 14 dias. 


\subsubsection{Expressão de $\mathrm{RNA}_{\mathrm{m}}$ para $A T_{2}$ em relação ao RPL13A nos animais DP aos 7 e aos 14 dias}

Com relação à expressão de $R N A_{m}$ para $A T_{2}$ foi observada uma maior expressão desses receptores nos animais com DP tratados com losartan (grupo 2) aos 7 dias em comparação com 14 dias de tratamento, e nos animais do grupo 3 (alisquireno) aos 14 dias em comparação com 7 dias de tratamento (Figura 36).

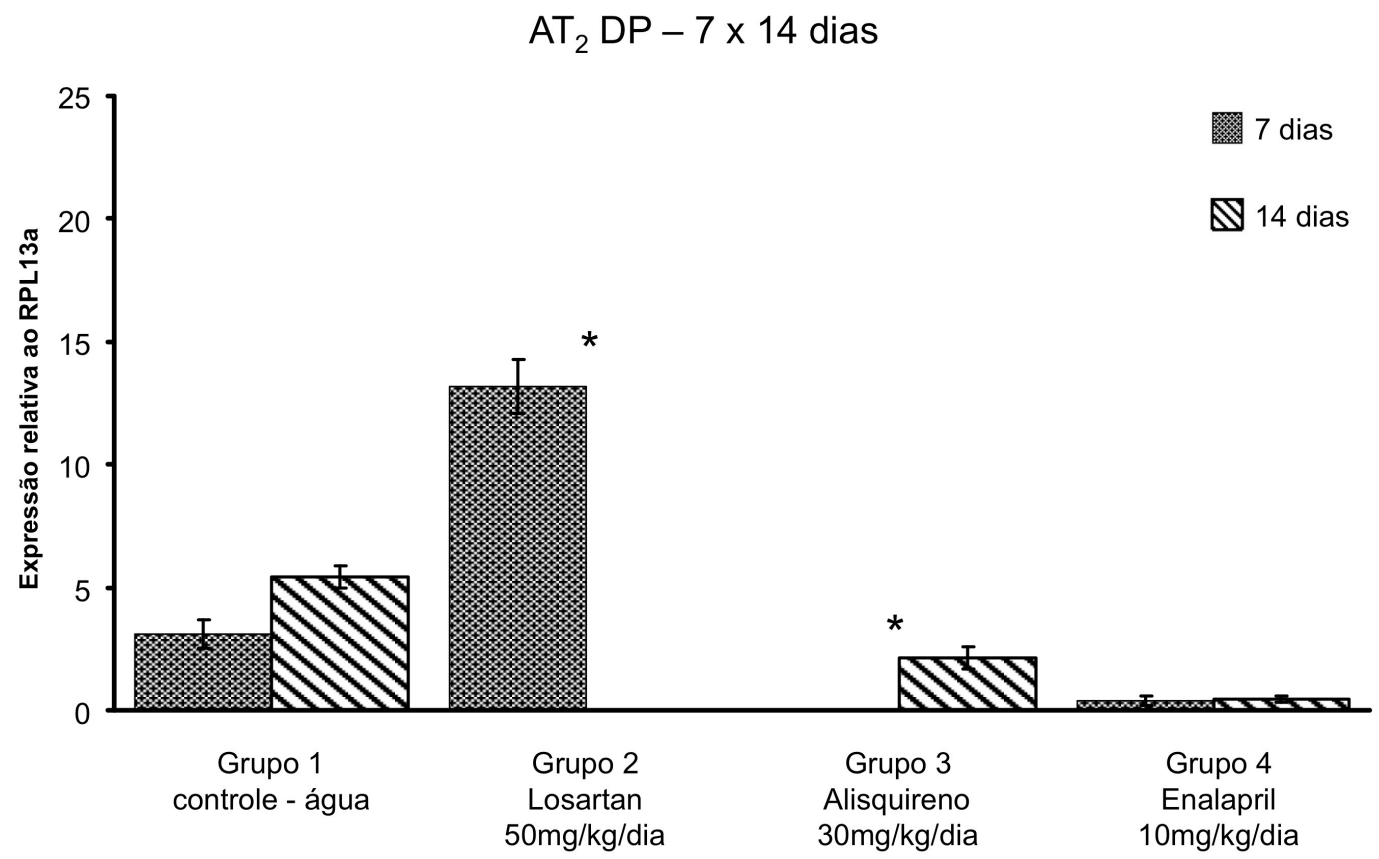

Figura 36 - Representação gráfica da expressão do receptor $A T_{2}$ em relação ao RPL13A em amostras de animais sham operados e com tecidos afetados pela doença periodontal induzida experimentalmente por 7 e 14 dias ( $n=5$ em todos os períodos), nos diferentes tratamentos farmacológicos. DP: doença periodontal induzida experimentalmente.

$\left.{ }^{*}\right)$ diferença estatisticamente significativa $(p<0,05)$ em relação aos animais do mesmo grupo (tratamento farmacológico) entre animais com DP 7 e 14 dias. 


\subsubsection{Expressão de RNA $m$ para ECA em relação ao RPL13A nos animais DP aos 7 e aos 14 dias}

Com relação à expressão de RNA $_{m}$ para ECA foi observada uma maior expressão dessa enzima nos animais do grupo 1 (controle-água) e no grupo 3 (alisquireno) aos 14 dias em comparação com 7 dias de tratamento. O inverso ocorreu com os grupos 2 (losartan) e 4 (enalapril) que apresentou maior

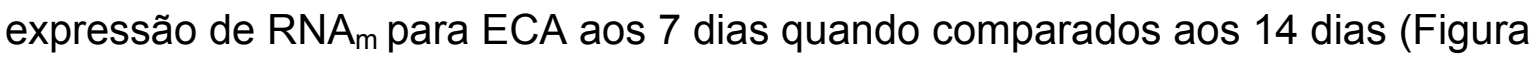
$37)$.

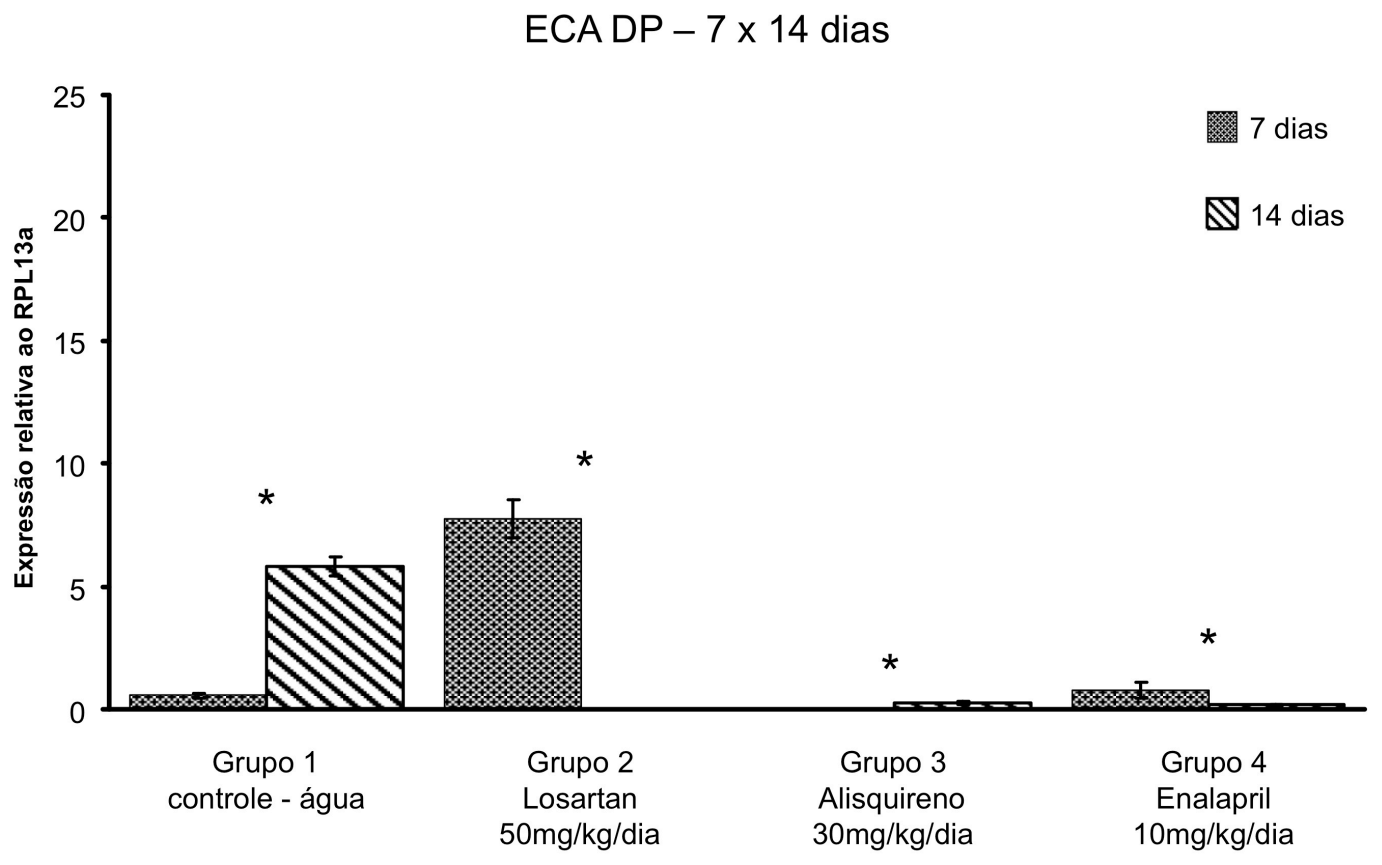

Figura 37 - Representação gráfica da expressão do receptor $A T_{2}$ em relação ao RPL13A em amostras de animais sham operados e com tecidos afetados pela doença periodontal induzida experimentalmente por 7 e 14 dias ( $n=5$ em todos os períodos), nos diferentes tratamentos farmacológicos. DP: doença periodontal induzida experimentalmente.

$\left({ }^{*}\right)$ diferença estatisticamente significativa $(p<0,05)$ em relação aos animais do mesmo grupo (tratamento farmacológico) entre animais com DP 7 e 14 dias. 


\subsection{Análise imunoistoquímica}

Foi feita imunolocalização das proteínas renina, AT1, AT2 e ECA durante a progressão da DP induzida experimentalmente em ratos farmacologicamente tratados ou não com drogas que afetam o SRA. Os resultados foram submetidos à Análise de Variância 2 e 3 critérios (ANOVA), sendo adotado nível de significância de 5\%. Estas proteínas foram marcadas em regiões distintas do tecido periodontal e identificadas conforme a proteína-alvo. Por questões didáticas, os períodos de 7 e 14 dias serão apresentados separadamente e logo em seguida comparados.

\subsubsection{Imunomarcação nos animais tratados farmacologicamente ou com água por 7 dias}

\subsubsection{Imunomarcação para renina 7 dias}

O tecido analisado, que foi a hemimandíbula do lado direito, mostrou imunomarcação para renina nas arteríolas da região mesial e distal, próximas à região muscular (Figura 38). 


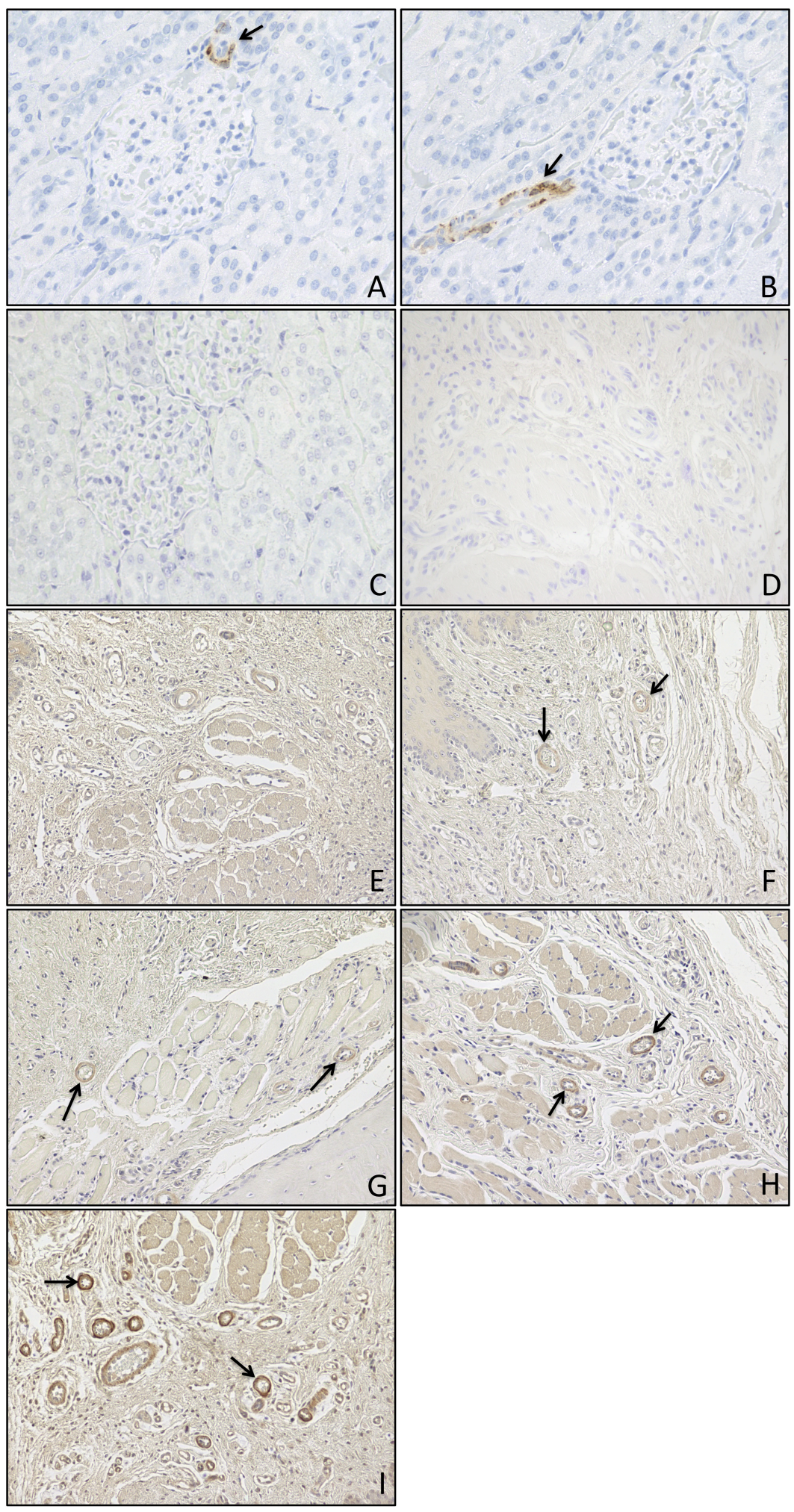

Figura 38- A) Controle positivo da imunomarcação para renina, mostra marcação das células juxtaglomerulares da arteríola aferente renal em corte transversal e B) longitudinal. C) Controle negativo com ausência de imunomarcação para as células juxtaglomerulares da arteríola aferente renal (aumento de 40X). D) Controle negativo no tecido analisado, com ausência de imunomarcação das arteríolas das regiões mesial e distal mandibular. E) Exemplo de tecido analisado das regiões mesial e distal mandibular apresentando imunomarcação com escore 0 , F) com escore 1, G) com escore 2, H) com escore 3 e I) com escore 4 (aumento de 10X). As setas indicam imunomarcação. 
Ao analisar a imunomarcação para renina não houve diferença estatisticamente significativa quando comparadas as condições (sham X DP). Houve diferença estatisticamente significativa quando comparados os tratamentos água $X$ losartan; água $X$ alisquireno; água $X$ enalapril; losartan $X$ alisquireno $\mathrm{e}$ losartan $X$ enalapril, tanto para os animais sham quanto para os com DP (Figura 39).

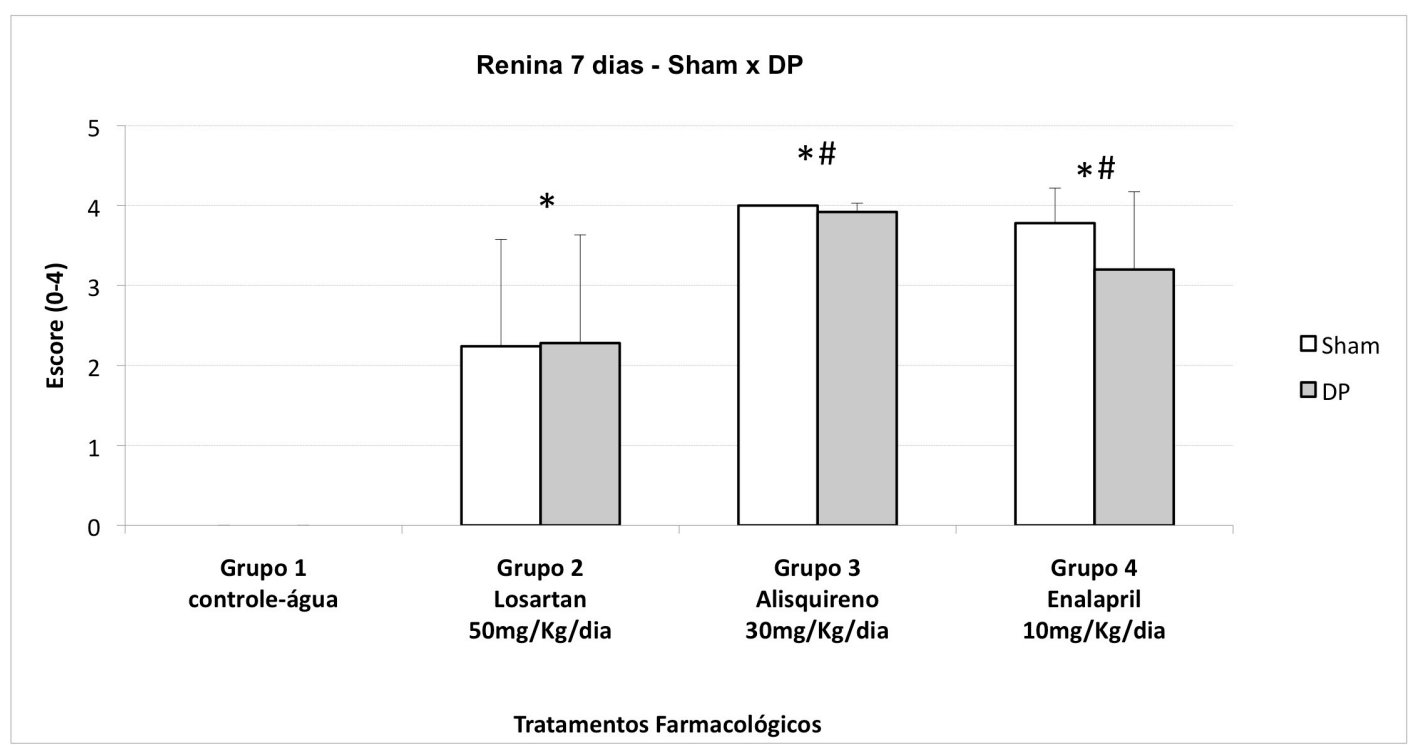

Figura 39 - Representação gráfica da imunomarcação para renina em amostras de ratos sham operados e com tecidos afetados pela doença periodontal induzida experimentalmente por 7 dias ( $n=5$ em todos os períodos), nos diferentes tratamentos farmacológicos. SHAM: operação fictícia para indução da doença periodontal. DP: doença periodontal induzida experimentalmente.

$\left.{ }^{*}\right)$ diferença estatisticamente significativa $(p<0,05)$ em relação ao grupo 1 (controle - água) tanto para animais sham e com DP.

$(\#)$ diferença estatisticamente significativa $(p<0,05)$ em relação ao grupo 2 (losartan) tanto para animais sham e com DP. 


\subsubsection{Imunomarcação para AT1 7dias}

O tecido analisado, que foi a hemimandíbula do lado direito, mostrou imunomarcação para o receptor AT1 no ligamento periodontal na região interproximal entre o primeiro e segundo molares (Figura 40)..
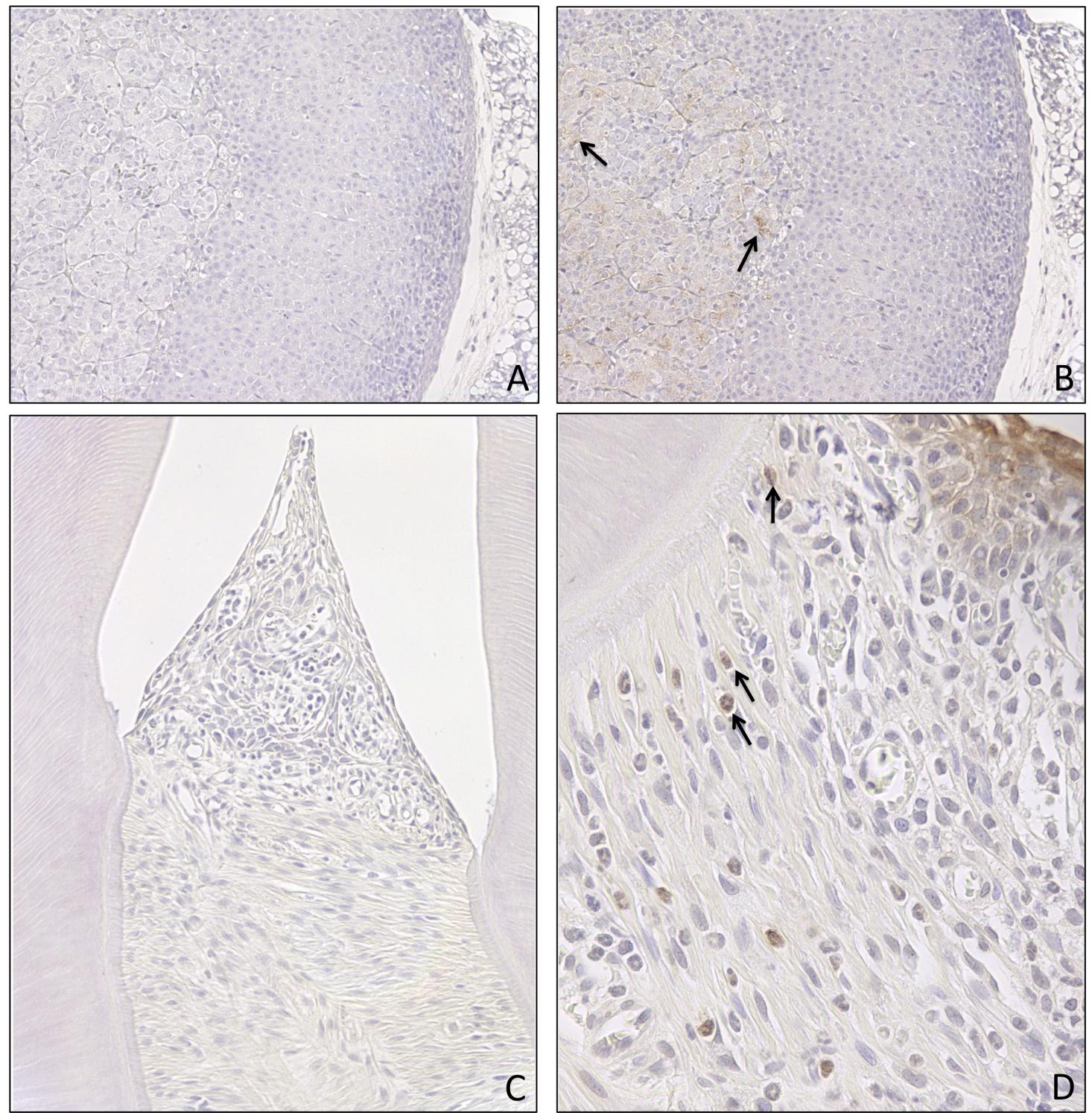

Figura 40 - A) Glândula adrenal foi utilizada como controle negativo da imunomarcação para o receptor AT1. B) Controle positivo em corte seriado da glândula adrenal mostra imunomarcação para o receptor AT1 na região medular (aumento de 10X). C) Controle negativo no tecido analisado, com ausência de imunomarcação para AT1 no ligamento periodontal, área interproximal entre primeiro e segundo molar (aumento de 20X). D) Controle positivo no tecido analisado, com imunomarcação para AT1 no ligamento periodontal (aumento de 40X). As setas indicam imunomarcação. 
Ao analisar a imunomarcação para o receptor AT1 não houve diferença estatisticamente significativa quando comparados os animais sham provenientes dos vários tratamentos. Quando comparadas as condições sham e DP houve diferença estatisticamente significativa no grupo 3 (alisquireno) e no grupo 4 (enalapril), ou seja, os animais com DP dos grupos 3 e 4 apresentaram maior numero de marcações para o receptor AT1.

Houve diferença estatisticamente significativa quando comparados os grupos com DP provenientes dos tratamentos água $X$ alisquireno; água $X$ enalapril.

Estes resultados sugerem uma interação entre os fatores tratamento farmacológico e condição (DP), já que o mesmo não é observado nos animais sham (Figura 41).

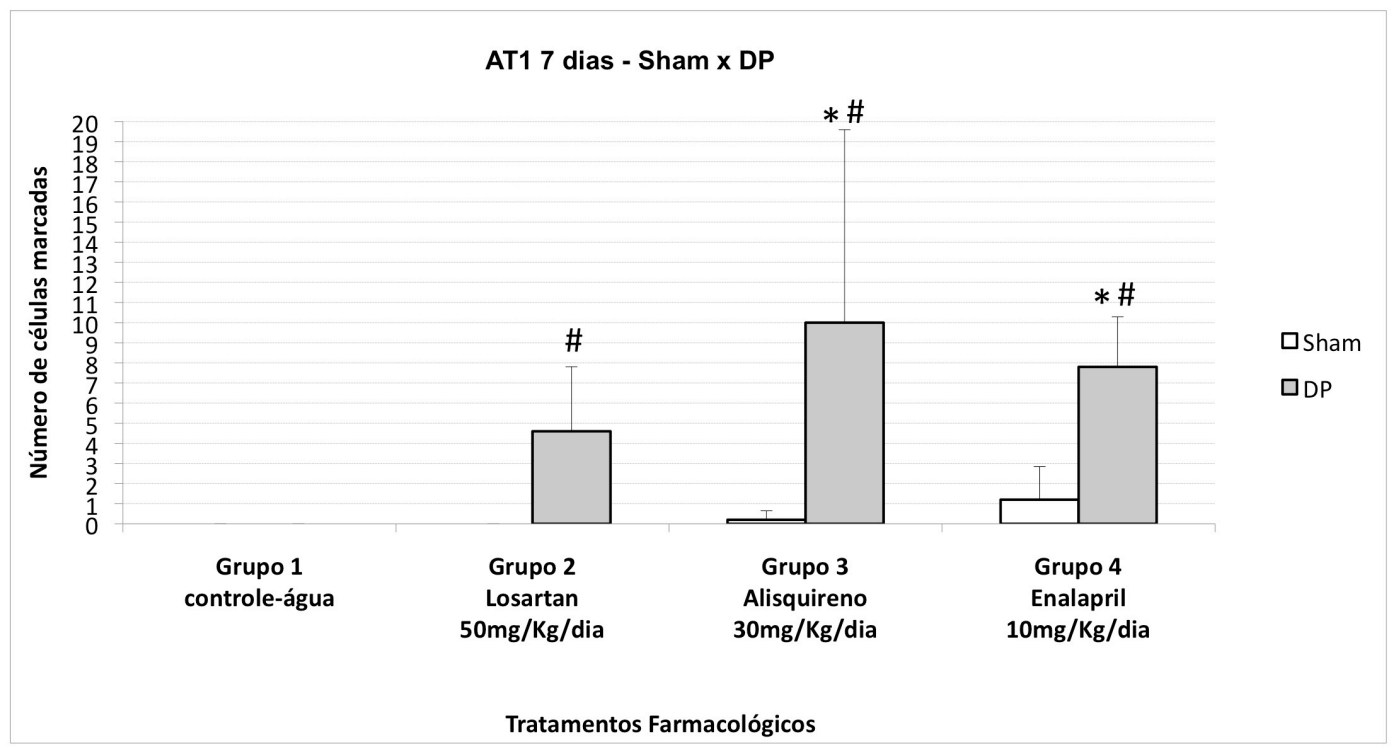

Figura 41 - Representação gráfica da imunomarcação para receptor AT1 em amostras de ratos sham operados e com tecidos afetados pela doença periodontal induzida experimentalmente por 7 dias ( $n=5$ em todos os períodos), nos diferentes tratamentos farmacológicos. SHAM: operação fictícia para indução da doença periodontal. DP: doença periodontal induzida experimentalmente.

$\left({ }^{*}\right)$ diferença estatisticamente significativa $(p<0,05)$ em relação ao grupo 1 (controle - água) para animais com DP.

$(\#)$ diferença estatisticamente significativa $(p<0,05)$ em relação aos animais do mesmo grupo (tratamento farmacológico) entre animais sham e DP. 


\subsubsection{Imunomarcação para AT2 7dias}

O tecido analisado, que foi a hemimandíbula do lado direito, mostrou imunomarcação para o receptor AT2 no trabeculado da região de furca do primeiro molar (Figura 42). 


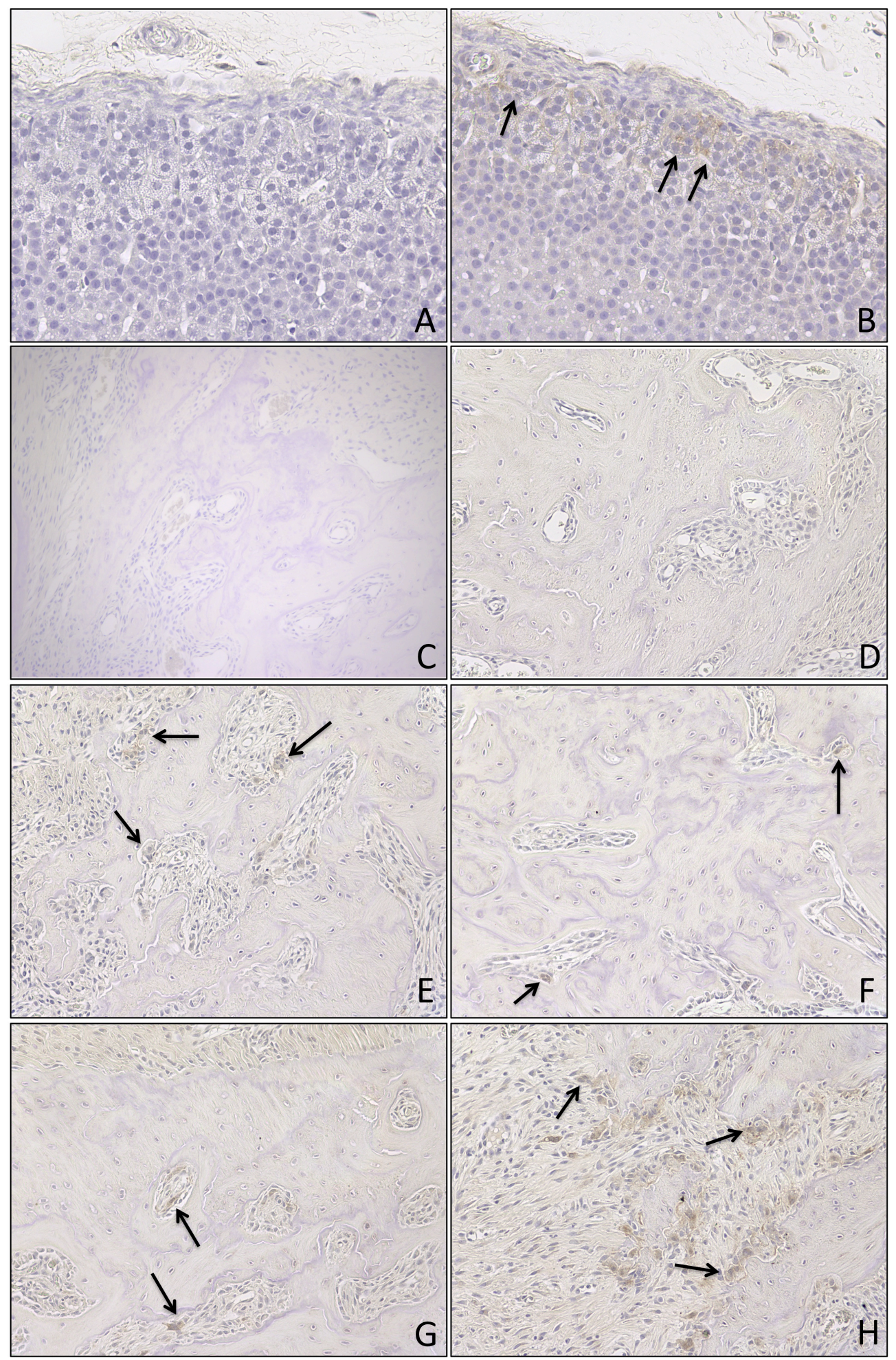

Figura 42 - A) Glândula adrenal (controle negativo da imunomarcação para o receptor AT2). B) Glândula adrenal (controle positivo) em corte seriado da glândula adrenal mostra imunomarcação para o receptor AT2 na região cortical (aumento de 40X). C) Controle negativo no tecido analisado, com ausência de imunomarcação no trabeculado da região de furca do primeiro molar inferior. D) Exemplo de tecido analisado da região de furca do primeiro molar inferior apresentando imunomarcação com escore 0 , E) com escore 1, F) com escore 2, G) com escore 3 e H) com escore 4 (aumento de 20X). As setas indicam imunomarcação. 
Ao analisar a imunomarcação para o receptor AT2 não houve diferença estatisticamente significativa quando comparados os animais sham provenientes dos vários tratamentos. Quando comparadas as condições sham e DP houve diferença estatisticamente significativa nos grupos 2 (losartan), 3 (alisquireno) e 4 (enalapril), ou seja, os animais com DP dos grupos 2, 3 e 4 apresentaram maior escore para a marcação do receptor AT2.

Houve diferença estatisticamente significativa quando comparados os grupos com DP provenientes dos tratamentos água $X$ losartan; água $X$ alisquireno e água $X$ enalapril.

Estes resultados sugerem uma interação entre os fatores tratamento farmacológico e condição (DP), já que o mesmo não é observado nos animais sham (Figura 43).

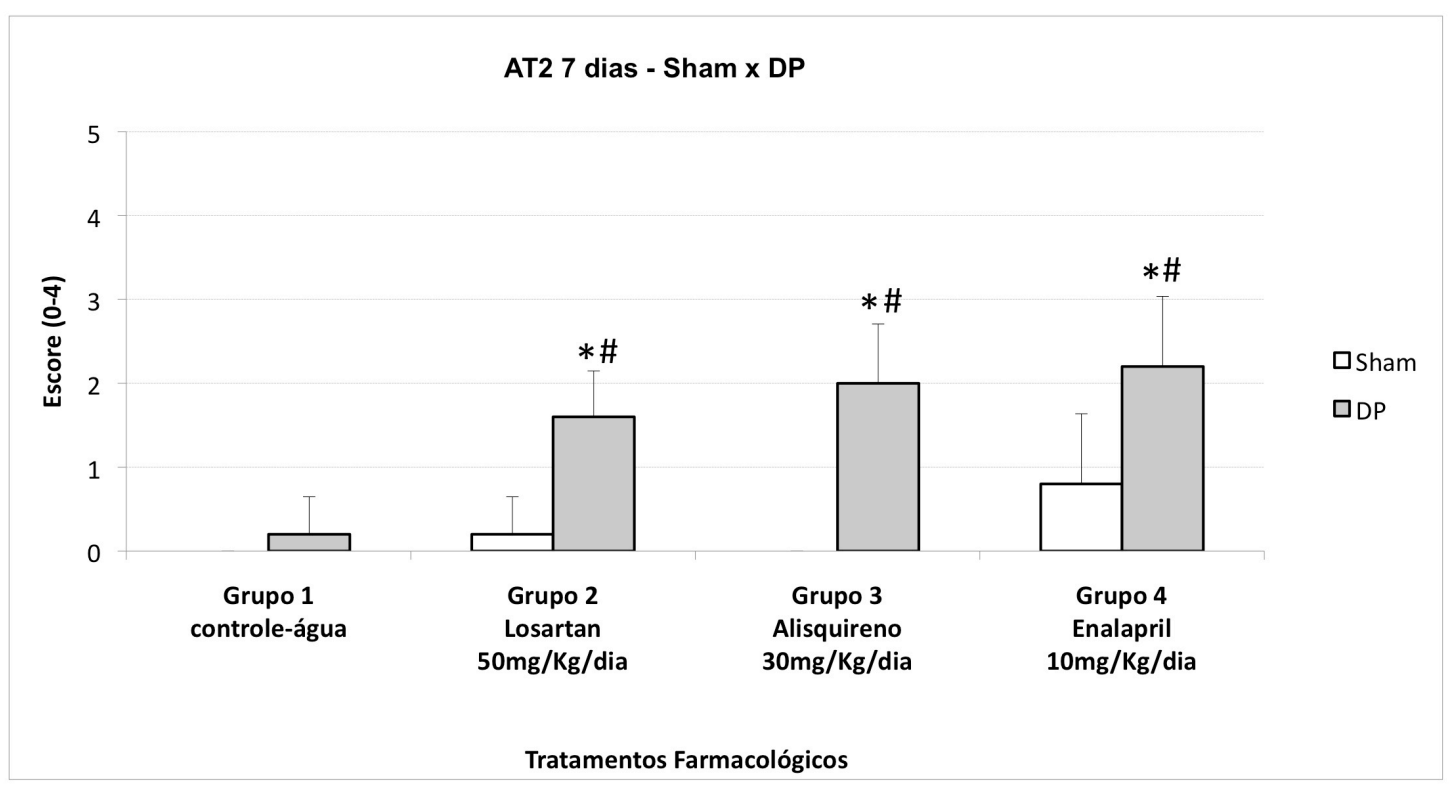

Figura 43 - Representação gráfica da imunomarcação para receptor AT2 em amostras de ratos sham operados e com tecidos afetados pela doença periodontal induzida experimentalmente por 7 dias ( $n=5$ em todos os períodos), nos diferentes tratamentos farmacológicos. SHAM: operação fictícia para indução da doença periodontal. DP: doença periodontal induzida experimentalmente. $\left({ }^{*}\right)$ diferença estatisticamente significativa $(p<0,05)$ em relação ao grupo 1 (controle - água) para animais com DP.

(\#) diferença estatisticamente significativa $(p<0,05)$ em relação aos animais do mesmo grupo (tratamento farmacológico) entre animais sham e DP. 


\subsubsection{Imunomarcação para ECA 7dias}

O tecido analisado, que foi a hemimandíbula do lado direito, mostrou imunomarcação para ECA no trabeculado da região de furca do primeiro molar (Figura 44).

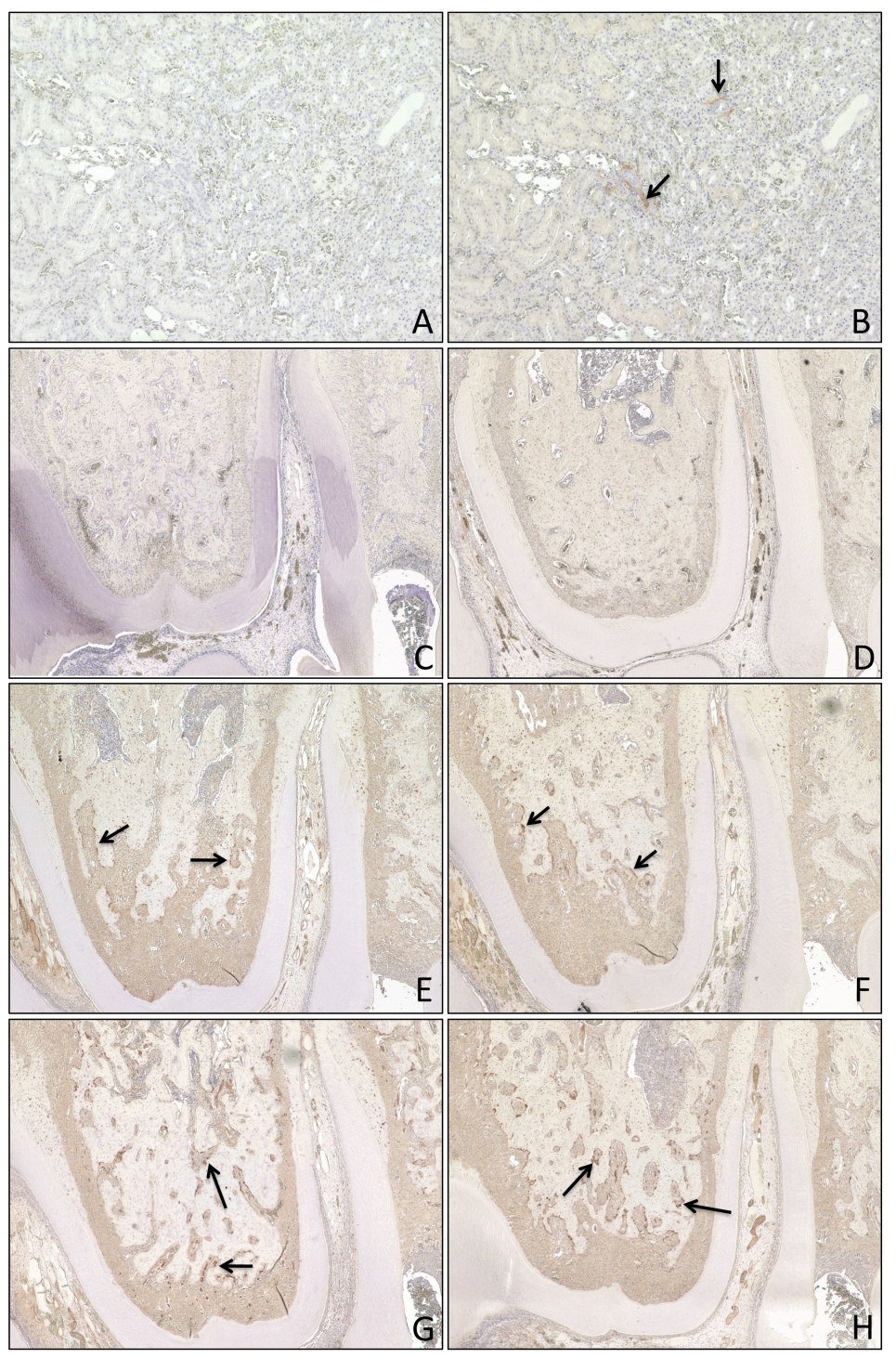

Figura 44 - A) Região tubular renal (controle negativo) da imunomarcação para ECA. B) Controle positivo em corte seriado mostra imunomarcação para ECA na região peritubular (aumento de 10X). C) Controle negativo no tecido analisado, com ausência de imunomarcação no trabeculado da região de furca do primeiro molar inferior. D) Exemplo de tecido analisado da região de furca do primeiro molar inferior apresentando imunomarcação com escore 0 , E) com escore 1, F) com escore 2, G) com escore 3 e H) com escore 4 (aumento de 10X). As setas indicam imunomarcação. 
Ao analisar a imunomarcação para a enzima ECA não houve diferença estatisticamente significativa quando comparados os animais sham provenientes dos vários tratamentos. Quando comparadas as condições sham e DP houve diferença estatisticamente significativa nos grupos 2 (losartan), 3 (alisquireno) e 4 (enalapril), ou seja, os animais com DP dos grupos 2, 3 e 4 apresentaram maior escore para a marcação da enzima ECA.

Houve diferença estatisticamente significativa quando comparados os grupos com DP provenientes dos tratamentos água $X$ losartan; água $X$ alisquireno; água $X$ enalapril e losartan $X$ alisquireno.

Estes resultados sugerem uma interação entre os fatores tratamento farmacológico e condição (DP), já que o mesmo não é observado nos animais sham (Figura 45).

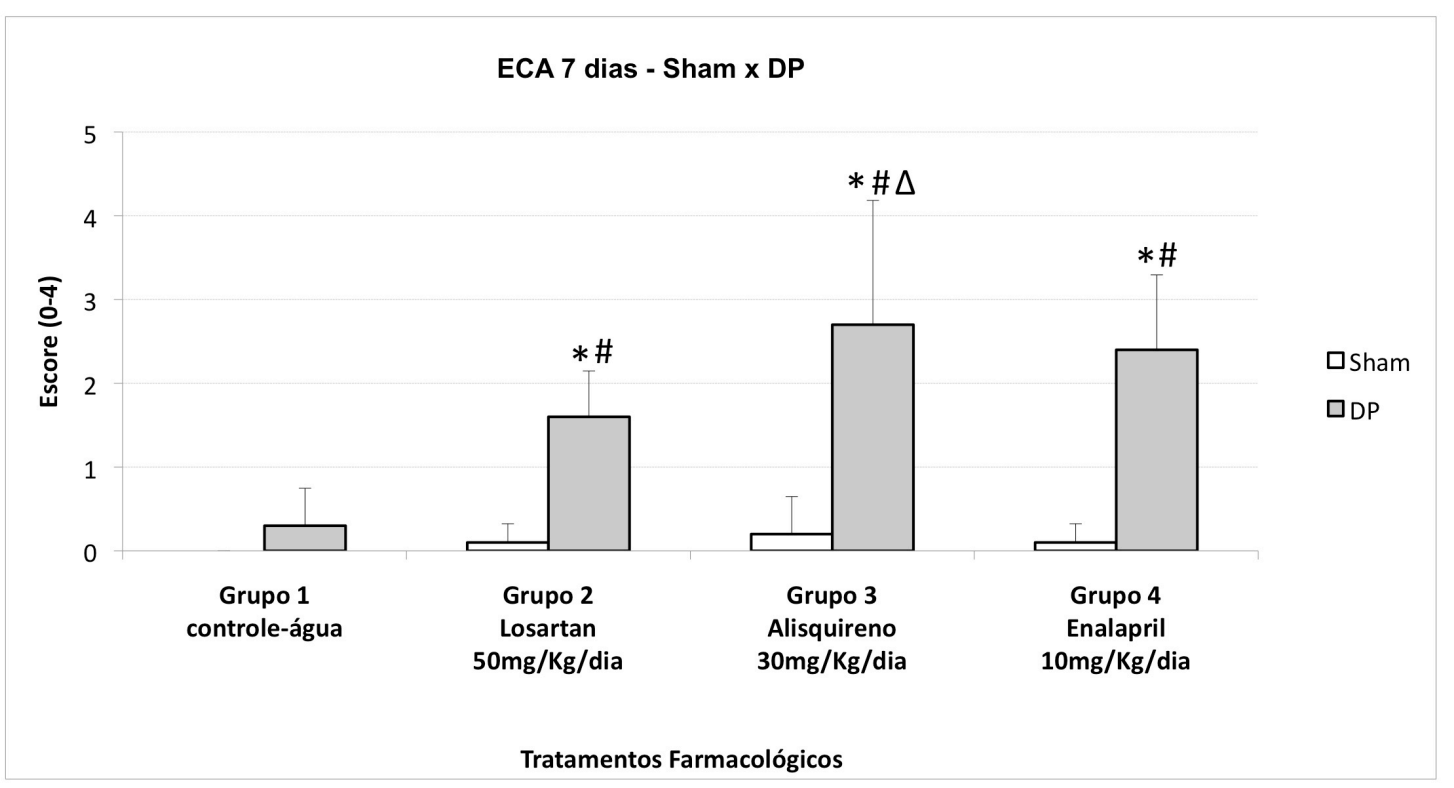

Figura 45 - Representação gráfica da imunomarcação para ECA em amostras de ratossham operados e com tecidos afetados pela doença periodontal induzida experimentalmente por 7 dias ( $n=5$ em todos os períodos), nos diferentes tratamentos farmacológicos. SHAM: operação fictícia para indução da doença periodontal. DP: doença periodontal induzida experimentalmente.

$\left({ }^{*}\right)$ diferença estatisticamente significativa $(p<0,05)$ em relação ao grupo 1 (controle - água) para animais com DP.

(\#) diferença estatisticamente significativa $(p<0,05)$ em relação aos animais do mesmo grupo (tratamento farmacológico) entre animais sham e DP.

$(\Delta)$ diferença estatisticamente significativa $(p<0,05)$ em relação ao grupo 2 (losartan) para animais com DP. 


\subsubsection{Imunomarcação nos animais tratados farmacologicamente ou com água por 14 dias}

\subsubsection{Imunomarcação para renina 14 dias}

Ao analisar a imunomarcação para renina, nos animais medicados por 14 dias, não houve diferença estatisticamente significativa quando comparadas as condições (sham X DP). Houve diferença estatisticamente significantiva quando comparados os tratamentos água $X$ losartan; água $X$ alisquireno e água $X$ enalapril, tanto para os animais sham quanto para os com DP (Figura 46).

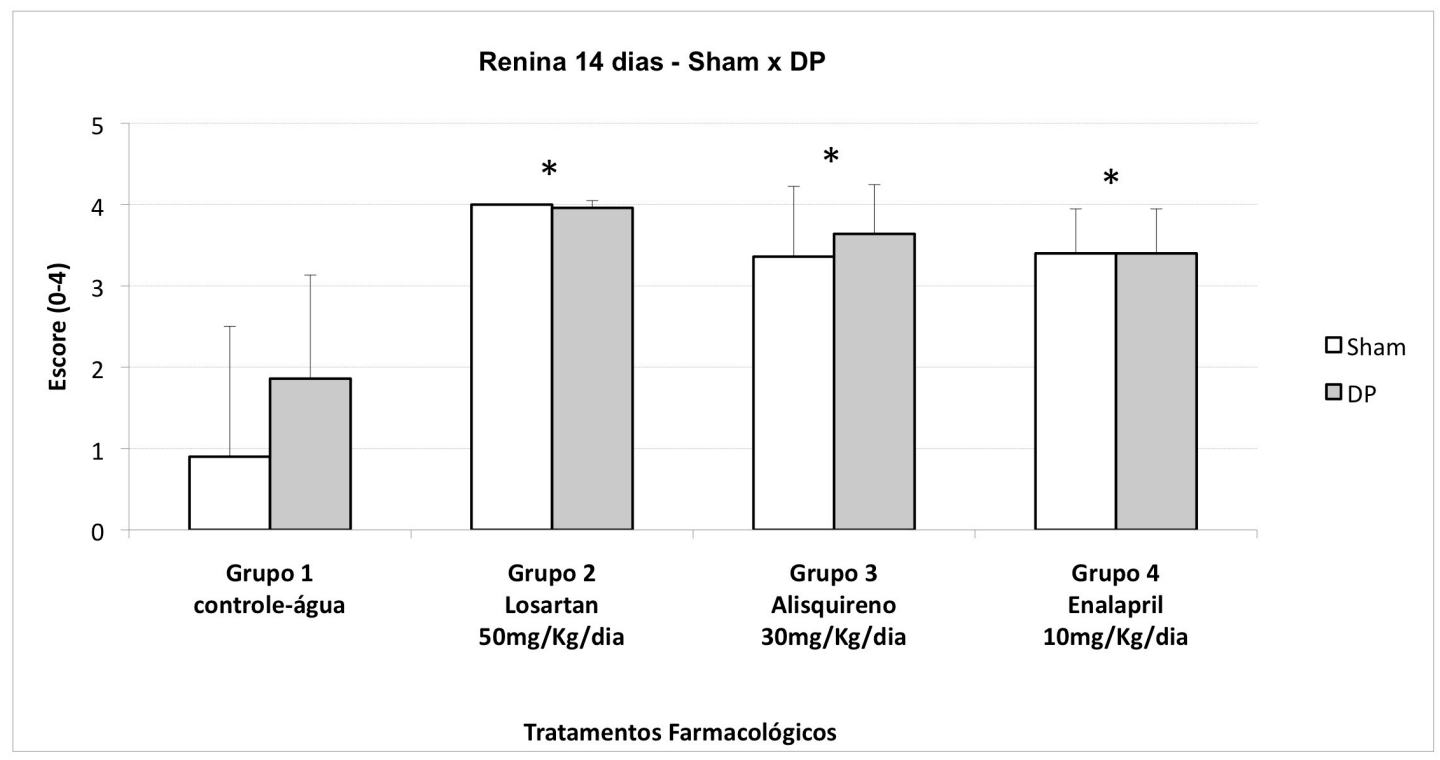

Figura 46 - Representação gráfica da imunomarcação para renina em amostras de ratos sham operados e com tecidos afetados pela doença periodontal induzida experimentalmente por 14 dias ( $n=5$ em todos os períodos), nos diferentes tratamentos farmacológicos. SHAM: operação fictícia para indução da doença periodontal. DP: doença periodontal induzida experimentalmente.

$\left({ }^{*}\right)$ diferença estatisticamente significativa $(p<0,05)$ em relação ao grupo 1 (controle - água) para animais sham e com DP. 


\subsubsection{Imunomarcação para AT1 14 dias}

Ao analisar a imunomarcação para o receptor AT1, nos animais medicados por 14 dias, não houve diferença estatisticamente significativa quando comparados os animais sham provenientes dos diferentes tratamentos farmacológicos. Quando comparadas as condições sham e DP houve diferença estatisticamente significativa nos grupos 2 (losartan), 3 (alisquireno) e 4 (enalapril), ou seja, os animais com DP dos grupos 2, 3 e 4 apresentaram maior número de células marcadas para o receptor AT1.

Houve diferença estatisticamente significantiva quando comparados os animas com DP dos tratamentos água $X$ losartan; água $X$ alisquireno e água $X$ enalapril (Figura 47).

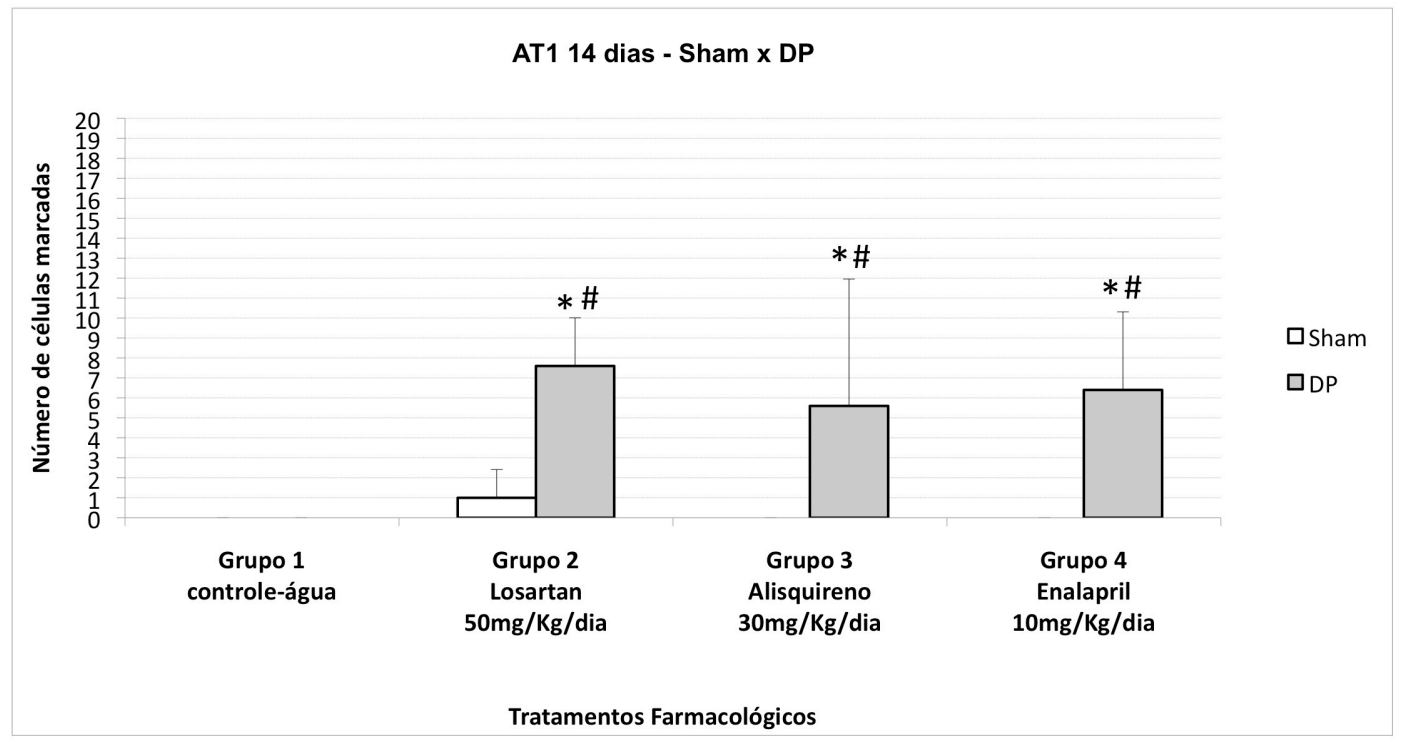

Figura 47 - Representação gráfica da imunomarcação para receptor AT1 em amostras de ratos sham operados e com tecidos afetados pela doença periodontal induzida experimentalmente por 14 dias ( $n=5$ em todos os períodos), nos diferentes tratamentos farmacológicos. SHAM: operação fictícia para indução da doença periodontal. DP: doença periodontal induzida experimentalmente. $\left.{ }^{*}\right)$ diferença estatisticamente significativa $(p<0,05)$ em relação ao grupo 1 (controle - água) para animais com DP.

(\#) diferença estatisticamente significativa $(p<0,05)$ em relação aos animais do mesmo grupo (tratamento farmacológico) entre animais sham e DP. 


\subsubsection{Imunomarcação para AT2 14 dias}

Ao analisar a imunomarcação para o receptor AT2, nos animais medicados por 14 dias, quando comparados os animais sham do grupo 1 (controle - água) com os animais sham provenientes dos diferentes tratamentos farmacológicos somente houve diferença estatisticamente significativa com o grupo 4 (enalapril). Quando comparadas as condições sham e DP houve diferença estatisticamente significativa no grupo 1 (controle - água), ou seja, os animais com DP do grupo 1 apresentaram maior escore para a marcação do receptor AT2.

Não houve diferença estatisticamente significantiva quando comparados os animas com DP dos tratamentos água $X$ losartan; água $X$ alisquireno e água $X$ enalapril (Figura 48).

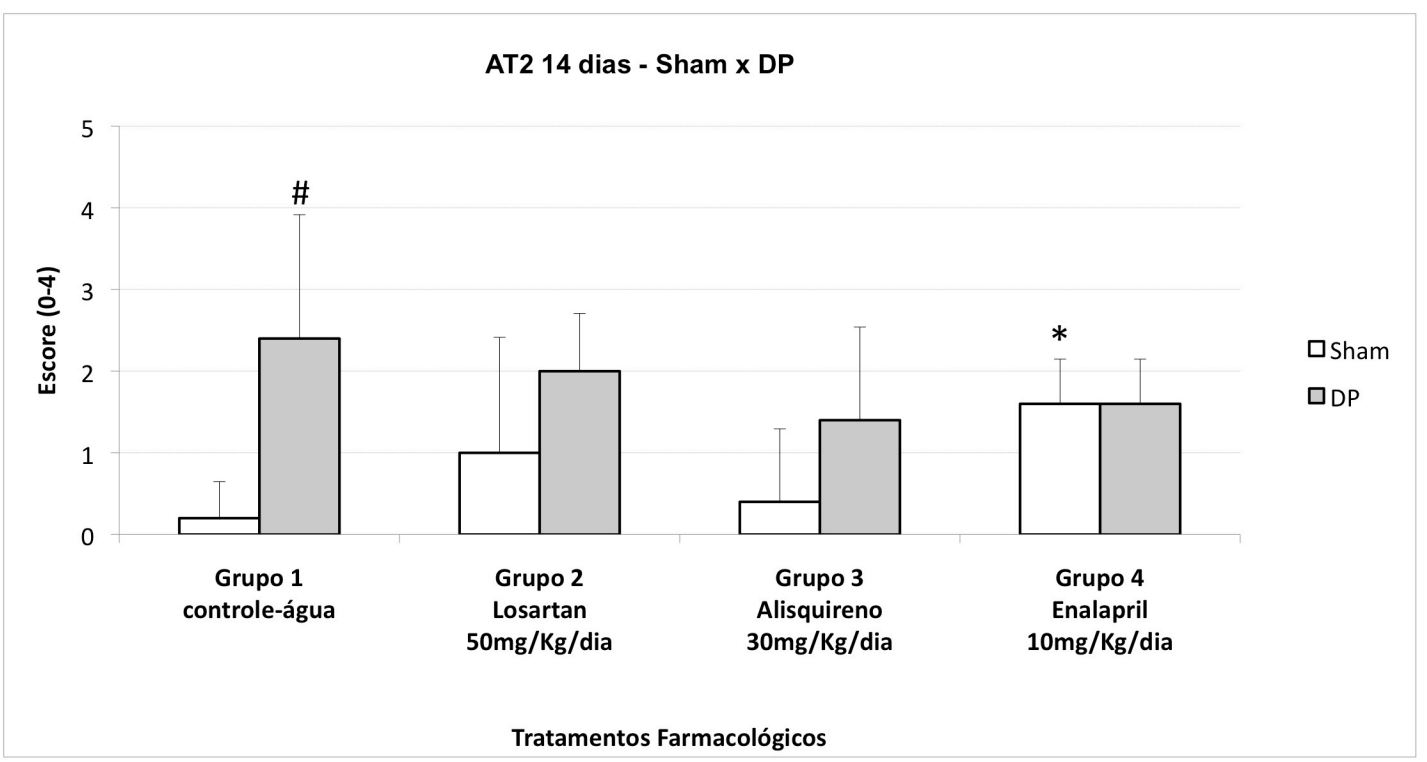

Figura 48 - Representação gráfica da imunomarcação para receptor AT2 em amostras de ratos sham operados e com tecidos afetados pela doença periodontal induzida experimentalmente por 14 dias ( $n=5$ em todos os períodos), nos diferentes tratamentos farmacológicos. SHAM: operação fictícia para indução da doença periodontal. DP: doença periodontal induzida experimentalmente.

$\left({ }^{*}\right)$ diferença estatisticamente significativa $(p<0,05)$ em relação ao grupo 1 (controle - água) para animais sham.

(\#) diferença estatisticamente significativa $(p<0,05)$ em relação aos animais do mesmo grupo (tratamento farmacológico) entre animais sham e DP. 


\subsubsection{Imunomarcação para ECA 14 dias}

Ao analisar a imunomarcação para a ECA, nos animais medicados por 14 dias, quando comparados os animais sham do grupo 1 (controle - água) com os animais sham provenientes dos diferentes tratamentos farmacológicos houve diferença estatisticamente significativa na comparação com o grupo 2 (losartan) e grupo 3 (alisquireno). Quando comparadas as condições sham e DP de animais provenientes do mesmo tratamento farmacológico houve diferença estatisticamente significativa no grupo 1 (controle - água) e no grupo 4 (enalapril), ou seja, os animais com DP do grupo 1 e 4 apresentaram maior escore para a marcação da ECA quando comparados com os animais sham que receberam o mesmo tratamento farmacológico .

Não houve diferença estatisticamente significante quando comparados os animas com DP dos tratamentos água $X$ losartan; água $X$ alisquireno e água $X$ enalapril (Figura 49).

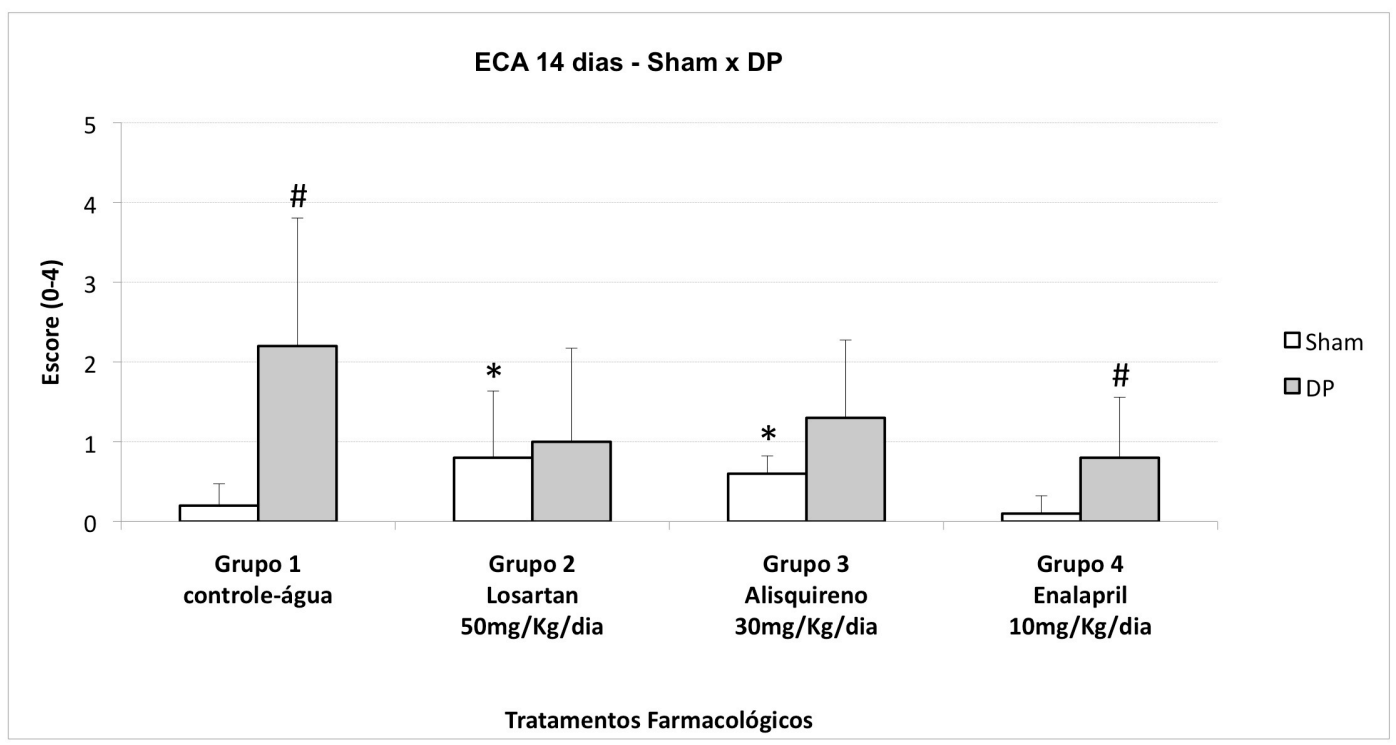

Figura 49 - Representação gráfica da imunomarcação para ECA em amostras de ratos sham operados e com tecidos afetados pela doença periodontal induzida experimentalmente por 14 dias ( $n=5$ em todos os períodos), nos diferentes tratamentos farmacológicos. SHAM: operação fictícia para indução da doença periodontal. DP: doença periodontal induzida experimentalmente.

$\left(^{*}\right)$ diferença estatisticamente significativa $(p<0,05)$ em relação ao grupo 1 (controle - água) para animais sham.

(\#) diferença estatisticamente significativa $(p<0,05)$ em relação ao animais do mesmo grupo (tratamento farmacológico) entre animais sham e DP. 


\subsubsection{Comparação da Imunomarcação nos animais tratados farmacologicamente ou com água por 7 e 14 dias}

\subsubsection{Imunomarcação para renina sham}

A comparação entre animais sham 7 dias e sham 14 dias mostrou diferença estatisticamente significativa nos grupos 2 (losartan), 3 (alisquireno) e 4 (enalapril). No grupo 2 (losartan) houve aumento na marcação para renina dos 7 aos 14 dias, já nos grupos 3 (alisquireno) e 4 (enalapril) houve diminuição da marcação para renina (Figura 50).

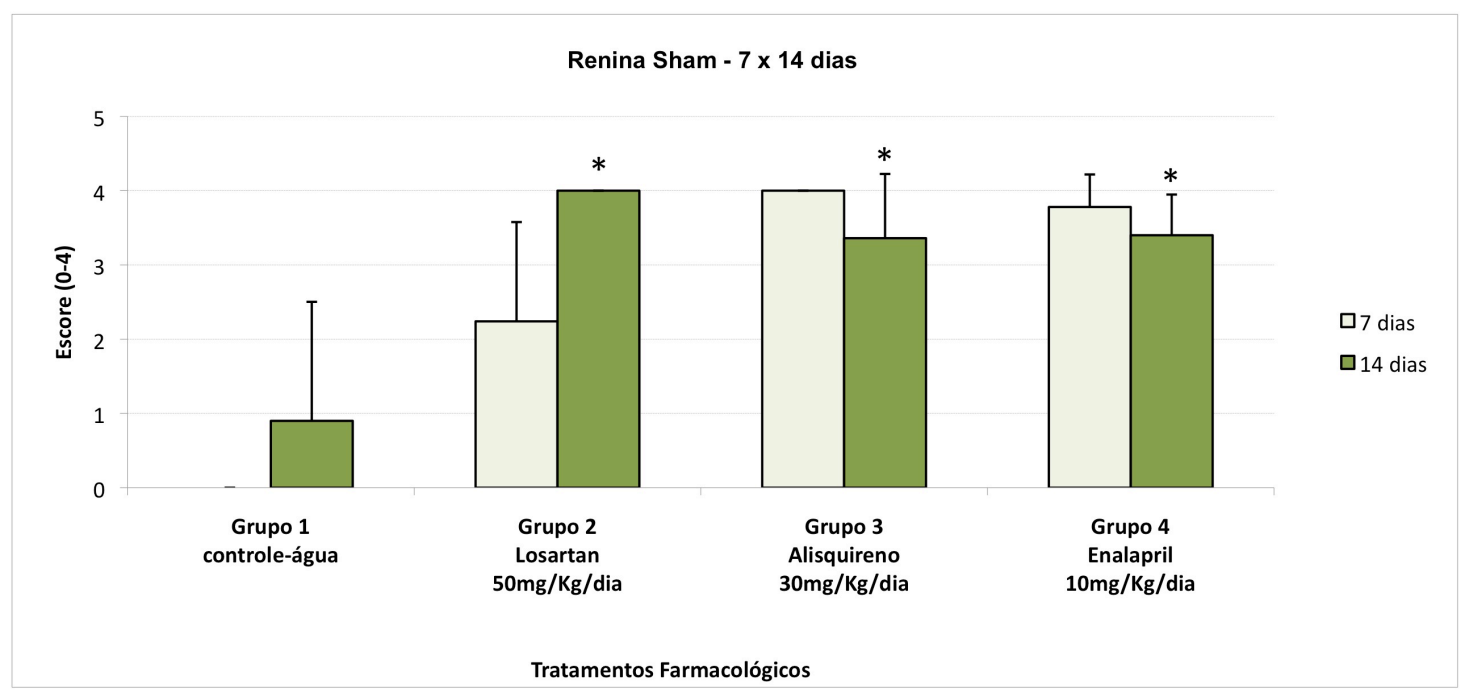

Figura 50 - Representação gráfica da imunomarcação para renina em amostras de ratos sham operados no período de 7 e 14 dias ( $n=5$ em todos os períodos), nos diferentes tratamentos farmacológicos. SHAM: operação fictícia para indução da doença periodontal.

$\left(^{*}\right)$ diferença estatisticamente significativa $(p<0,05)$ em relação aos animais do mesmo grupo (tratamento farmacológico) entre animais sham 7 dias e sham 14 dias. 


\subsubsection{Imunomarcação para renina DP}

A comparação entre animais com DP 7 dias e DP 14 dias mostrou diferença estatisticamente significativa nos grupos 1 (controle - água), 2 (losartan) e 3 (alisquireno). Nos grupos 1 (controle - água) e 2 (losartan) houve aumento na marcação para renina dos 7 aos 14 dias, já no grupo 3 (alisquireno) houve diminuição da marcação para renina (Figura 51).

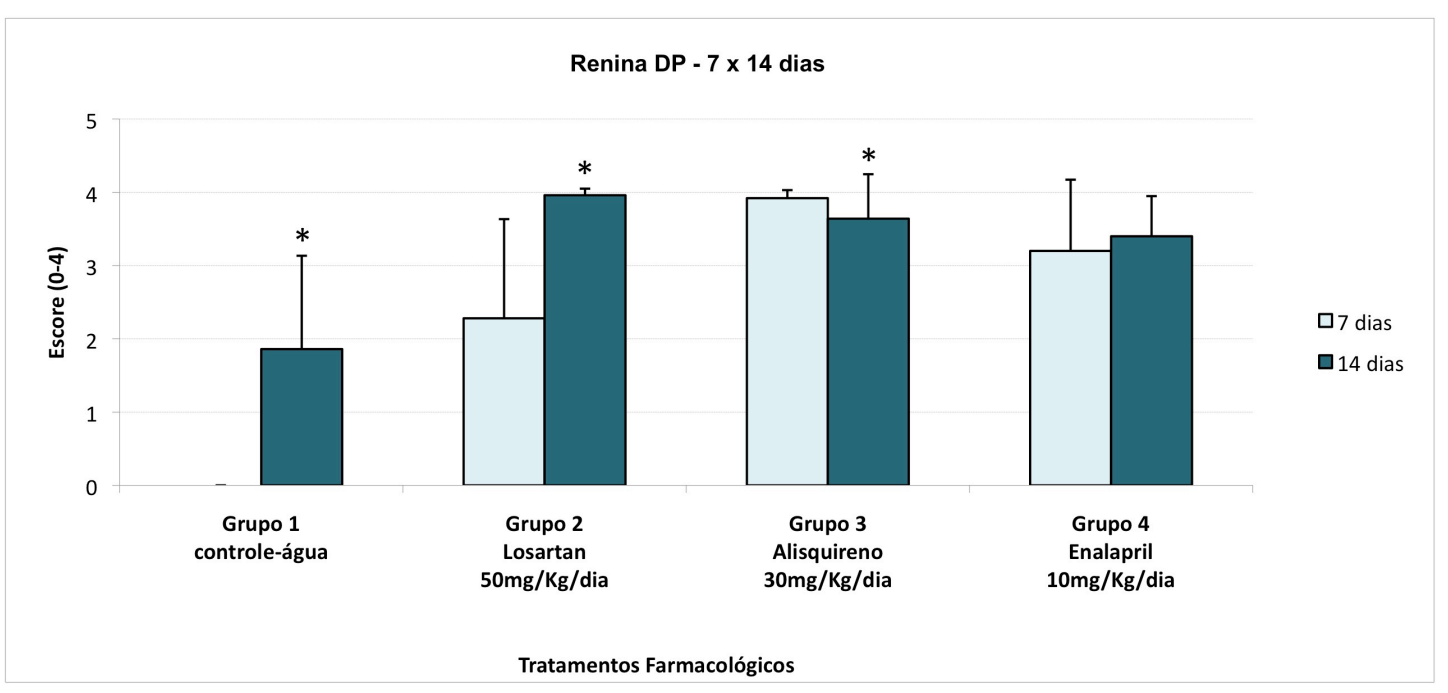

Figura 51 - Representação gráfica da imunomarcação para renina em amostras de ratos tecidos afetados pela doença periodontal induzida experimentalmente por 7 e 14 dias ( $n=5$ em todos os períodos), nos diferentes tratamentos farmacológicos. DP: doença periodontal induzida experimentalmente.

$\left({ }^{*}\right)$ diferença estatisticamente significativa $(p<0,05)$ em relação aos animais do mesmo grupo (tratamento farmacológico) entre animais DP 7 dias e DP 14 dias 


\subsubsection{Imunomarcação para AT1 sham}

A comparação entre animais sham 7 dias e sham 14 dias não apresentou diferença estatisticamente significativa em nenhum dos diferentes tratamentos farmacológicos (Figura 52).

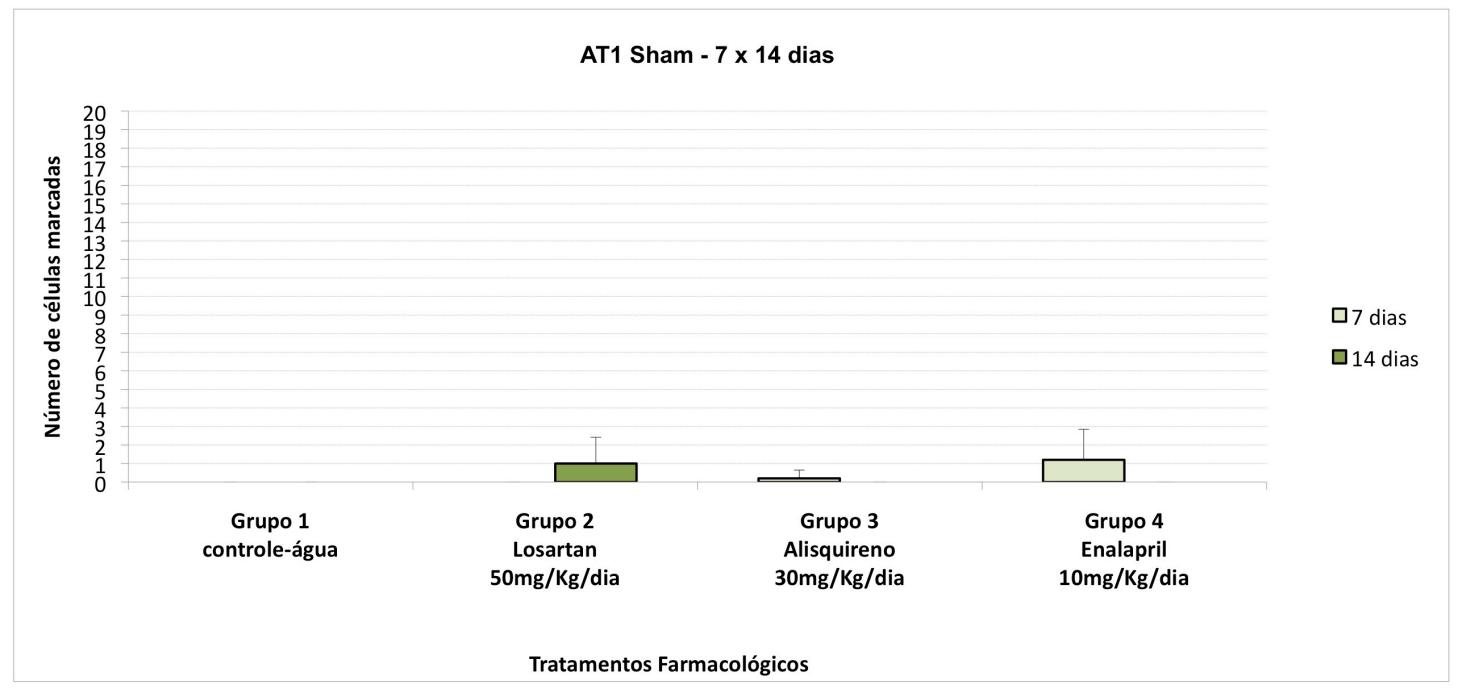

Figura 52 - Representação gráfica da imunomarcação para o receptor AT1 em amostras de ratos sham operados nos períodos de 7 e 14 dias ( $\mathrm{n}=5 \mathrm{em}$ todos os períodos), nos diferentes tratamentos farmacológicos. SHAM: operação fictícia para indução da doença periodontal. 


\subsubsection{Imunomarcação para AT1 DP}

A comparação entre animais com DP 7 dias e DP 14 dias não apresentou diferença estatisticamente significativa em nenhum dos diferentes tratamentos farmacológicos (Figura 53).

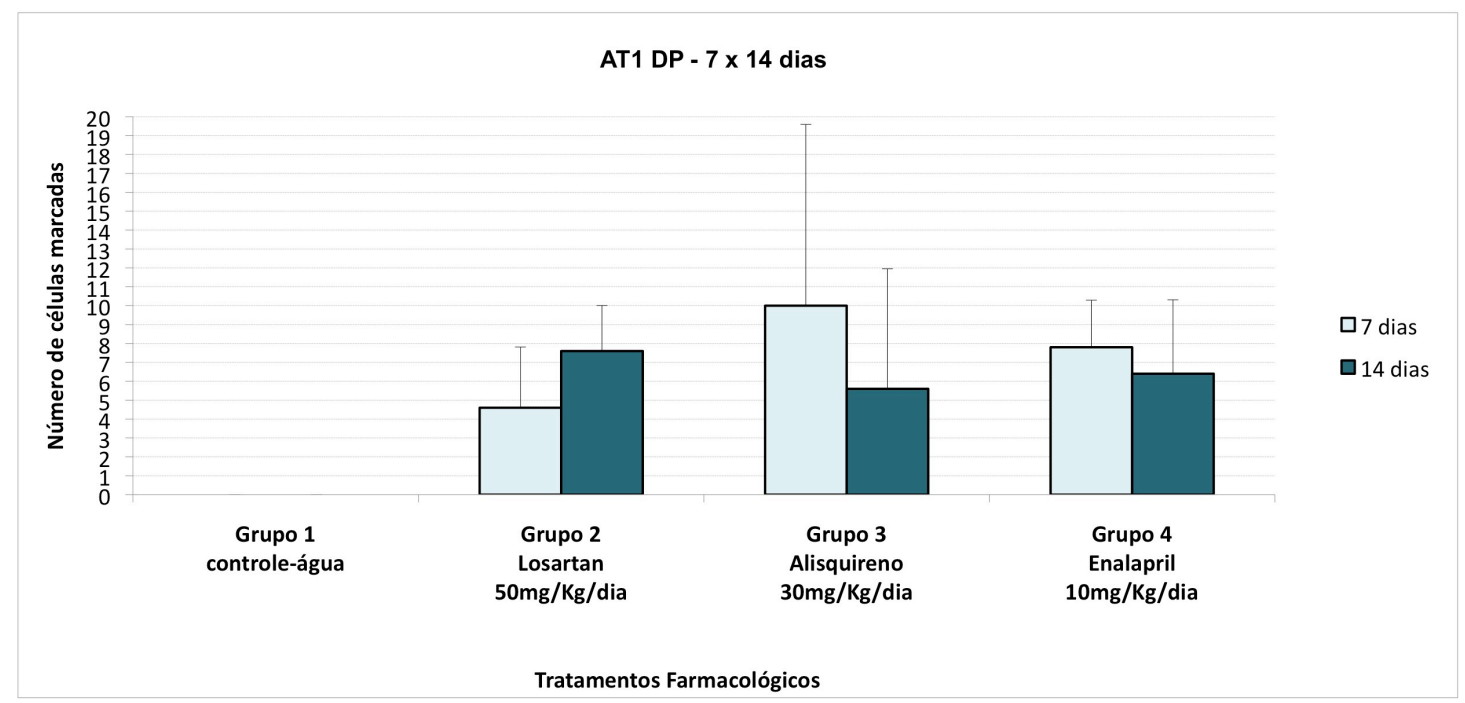

Figura 53 - Representação gráfica da imunomarcação para o receptor AT1 em amostras de ratos tecidos afetados pela doença periodontal induzida experimentalmente por 7 e 14 dias $(n=5$ em todos os períodos), nos diferentes tratamentos farmacológicos. DP: doença periodontal induzida experimentalmente. 


\subsubsection{Imunomarcação para AT2 sham}

A comparação entre animais sham 7 dias e sham 14 dias mostrou diferença estatisticamente significativa apenas no grupo 4 (enalapril). Houve aumento na marcação para o receptor AT2 dos 7 aos 14 dias (Figura 54).

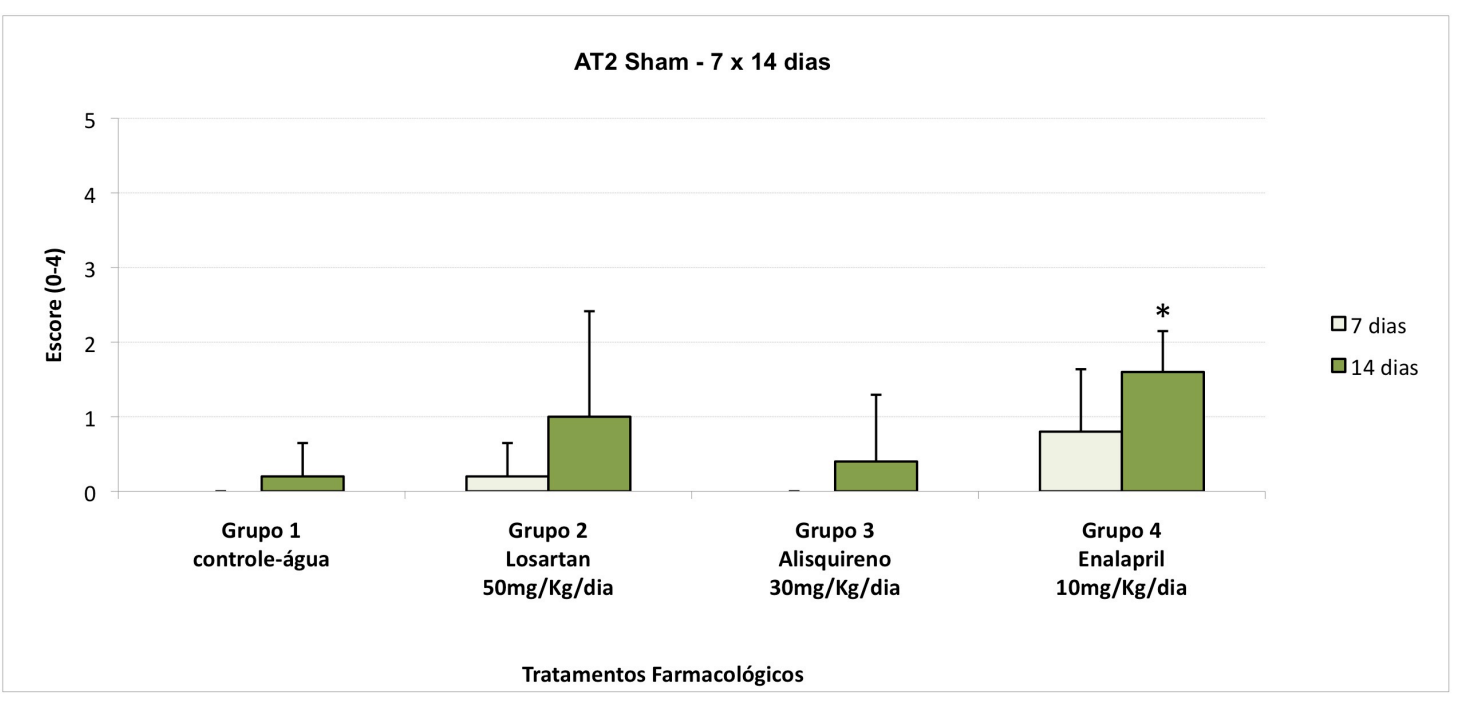

Figura 54 - Representação gráfica da imunomarcação para renina em amostras de ratos sham operados no período de 7 e 14 dias ( $n=5$ em todos os períodos), nos diferentes tratamentos farmacológicos. SHAM: operação fictícia para indução da doença periodontal.

$\left({ }^{*}\right)$ diferença estatisticamente significativa $(p<0,05)$ em relação aos animais do mesmo grupo (tratamento farmacológico) entre animais sham 7 dias e sham 14 dias. 


\subsubsection{Imunomarcação para AT2 DP}

A comparação entre animais com DP 7 dias e DP 14 dias mostrou diferença estatisticamente significativa apenas no grupo 1 (controle - água), houve aumento na marcação para o receptor AT2 dos 7 aos 14 dias (Figura 55).

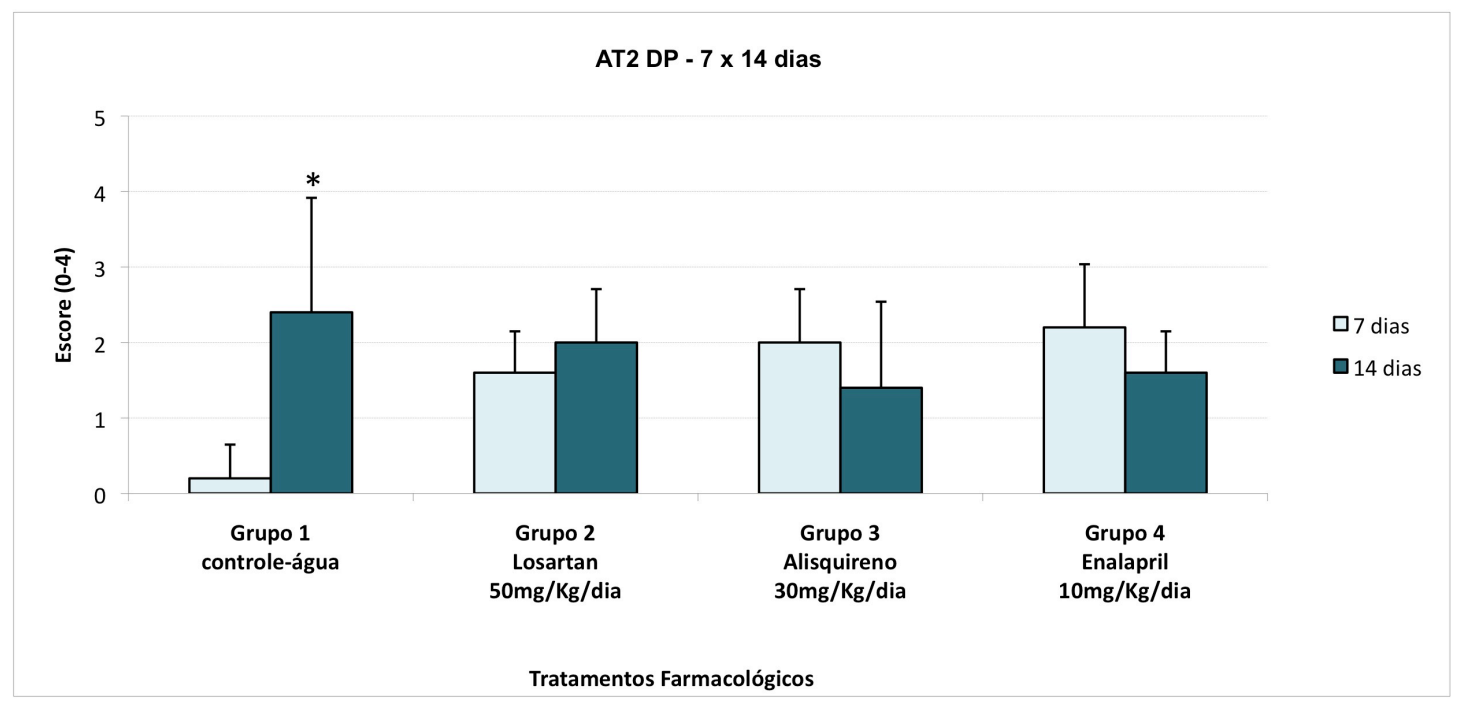

Figura 55 - Representação gráfica da imunomarcação para renina em amostras de ratos afetados pela doença periodontal induzida experimentalmente por 7 e 14 dias ( $n=5$ em todos os períodos), nos diferentes tratamentos farmacológicos. DP: doença periodontal induzida experimentalmente. $\left.{ }^{*}\right)$ diferença estatisticamente significativa $(p<0,05)$ em relação aos animais do mesmo grupo (tratamento farmacológico) entre animais DP 7 dias e DP 14 dias 


\subsubsection{Imunomarcação para ECA sham}

A comparação entre animais sham 7 dias e sham 14 dias mostrou diferença estatisticamente significativa apenas no grupo 2 (losartan) e 3 (alisquireno). Nestes grupos houve aumento na marcação para ECA dos 7 aos 14 dias (Figura 56).

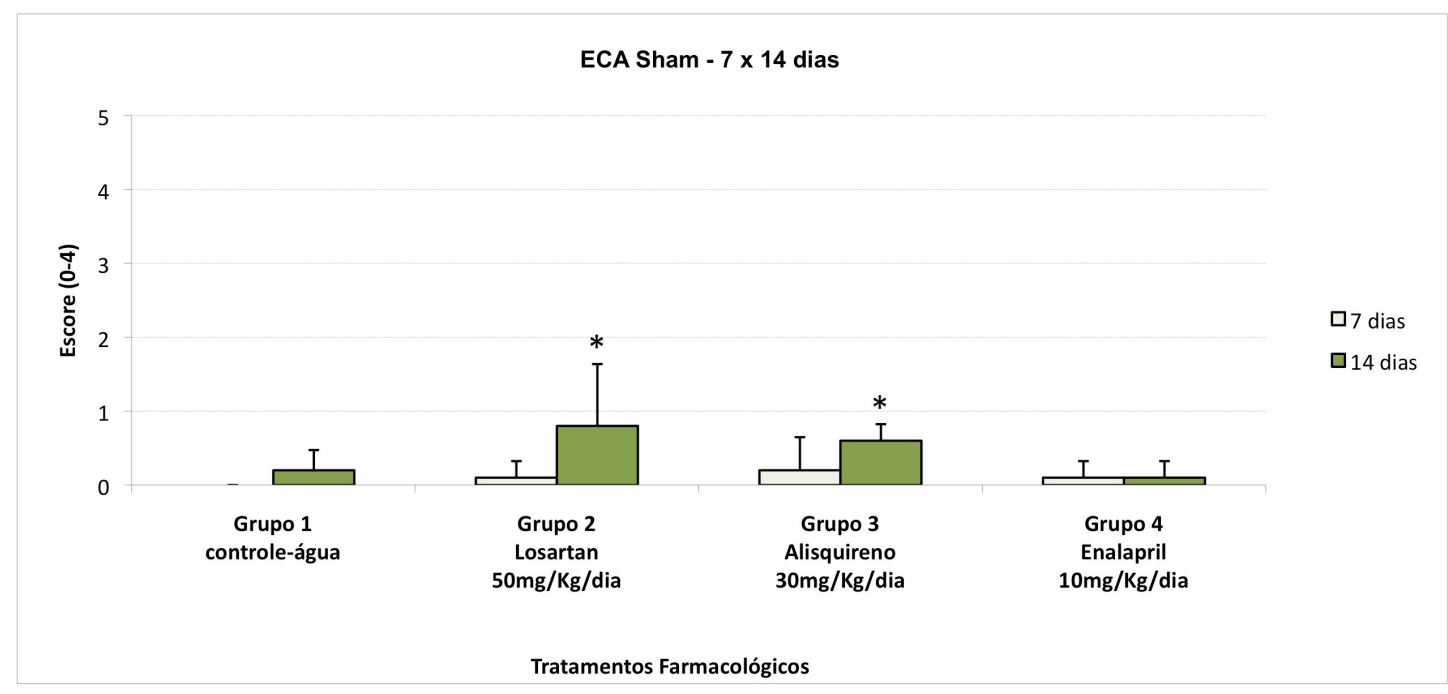

Figura 56 - Representação gráfica da imunomarcação para ECA em amostras de ratos sham operados no período de 7 e 14 dias ( $n=5$ em todos os períodos), nos diferentes tratamentos farmacológicos. SHAM: operação fictícia para indução da doença periodontal.

$\left({ }^{*}\right)$ diferença estatisticamente significativa $(p<0,05)$ em relação aos animais do mesmo grupo (tratamento farmacológico) entre animais sham 7 dias e sham 14 dias. 


\subsubsection{Imunomarcação para ECA DP}

A comparação entre animais com DP 7 dias e DP 14 dias mostrou diferença estatisticamente significativa apenas no grupo 4 (enalapril). Houve aumento na marcação para o receptor ECA dos 7 aos 14 dias (Figura 57).

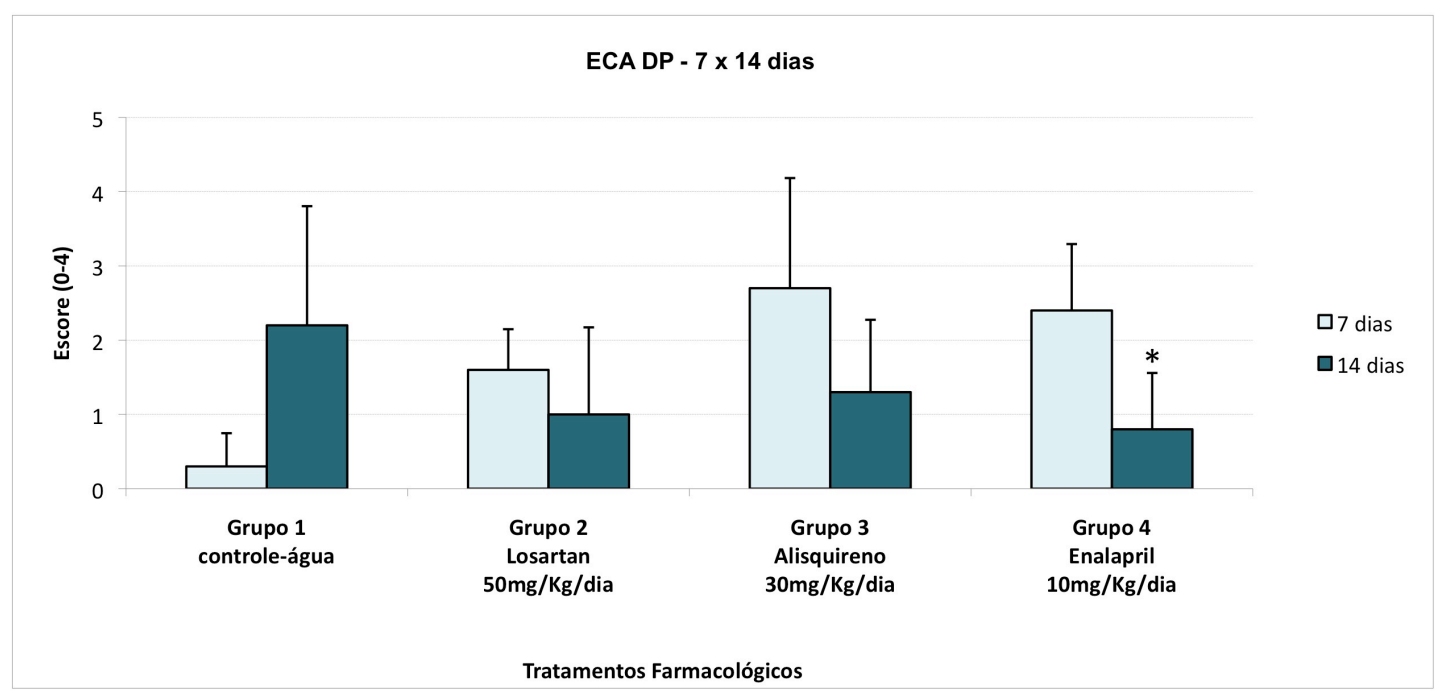

Figura 57 - Representação gráfica da imunomarcação para ECA em amostras de ratos afetados pela doença periodontal induzida experimentalmente por 7 e 14 dias $(n=5$ em todos os períodos), nos diferentes tratamentos farmacológicos. DP: doença periodontal induzida experimentalmente.

$\left.{ }^{*}\right)$ diferença estatisticamente significativa $(p<0,05)$ em relação aos animais do mesmo grupo (tratamento farmacológico) entre animais DP 7 dias e DP 14 dias 

Discussão 



\section{DISCUSSÃo}

Com o objetivo de tornar a discussão desse trabalho clara, inicialmente serão discutidos aspectos pertinentes à amostra, posteriormente à precisão da metodologia, e finalmente aos resultados encontrados.

\subsection{A amostra}

Foram utilizados para a composição da amostra 160 ratos Wistar, com idade de aproximadamente 60 dias, quando o ponto de contato dental já está bem estabelecido. $O$ estabelecimento da função oclusal nesta espécie ocorre aos 25 , 28 e 40 dias para primeiro, segundo e terceiro molares, respecivamente, (após a irrupção dos molares aos 19, 22 e 35 dias de vida animal para primeiro, segundo e terceiro molares, respectivamente) (Madden, Caton 1994). No entanto, com a idade, ocorre uma perda óssea fisiológica resultante dos processos de remodelação óssea conforme a atrição interproximal dos molares (Weinberg, Bral 1999). Devido a esta reabsorção fisiológica, o presente estudo foi baseado na comparação com amostras de animais sham operados, ou seja, sem DP induzida experimentalmente.

Utilizou-se um modelo experimental bem estabelecido em ratos para indução da doença periodontal inflamatória , que envolve a colocação de ligadura ao redor da região cervical do primeiro molar inferior (Madden, Caton 1994). A inserção da ligadura e sua manutenção subgengival, porém sem destruir completamente a adesão propiciada pela junção dentogengival, possibilita o acúmulo progressivo e espontâneo de biofilme composto por bactérias presentes na própria microbiota do animal e na sua dieta, sem qualquer manipulação adicional. A ligadura age como um fator promotor da formação de biofilme na área dentogengival, provocando achatamento e deslocamento dos tecidos gengivais mesial e distal, bem como reduz a integridade tecidual pela ulceração ocasional do epitélio sulcular, o que permite interação entre hospedeiro e biofilme dentário. Apesar de não ser uma doença espontânea, a manipulação do animal para sua indução é feita uma única vez e, a partir de então, a doença periodontal inflamatória progride naturalmente (Bezerra et al., 2000). 
Modelos animais são largamente utilizados em benefício da compreensão da patogênese da doença periodontal inflamatória e na avaliação de suas variadas modalidades terapêuticas (Madden, Caton 1994; Bezerra et al., 2000; Rodini et al., 2008; Oliveira et al., 2008). Embora não se possam esperar respostas idênticas e agressões semelhantes entre as diferentes espécies, modelos animais podem funcionar como modelos de tendências biológicas e fornecer informações impossíveis de se obter em humanos. Neste sentido, rato geralmente é alvo de estudos experimentais da doença periodontal inflamatória, devido às grandes semelhanças com os humanos em relação à anatomia da região de molares, inclusive da junção dentogengival, baixo custo de pesquisa, fácil manuseio e disponibilidade de utilização de várias raças com diferentes estados microbiológicos e imunológicos (Madden, Caton 1994; Weinberg, Bral 1999). Além disso, estudos longitudinais da doença periodontal inflamatória em humanos levantam vários problemas como a determinação do nível de atividade da doença, riscos individuais e suscetibilidade à progressão da doença. Então, é importante escolher um modelo animal experimental que possua características semelhantes com relação à anatomia e à doença periodontal inflamatória humana (Weinberg, Bral 1999). Uma das vantagens de se estudar uma doença experimentalmente induzida é poder observar seu curso ao longo do tempo, a fim de se compreender sua patogênese e definir a melhor forma de tratá-la (Madden, Caton 1994).

\subsection{Precisão da metodologia}

Para a análise da perda óssea alveolar calculou-se a precisão do investigador pelo erro sistemático inter e intra-examinador, visto que, o procedimento visava estabelecer a área da junção amelocementária das mandíbulas coradas com azul de metileno. A análise da perda óssea alveolar foi realizada por dois examinadores diferentes, e cada deles realizou as medições em duplicata. Isto reforça a confiabilidade ao trabalho, já que o erro sistemático $(p>0,05)$ reflete uma falta de padronização do método, uma vez que o examinador tende a sub ou superestimar os valores de suas medições de maneira inconsciente, de modo a direcionar os resultados de acordo com as suas 
expectativas em relação às conclusões do estudo (Estrela 2005). Assim, observou-se que erros na verificação da precisão desta metodologia foram admissíveis para erro sistemático intra-examinadores: $p=0,462$ (DP - examinador 1); $p=0,405$ (sham - examinador 1); $p=0,276$ (DP - examinador 2); $p=0,117$ (sham - examinador 2) e para erro sistemático inter-examinadores: $p=0,399$ (DP examinador 1 e 2); $p=0,249$ (sham - examinador 1 e 2), promovendo resultados transparentes e fidedignos.

\subsection{Discussão dos resultados}

Não existem na literatura científica trabalhos que comparem a eficácia de drogas que afetam o SRA utilizando a mesma metodologia realizada nesse trabalho. Portanto torna-se difícil estabelecer parâmetros de comparação para discussão dos resultados obtidos neste estudo.

Este trabalho confirma que a metodologia é efetiva para induzir perda óssea em ratos submetidos à indução da doença periodontal por meio do cálculo da área de perda óssea das mandíbulas coradas com azul de metileno (Oliveira et al., 2008). Os resultados obtidos mostram claramente que houve perda óssea significativa aos 14 dias de indução da DP e não aos 7 dias (Figura 18), o que sugere que o modelo é sensível ao tempo de indução para a análise da perda óssea alveolar.

Com auxílio das observações microscópicas realizadas, verificou-se nos animais com ligadura conseqüente acúmulo de agregados e biofilme no fio e na própria superfície dentária, revelando a disposição do infiltrado inflamatório, inclusive nas proximidades do tecido ósseo. As características básicas da acentuada perda óssea alveolar foram bem definidas no modelo experimental utilizado aos 14 dias, o que não foi observado nas amostras dos animais sham (sem doença periodontal), fortalecendo o papel do biofilme dentário e do fio como um fator irritante local para o acúmulo do referido biofilme e conseqüente iniciação da DP. Os resultados do presente estudo estão de acordo com vários outros trabalhos envolvendo a mesma metodologia de indução da doença periodontal inflamatória que relatam maior exuberância da inflamação e da perda óssea alveolar nas primeiras duas semanas após a colocação da ligadura (Bezerra et 
al., 2000; Rodini et al., 2008; Oliveira et al., 2008; de Almeida 2008; Garcia et al., 2009). Por este motivo fica justificada a escolha dos tempos de 7 e 14 dias de experimento. Além disso, o elevado metabolismo destes animais acelera a cinética de evolução da doença, o que acaba permitindo um estudo longitudinal em menor tempo, quando comparado com outras espécies.

Um dos objetivos desse trabalho foi avaliar a perda óssea alveolar em ratos submetidos à indução experimental da DP e tratados com drogas que afetam o SRA.

Aos 14 dias, os animais medicados com losartan (grupo 2) ou alisquireno (grupo 3) tiveram diminuição significativa da perda óssea quando comparados com o grupo tratado com água (grupo 1 controle - água). A eficácia do tratamento com losartan (antagonista de receptores AT1) para diminuir a perda óssea alveolar aos 14 dias de indução sugere fortemente a importante participação da Ang II na DP. Em outros modelos experimentais já está comprovada a participação da Ang II em todas as etapas do processo inflamatório (Marchesi et al, 2008).

Também houve uma diminuição da perda óssea nos animais tratados com enalapril (grupo 4) em relação ao grupo tratado com água (grupo 1, controle água), embora a diferença não tenha sido estatisticamente significativa. Em conjunto estes resultados sugerem que o bloqueio de receptores AT1 para Ang II (provocado pelo losartan) e a inibição da ação da renina (pelo alisquireno), mas não a inibição da ECA (pelo enalapril), são tratamentos eficazes para frear a progressão da perda óssea na DP induzida experimentalmente em ratos no período de 14 dias de indução. Assim, os resultados do presente estudo mostram de maneira inédita que o tratamento sistêmico com drogas que interferem com o Sistema Renina-Angiotensina pode modificar a progressão da doença periodontal inflamatória experimental no período de 14 dias.

Outro objetivo deste trabalho foi avaliar se existe aumento dos componentes do SRA no modelo de DP induzida experimentalmente em ratos. Com esse intuito foi realizada quantificação da imunomarcação por meio de microscopia e PCR. No período de 7 dias não houve marcação para renina no grupo 1 (controle - água) tanto nas condições DP e sham, ou seja, a renina não está presente nos tecidos gengivais neste grupo. Já quando foram analisados os grupos tratados com losartan (grupo 2), alisquireno (grupo 3 ) e enalapril (grupo 4) 
foi revelada marcação para renina nos vasos da região mesial e distal da mandíbula, nas proximidades da região muscular. Não existe diferença estatisticamente significantiva entre as condições DP e sham, o que demonstra não haver relação entre a marcação para a renina e a condição e sim relação entre a marcação para renina nos tecidos estudados e os tratamentos, já que os grupos 2 (losartan), 3 (alisquireno) e 4 (enalapril) apresentaram diferença estatisticamente significativa quando comparados ao grupo 1 (controle - água).

O grupo 3, tratado com alisquireno, foi o que teve a maior marcação pela renina. $O$ alisquireno se liga ao sítio da renina, que cliva o angiotensinogênio em angiotensina I impedindo, portanto, que a clivagem ocorra. Como conseqüência, não há feedback para diminuição da produção de renina e então aumento da renina circulante. Este aumento é superior ao induzido por inibidores da ECA e bloqueadores dos receptores de Ang II (Verdecchia 2008).

A marcação para renina nos animais tratados com enalapril (grupo 4) foi a segunda em abundância, embora a ação da ECA estivesse inibida. Uma possível explicação para este resultado é a existência de vias alternativas à produção de Ang II a partir da Ang I via quimase e catepsinas (Kher 2009) e elastase-2 (Santos et al., 2002a). Estas vias alternativas são responsáveis pela clivagem de $40 \%$ da angiotensina I em angiotensina II. Conseqüentemente a produção de angiotensina Il diminui, mas ainda existe, há feedback parcial para diminuição da produção de renina e então aumento parcial da renina circulante (Verdecchia 2008). Vale ressaltar que nesse trabalho foi feita a PCR para elastase-2. Embora inconsistente, foi revelada a presença desta enzima no tecido gengival, o que pode explicar a não efetividade do tratamento com enalapril no bloqueio da perda óssea, pois se sabe que a elastase-2 pode formar Ang II diretamente a partir do tetradecapeptídeo substrato de renina, um substrato semelhante ao angiotensinogênio.

A menor marcação para a renina ocorreu no grupo tratado com losartan, possivelmente pelo feedback minimizado via ligação de Ang II nos receptores AT2, que não estavam bloqueados pela droga, e por conseguinte menor marcação para renina dentre os grupos estudados. Os inibidores da renina e da ECA e os bloqueadores dos receptores de angiotensina interrompem os mecanismos de retroalimentação negativa tanto da alça curta quanto da alça longa e, portanto aumentam a liberação de renina (Goodman and Gilman, 2007). 
Os resultados fazem sentido já que a inibição do SRA em qualquer etapa da cascata aumenta a secreção de renina por meio da atenuação do efeito de feedback negativo da Ang II (Verdecchia 2008).

Como a marcação para a renina ocorreu no endotélio das arteríolas, não é possível neste caso comprovar se a produção da renina é local ou, proveniente da recaptação da renina circulante pelas células endoteiais como demonstrado por Swales et al. (1983).

Comparando-se os resultados da marcação para renina de 7 e 14 dias a única mudança significativa foi nos animais com doença periodontal sem tratamento. Ao longo do curso da doença periodontal houve um aumento na marcação para a renina nos animais com doença periodontal de 7 para 14 dias, o que sugere que a doença esteja agindo como estímulo para o aumento da expressão ou captação de renina nos tecidos estudados.

Ao analisar os gráficos da imunomarcação para renina e para o receptor AT1 lado a lado pode-se constatar que ambos seguem a mesma tendência: maior marcação para os animais tratados com alisquireno, seguida dos tratados com enalapril e então losartan. O raciocínio é exatamente o mesmo seguido para a marcação para a renina, ou seja, a inibição do SRA em qualquer etapa aumenta a quantidade de renina circulante e a quantidade de receptores AT1.

Houve imunomarcação para o receptor AT1 no ligamento periodontal na região interproximal entre o primeiro e segundo molares. Quando comparadas as amostras sham com as amostras DP, nos diferentes tratamentos, apenas o grupo 1 (controle - água) não apresentou diferença significativa, tanto aos 7 dias quanto aos 14 dias, portanto não foi a doença periodontal per si que causou a marcação para os receptores AT1 pois não há marcação nos animais com doença periodontal tratados com água (grupo 1, controle - água), nem apenas os tratamentos, pois os animais sham tratados com losartan, alisquireno e enalapril não apresentam marcação. Estes dados sugerem que: houve uma ação conjunta da condição e do tratamento que causou este aumento na marcação para receptores AT1, tanto aos 7 dias quanto aos 14 dias. Apenas no grupo 2 (losartan), aos 7 dias, os animais com DP não tiveram diferença estatisticamente significante quando comparados com DP do grupo 1 (controle - água), diferença 
esta que somente pôde ser notada aos 14 dias. Com relação à expressão de $\mathrm{RNA}_{\mathrm{m}}$ para $\mathrm{AT} 1_{\mathrm{a}}$ (análogo ao AT1) foi observada uma maior expressão desses receptores nos animais com DP do grupo 3 (alisquireno) aos 14 dias em comparação com 7 dias de tratamento.

A marcação para o receptor AT2, no trabeculado da região de furca do primeiro molar, também foi semelhante à marcação para AT1. A única diferença foi um aumento na marcação nas amostras dos animais com doença periodontal tratados com enalapril, que ultrapassou a marcação dos animais medicados com alisquireno e losartan. Ao se comparar os tratamentos de 7 e 14 dias, houve diferença estatisticamente significativa quando comparadas as amostras dos animais sham do grupo 4 (enalapril) e quando comparadas as amostras com DP do grupo 1 (controle - água). Provavelmente o grupo 4 (enalapril) seguiu a mesma tendência que o grupo 1 (controle - água) pois a perda óssea nestes casos foi parecida. O aumento de receptores AT2 pode ter ocorrido pois estes têm papel antiinflamatório (Marchesi, 2008). Já com relação à expressão de $\mathrm{RNA}_{\mathrm{m}}$ para AT2 revelou-se uma maior expressão desse receptor nos animais com DP do grupo 1 (controle-água) aos 7 e 14 dias, em relação ao seu respectivo sham, há aumento dos receptores AT2 na inflamação possivelmente pela ação antiinflamatória da ligação da Ang II no receptor AT2. O mesmo ocorreu no grupo 2 (losartan), o qual não bloqueou o aumento dos receptores AT2, o que ocorreu após tratamento com alisquireno (grupos 3) e enalapril (grupo 4). Provavelmente a maior quantidade circulante de Ang II, que não pode se ligar aos receptores AT1 (devido à ação antagonista do losartan), sobrecarrega os receptores AT2 havendo, então, uma necessidade de maior produção destes.

A marcação para ECA ocorreu no trabeculado do osso alveolar e a área analisada foi a área de furca. O efeito de ação conjunta da condição e do tratamento também pôde ser observado aos 7 dias de tratamento, quando todos os grupos, exceto o grupo 1 (controle - água), tiveram aumento significativo na marcação para ECA quando comparadas as amostras sham e DP, sendo que a análise por PCR confirmou esta diferença (entre sham e DP) nos tratamentos com losartan (grupo 2) e enalapril (grupo 4). Observa-se a mesma tendência da marcação tanto para a renina quanto para os receptores AT1. Pode-se especular 
que a quantidade de renina circulante implica na quantidade de ECA e também na quantidade de receptores AT1 (Verdecchia 2008).

Aos 14 dias de experimento houve um aumento considerável de marcação para ECA no grupo 1 (controle - água) nos animais com DP. O mesmo aconteceu com a expressão de RNA $\mathrm{m}_{\mathrm{m}}$ para ECA. Portanto, a doença per si aumenta a expressão desta enzima nos tecidos estudados, o que pode acarretar numa maior produção de Ang II, que sabidamente é um mediador da inflamação (Marchesi et al, 2008). E o inverso aconteceu no grupo 4 (enalapril) onde houve diminuição da marcação para ECA também nos animais com DP, passando a ocorrer diferença estatisticamente significativa quando comparadas as amostras sham e DP do grupo 1 (controle - água) bem como as amostras sham e DP do grupo 4 (enalapril). Nos grupos 2 (losartan) e 3 (alisquireno) a marcação para ECA praticamente se igualou entre as amostras sham e DP. Com relação à expressão de RNA $_{m}$ para ECA foi observada maior expressão dessa enzima nos animais tratados com alisquireno (grupo 3) aos 14 dias em comparação com 7 dias de tratamento independente da condição experimental (sham X DP). Ao se comparar os tratamentos de 7 e 14 dias houve diferença estatisticamente significativa quando comparados os animais sham do grupo 2 (losartan) e 3 (alisquireno) e os animais com DP do grupo 4 (enalapril).

Não se sabe exatamente o papel do SRA na DP, mas levando-se em consideração os resultados deste trabalho sugere-se que as drogas que afetam o SRA provoquem alterações na progressão da DP, uma vez que o tratamento com losartan e alisquireno foi efetivo em diminuir a perda óssea na DP induzida experimentalmente.

Diante dos resultados encontrados até o momento e dos achados da literatura, percebe-se o quão importante é entender o efeito das drogas que afetam o SRA e sua ação sobre a perda óssea alveolar na DP. São necessários mais estudos na área afim de elucidar tais efeitos, bem como os processos moleculares que levam à instalação e progressão desta patologia. Mesmo sendo o primeiro trabalho na literatura mundial, esta tese mostra de maneira inequívoca o envolvimento do SRA na iniciação e progressão da DP induzida experimentalmente em ratos. 
Conclusões 



\section{CONCLUSÕES}

Após a análise dos resultados obtidos podemos concluir que:

1. O Sistema Renina-Angiotensina exerce importante papel na iniciação e progressão da doença peridontal induzida experimentalmente em ratos, pois:

- Losartan (antagonista de receptores da Ang II) e alisquireno (inibidor de renina) foram capazes de diminuir a perda óssea alveolar na doença periodontal neste modelo experimental;

- Enalapril (inibidor da ECA), losartan e alisquireno foram capazes de alterar a expressão e/ou produção de vários componentes do SRA nos tecidos periodontais de ratos no modelo experimental empregado neste estudo.

2. Houve aumento da renina quando os animais foram tratados com as diferentes drogas (losartan, alisquireno e enalapril). Houve aumento dos componentes ECA, AT1 e AT2 nos animais com doença periodontal, grupo 7 dias, tratados com Losartan, Alisquireno e Enalapril, bem como do componente AT2 dos animais tratados por 14 dias. Este aumento não ocorreu nos animais do grupo sham sujeitos ao mesmos tratamentos. Este aumento só pode ser constatado na presença da condição (doença) e tratamento. Os animais somente com a doença pertencentes ao grupo controle, medicado com água, não apresentaram aumento da expressão destes componentes citados.

Também houve aumento dos componentes ECA e AT2 relacionado somente com a doença periodontal no grupo sem tratamento apenas do período de 14 dias.

Este trabalho não deixa dúvida de que os resultados encontrados indicam importante relação entre drogas que afetam o Sistema Renina-Angiotensina e a progressão da doença periodontal inflamatória.

Neste sentido, o trabalho contribui para o estudo do Sistema ReninaAngiotensina localizado em tecidos específicos com doença periodontal inflamatória. 



\section{Referências}





\section{REFERÊNCIAS BIBLIOGRÁFICAS}

Amaral SL, Papanek PE, Greene AS. Angiotensin II and VEGF are involved in angiogenesis induced by short-term exercise training. Am J Physiol Hear Circ Physiol 2001 Sep;281(3):H1163-9.

Arakawa K. Serine protease angiotensin II systems. J Hypertens Suppl 1996 Dec;14(5):S3-7.

Bader M. Tissue renin-angiotensin-aldosterone systems: Targets for pharmacological therapy. Annu. Rev. Pharmacol. Toxicol. 2010. 50:439-65.

Bastos M, Maeji NJ, Abeles RH. Inhibitors of human heart chymase based on a peptide library. Proc Natl Acad Sci U S A 1995 Jul;92(15):6738-42.

Bem-Ari ET, Garrison JC. Regulation of angiotensin mRNA accumulation in rat hepatocytes. Am J Physiol. 1988; 255:E70-9.

Berggreen E, Heyeraas KJ. Role of K+ATP channels, endothelin A receptors, and effect of angiotensin II on blood flow in oral tissues. J Dent Res 2003 Jan;82(1):337.

Berstein KE, Martin BM, Edwards AS, Berstein EA. Mouse angiotensin-converting enzyme is a protein composed of two homologous domains. J Biol Chem. 1989; 264: 11945-51.

Bezerra, MM; de Lima, V; Alencar, VB; Vieira, IB; Brito, GA; Ribeiro, RA; Rocha, FA. Selective cyclooxygenase-2 inhibition prevents alveolar bone loss in experimental periodontitis in rats. J Periodontol. 2000; 71 (6):1009-14.

Borges Jr I, Moreira EAM, Wilhem Filho D, Oliveira TB, Silva MBS, and Tânia Silvia Fröde, "Proinflammatory and Oxidative Stress Markers in Patients with Periodontal Disease," Mediators of Inflammation, vol. 2007, Article ID 45794, 5 pages, 2007. doi:10.1155/2007/45794

Boucher R, Asselin J, Genest J. A new enzyme leading to the direct formation of angiotensin II. Circ Res 1974;34-35(Suppl 1):203-9.

Broulik PD, Tesar V, Zima T, Jirsa M. Impact of antihypertensive therapy on the skeleton: effects of enalapril and AT1 receptor antagonist losartan in female rats. Physiol Res. 2001;50(4):353-8.

Burt B. Position paper: epidemiology of periodontal diseases. J Periodontol. 2005 Aug;76(8):1406-19.

Caldwell PR, Seegal BC, Hsu KC, Das M, Soffer RL. Angiotensin-converting enzyme: vascular endothelial localization. Science. 1976; 191(4231):1050-1. 
Campbell DJ. Circulating and tissue angiotensin systems. J Clin Invest 1987 Jan;79(1):1-6.

Campbell DJ, Habener JF. Angiotensinogen gene is expressed and differentially regulated in multiple tissues of the rat. J Clin Invest. 1986; 78:31-9.

Cassis LA, Saye J, Peach MJ. Location and regulation of rat angiotensinogen messenger RNA. Hypertension. 1988; 11:591-6.

Chen Z, Tan F, Erdös EG, Deddish PA. Hydrolysis of angiotensin peptides by human angiotensin I-converting enzyme and the resensitization of B2 kinin receptors. Hypertension. 2005; 46(6):1368-73.

Cornish KG, Joyner WL, Gilmore JP. Evidence for the conversion of angiotensin I to angiotensin II by the coronary microcirculation. Blood Vessels 1979;16(5):241-6.

Cunha V, Salgado HC, Salgado COM. Enalapril prevents aortic hyperreactivity and remodelling in one-kidney, one-clip hypertensive rats without reducing arterial pressure. Clinical and Experimental Pharmacology and Physiology 2000; 27, 4749.

Cushman DW, Cheung HS, Sabo EF, Ondetti MA. Design of potent competitive inhibitors of angiotensin-converting enzyme. Carboxyalkanoyl and mercaptoalkanoyl amino acids. Biochemistry 1977 Dec;16(25):5484-91.

de Almeida JM, Theodoro LH, Bosco AF, Nagata MJ, Oshiiwa M, Garcia VG. Influence of photodynamic therapy on the development of ligature-induced periodontitis in rats. J Periodontol. 2007 Mar;78(3):566-75.

De Cavanagh EMV, Ferder LF, Ferder MD, Stella IY, Toblli JE, Inserra F. Vascular Structure and Oxidative Stress in Salt-Loaded Spontaneously Hypertensive Rats: Effects of Losartan and Atenolol. Am J Hypertension.december 2010. Dez;23(1):21318-25.

de Gasparo M, Siragy HM. The AT2 receptor: fact, fancy and fantasy. Regul Pept. 1999; 81(1-3):11-24.

de Gasparo M, Catt KJ, Inagami T, Wright JW, Unger T. International Union of Pharmacology. XXIII. The angiotensin II receptors. Pharmacol Rev. 2000; 52(3):415-72.

Delima AJ, Van Dyke TE. Origin and function of the cellular components in gingival crevice fluid. Periodontol 2003;31:55-76.

Ebersole JL. Humoral immune responses in gingival crevice fluid: local and systemic implications. Periodontol 2000 2003;31:135-66.

Erdös EG, Skidgel RA. The unusual substrate specificity and the distribution of human angiotensin I converting enzyme. Hypertension. 1986; 8 (Suppl 1):34-7. 31. 
Estrela, C. Metodologia Científica. 2.ed. São Paulo: Artes Médicas Editora. 2005; Cap. 22, p.509-56.

Flemmig TF. Periodontitis. Ann Periodontol 1999 Dec;4(1):32-8.

Garcia VG, Fernandes LA, de Almeida JM, Bosco AF, Nagata MJ, Martins TM, Okamoto T, Theodoro LH. Comparison between laser therapy and non-surgical therapy for periodontitis in rats treated with dexamethasone. Lasers Med Sci. 2009 May 14.

Garlet GP, Cardoso CR, Silva TA, Ferreira BR, Avila-Campos MJ, Cunha FQ, Silva JS. Cytokine pattern determines the progression of experimental periodontal disease induced by Actinobacillus actinomycetemcomitans through the modulation of MMPs, RANKL, and their physiological inhibitors. Oral Microbiol Immunol. 2006 Feb;21(1):12-20.

Garlet GP, Martins W Jr, Fonseca BA, Ferreira BR, Silva JS. Matrix metalloproteinases, their physiological inhibitors and osteoclast factors are differentially regulated by the cytokine profile in human periodontal disease. J Clin Periodontol. 2004 Aug;31(8):671-9.

Garrison EA, Champion HC, Kadowitz PJ. [Pro11,D-Ala12]angiotensin I has rapid onset vasoconstrictor activity in the cat. Am J Physiol 1997 Dec;273(6 Pt 1):E1059-64.

Goker H, Haznedaroglu IC, Beyazit Y, Aksu S, Tuncer S, Misirlioglu M, et al. Local umbilical cord blood renin-angiotensin system. Ann Hematol. 2005; 84:277-81.

Gomez RA, Norling LL, Wilfong N, Isakson P, Lynch KR, Hock R, Quesenberry P. Leukocytes synthesize angiotensinogen. Hypertension 1993 Apr;21(4):470-5.

Gyorfi A, Fazekas A, Suba, Z, Ender F, Rosivall L. Neurogenic component in ligature-induced periodontitis in the rat. J Clin Periodontol 1994 Oct;21(9):601-5.

Hagiwara H, Hiruma $Y$, Inoue A, Yamaguchi A, Hirose S. Deceleration by angiotensin II of the differentiation and bone formation of rat calvarial osteoblastic cells. J Endocrinol 1998 Mar;156(3):543-50.

Hall ER, Kato J, Erdös EG, Robinson CJG, Oshima G. Angiotensin I-converting enzyme in the nephron. Life Sci. 1976; 18:1299-303.

Hirasawa K, Sato $\mathrm{Y}$, Hosoda $\mathrm{Y}$, Yamamoto T, Hanai H. Immunohistochemical localization of angiotensin II receptor and local rennin-angiotensin system in human colonic mucosa. J Histochem Cytochem. 2002; 50(2):275-82.

Hiruma $\mathrm{Y}$, Inoue A, Hirose $\mathrm{S}$, Hagiwara $\mathrm{H}$. Angiotensin II stimulates the proliferation of osteoblast-rich populations of cells from rat calvariae. Biochem Biophys Res Commun 1997 Jan;230(1):176-8.

Hoit BD, Shao Y, Kinoshita A, Gabel M, Husain A, Walsh RA. Effects of angiotensin II generated by an angiotensin converting enzyme-independent 
pathway on left ventricular performance in the conscious baboon. J Clin Invest 1995 Apr;95(4):1519-27.

Hollenberg NK, Fisher ND, Price DA. Pathways for angiotensin II generation in intact human tissue: evidence from comparative pharmacological interruption of the renin system. Hypertension 1998 Sep;32(3):387-92.

Inagami T, Iwai N, Sasaki K, Yamano Y, Bardhan S, Chaki S et al. Cloning, expression and regulation of angiotensin II receptors. Eur Heart J. 1994; 15 Suppl D:104-7.

Inoue K, Nishimura H, Kubota J, Kawamura K. Alternative angiotensin II formation in rat arteries occurs only at very high concentrations of angiotensin I. Hypertension 1999 Sep;34(3):525-30.

Jackman HL, Massad MG, Sekosan M, Tan F, Brovkovych V, Marcic BM, Erdös EG. Angiotensin 1-9 and 1-7 release in human heart: role of cathepsin A. Hypertension. 2002; 39(5):976-81.

Jackson EK, Garrison JC. Renin and angiotensin. In: Molinoff PB, Ruddon, Goodman \& Gilman's. The pharmacological basis of therapeutics. New York: Mcgraw-Hill, 1995. p. 733-58.

Jackson TR, Blair AC, Marshall J, Goedert M, Hanley MR. The Mas oncogene encodes an angiotensin receptor. Nature. 1988; 335: 437-40.

Kher V. Renin inhibition--benefit beyond hypertension control. J Assoc Physicians India. 2009; Jul;57:518-20.

Komlosi et al. Angiotensin I conversion to Angiotensin II stimulates cortical collecting duct sodium transport Hypertension. 2003, 42: 185-199.

Kramkowski K, Mogielnicki A, Buczko W. The physiological significance of the alternative pathways of angiotensin II production. 2006; 57(4):529-39.

Lam SY, Leung OS. A locally generated angiotensin system in rat carotid body. Regul Pept 2002; 107: 97-103.

Lamparter S, Kling L, Schrader M, Ziegler R, Pfeilschifter J. Effects of angiotensin II on bone cells in vitro. J Cell Physiol 1998 Apr;175(1):89-98.

Leung PS. The peptide hormone angiotensin II: its new functions in tissues and organs. Curr Protein Pept Sci . 2004; 5(4):267-73.

Linderman JR, Greene AS. Distribution of angiotensin II receptor expression in the microcirculation of striated muscle. Microcirculation. 2001; 8(4):275-81.

Listgarten MA. Nature of periodontal diseases: pathogenic mechanisms. J Periodontal Res 1987 May;22(3):172-8. 
Lohinai Z, Benedek P, Feher E, Gyorfi A, Rosivall L, Fazekas A, Salzman AL, Szabo C. Protective effects of mercaptoethylguanidine, a selective inhibitor of inducible nitric oxide synthase, in ligature-induced periodontitis in the rat. Brit $\mathrm{J}$ Pharmacol 1998 Feb;123(3):353-60.

Lundergan WP, Ferry D, Kobayashi H, Snowdowne KW. Angiotensin-II increases cytoplasmic calcium, cell number and total DNA for human periodontal ligamental cells in vitro. J Periodontal Res 1999 May;34(4):223-8.

Madden TE, Caton JG. Animal models for periodontal disease. Methods Enzymol 1994;253:106-19.

Marchesi C, Paradis P, Schiffrin EL. Role of the renin-angiotensin system in vascular inflammation. Trends in Pharmacological Sciences. 2008: 29(7): 367-74.

Marcic B, Deddish PA, Jackman HL, Erdös EG. Enhancement of bradykinin and resensitization of its B2 receptor. Hypertension. 1999; 33(3):835-43.

Maruta $\mathrm{H}$, Arakawa K. Confirmation of direct angiotensin formation by kallikrein. Biochem J 1983 Jul;213(1):193-200.

Nickenig G, Geisen G, Vetter H, Sachinidis A. Characterization of angiotensin receptors on human skin fibroblasts. J Mol Med 1997 Mar;75(3):217-22.

Nussberger J, Aubert JF, Bouzourene K, Pellegrin M, Hayoz D, Mazzolai L. Renin inhibition by aliskiren prevents atherosclerosis progression comparison with irbesartan, atenolol, and amlodipine. Hypertension. 2008;51:1306-11.

Nora EH et al. Localization of the ANG II type 2 receptor in the microcircultaion of skeletal muscle. Am J Physiol.275 (Heart Circ. Physiol. 44): H1395-1403, 1998.

O'Brien E, Barton J, Nussberger J, Mulcahy D, Jensen C, Dicker P, Stanton A. Aliskiren reduces blood pressure and suppresses plasma renin activity in combination with a thiazide diuretic, an angiotensin-converting enzyme inhibitor, or an angiotensin receptor blocker. Hypertension. 2007 Fev;49(2):276-84.

Obermüller N, Gentili M, Gauer S, Gretz N, Weigel M, Geiger H, et al. Immunohistochemical and mRNA localization of the angiotensin II receptor subtype 2 (AT2) in follicular granulosa cells of the rat ovary. J Histochem Cytochem. 2004; 52(4):545-8.

Ohuchi N, Hayashi K, Koike K, Kizawa Y, Kusama T, Ohsawa M, Taniguchi Y, Iwamoto K, Sano M, Murakami H. Pharmacological properties of angiotensin II receptors in cultured rabbit gingival fibroblasts. Comp Biochem Physiol C Toxicol Pharmacol 2004 Mar;137(3):281-9.

Ohuchi N, Koike K, Sano M, Kusama T, Kizawa Y, Hayashi K, Taniguchi Y, Ohsawa M, Iwamoto K, Murakami $\mathrm{H}$. Proliferative effects of angiotensin II and endothelin-1 on guinea pig gingival fibroblast cells in culture. Comp Biochem Physiol C Toxicol Pharmacol 2002 Aug;132(4):451-60. 
Okamura T, Okunishi H, Ayajiki K, Toda N. Conversion of angiotensin I to angiotensin II in dog isolated renal artery: role of two different angiotensin IIgenerating enzymes. J Cardiovasc Pharmacol 1990 Mar;15(3):353-9.

Okunishi H, Miyazaki M, Okamura T, Toda N. Different distribution of two types of angiotensin II-generating enzymes in the aortic wall. Biochem Biophys Res Commun 1987 Dec;149(3):1186-92.

Okunishi $\mathrm{H}$, Miyazaki M, Toda N. Evidence for a putatively new angiotensin IIgenerating enzyme in the vascular wall. J Hypertens 1984 Jun;2(3):277-84.

Oliveira MA, Fortes ZB, Santos RA, Kosla MC, De Carvalho MH. Synergistic effect of angiotensin-(1-7) on bradykinin arteriolar dilation in vivo. Peptides. 1999; 20(10):1195-201.

Oliveira TM, Sakai VT, Machado MAAM, Dionísio TJ, Cestari TM, Taga R, Amaral SL, Santos CF. COX-2 inhibition decreases VEGF expression and the alveolar bone loss during the progression of experimental periodontitis in rats. J Periodontol 2008 June;79(6):1062-9.

Oliver RC, Brown LJ, Loe H. Periodontal diseases in the United States population. J Periodontol. 1998 Feb;69(2):269-78.

Owen CA, Campbell EJ. Angiotensin II generation at the cell surface of activated neutrophils: novel cathepsin G-mediated catalytic activity that is resistant to inhibition. J Immunol 1998 Feb;160(3):1436-43.

Page RC. The role of inflammatory mediators in the pathogenesis of periodontal disease. J Periodontal Res 1991 May;26(3 Pt 2):230-42.

Paul M, Mehr AP, Kreutz, R. Physiology of local renin-angiotensin systems. Physiol Rev. 2006; 86:747-803.

Paula CA, Sousa MV, Salgado MC, Oliveira EB. Purification and substrate specificity of an angiotensin converting elastase-2 from the rat mesenteric arterial bed perfusate. Biochim Biophys Acta 1998 Oct;1388(1):227-38.

Peach MJ. Renin-angiotensin system: biochemistry and mechanisms of action. Physiol Rev 1977 Apr;57(2):313-70.

Phillips MI, Speakman EA, Kimura B. Levels of angiotensin and molecular biology of the tissue renin angiotensin systems. Regul Pept 1993 Jan;43(1-2):1-20.

Ram CV. Angiotensin blockade with eprosartan: vascular and functional implications. Curr Med Res Opin. 2007 Nov;23 Suppl 5:S5-11.

Raizada MK, Ferreira AJ. ACE2: a new target for cardiovascular disease therapeutics. J Cardiovasc Pharmacol. 2007; 50(2):112-9. 
Robbins SL, CR, Kumar VY. Inflamação e Reparo. In: Patologia Estrutural e Funcional. 6.ed. São Paulo: Guanabara Koogan Editora. 2000; Cap. 2, p.33-71.

Rodini CO, Batista AC, Dionísio TJ, Santos CF, Cunha FQ, Lara VS. Morphologic evaluation and expression of matrix metalloproteinases-2 and 9 and nitric oxide during experimental periodontal disease in rat. J Mol Histol. 2008 Jun;39(3):27582.

Ryan JW, Ryan US, Schultz DR, Whitaker C, Chung A, Dorer FE. Subcellular localization of pulmonary angiotensin-corventin enzyme (kininase II). Biochem J. $1975 ; 146: 497-9$.

Ryan JW, Day AR, Schultz DR, Ryan US, Chung A, Marlborough DI, et al. Localization of angiotensin-corventin enzyme (kininase II). Preparation of antibody- hemeoctapeptide conjugates. Tissue Cell. 1976; 8:111-24.

Enrique Sanchez-Lemus, Yuki Murakami, Ignacio M. Larrayoz-Roldan, Armen J. Moughamian, Jaroslav Pavel, Tsuyoshi Nishioku, and Juan M. Saavedra. Angiotensin II AT1 Receptor Blockade Decreases Lipopolysaccharide-Induced Inflammation in the Rat Adrenal Gland. Endocrinology 2008 149(10):5177-5188.

Santos CF, Akashi AE, Dionísio TJ, Didier DN, Greene AS, Oliveira SHP, Pereira HJ, Becari C, Oliveira EB, Salgado MCO. Characterization of a local reninangiotensin system in rat gingival tissue. J Periodontol 2009 Jan;80(1):130-9.

Santos CF, Caprio MA, Oliveira EB, Salgado MC, Schippers DN, Munzenmaier $\mathrm{DH}$, Greene AS. Functional role, cellular source and tissue distribution of rat elastase-2, an angiotensin II-forming enzyme. Am J Physiol Heart Circ Physiol 2003 Aug;285(2):H775-83.

Santos CF, Greene AS, Salgado MC, Oliveira EB. Conversion of renin substrate tetradecapeptide to angiotensin II by rat MAB elastase-2. Can J Physiol Pharmacol 2004 Nov;82(11):1000-5.

Santos CF, Oliveira EB, Salgado MC, Greene AS. Molecular cloning and sequencing of the cDNA for rat mesenteric arterial bed elastase-2, an angiotensin II-forming enzyme. J Cardiovasc Pharmacol 2002b May;39(5):628-35.

Santos CF, Paula CA, Salgado MCO, Oliveira EB. Kinetic characterization and inhibition of the rat MAB elastase-2, an angiotensin I-converting serine protease. Can J Physiol Pharmacol 2002a Jan;80(1):42-7.

Santos RAS, Brosnihan KB, Chappell MC, Pesquero JL, Chernicky CL, Greene $\mathrm{LJ}$, et al. Converting enzyme activity and angiotensin metabolism in the dog brainstem. Hypertension. 1988; 11:153-7.

Santos RAS, Campagnole-Santos MJ. Central and peripheral actions of Ang 1-7. Braz J Med Biol Res. 1994; 27: 1033- 47. 
Schmieder RE. Renin inhibitors: optimal strategy for renal protection. Curr Hypertens Rep. 2007 Nov;9(5):415-21.

Schulz W W, Hagler HK, Buja LM, Erdös EG. Ultrastructural localization of angiotensin I-converting enzyme (EC 3.4.15.1) and neutral metalloendopeptidase (EC 3.4.24.11) in the proximal tubule of the human kidney. Lab Invest. 1988; 59(6):789-97.

Segawa M, Nakao S, Ogata $Y$, Sugiya H, Furuyama S. Angiotensin II induces prostaglandin $E(2)$ release in human gingival fibroblasts. Life Sci 2003 Jan;72(7):795-803.

Schiffrin, E.L. (2002) Beyond blood pressure: the endothelium and atherosclerosis progression. Am. J. Hypertens. 15, 115S-122S.

Shimizu N, Yamaguchi M, Uesu K, Goseki T, Abiko Y. Stimulation of prostaglandin $\mathrm{E} 2$ and interleukin-1 $\beta$ production from old rat periodontal ligament cells subjected to mechanical stress. J Gerontol A Biol Sci Med Sci 2000 Oct;55(10):B489-95.

Singh VP, Le B, Khode R, Baker KM, Kumar R. Intracellular angiotensin II production in diabetic rats is correlated with cardiomyocyte apoptosis, oxidative stress, and cardiac fibrosis. Diabetes 2008 Dec;57:3297-306.

Snyder RA, Wintroub BU. Inhibition of angiotensin-converting enzyme by desLeu10-angiotensin I: a potential mechanism of endogenous angiotensin-converting enzyme regulation. Biochim Biophys Acta. 1986; 871(1):1-5.

Soubrier F, Alheng-Gelas F, Hubert C, Allegrini J, John M, Tregear G, et al. Two putative active centers in human angiotensin I-converting enzyme revealed by molecular cloning. Proc Natl Acad Sci USA. 1988; 85:9386-90.

Souza PPC, Fukada SY, Cunha FQ, Costa CAS, Costa-Neto CM. Regulation of angiotensin II receptors levels during rat induced pulpitis. Regul Pept. 2007; 140:27-31.

Speth RC, Thompson SM, Johns SJ. Angiotensin II receptors. Structural and functional considerations. Adv Exp Med Biol. 1995; 377:169-92.

Suzuki Y, Ruiz-Ortega M, Lorenzo O, Ruperez M, Esteban V, Egido J. Inflammation and angiotensin II. Int J Biochem Cell Biol 2003 Jun;35(6):881-900.

Swales JD, Abramovici A, Beck F, Bing RF, Loudon M, Thurston H. Arterial wall renin. J Hypertens Suppl 1983;1:17-22.

Takai S, Shiota N, Yamamoto D, Okunishi H, Miyazaki M. Purification and characterization of angiotensin II-generating chymase from hamster cheek pouch. Life Sci 1996;58(7):591-7. 
Tan, $\mathrm{PH}$ et al. Cytokeratins in papillary lesions of the breast. Is there a roe in distinguishing intraductal papilloma from papillary ductal carcinoma in situ? AM. J. Surg. Pathol. 2005, 29(5): 625-32.

Trask AJ, Ferrario CM. Angiotensin 1-7: Pharmacology and new perspectives in cardiovascular treatments. Cardio Vasc Reviews. 2007; 25 (2):162-74.

Tonnesen MG, Klempner MS, Austen KF, Wintroub BU. Identification of a human neutrophil angiotensin II-generating protease as cathepsin G. J Clin Invest. 1982; 69:25-30.

Urata H, Nishimura H, Ganten D, Arakawa K. Angiotensin-converting enzymeindependent pathways of angiotensin II formation in human tissues and cardiovascular diseases. Blood Press Suppl 1996;2:22-8.

Urata $\mathrm{H}$, Nishimura $\mathrm{H}$, Ganten D. Mechanisms of angiotensin II formation in humans. Eur Heart J 1995 Dec;16 Suppl N:79-85.

Van Dyke TE, Serhan CN. Resolution of inflammation: a new paradigm for the pathogenesis of periodontal diseases. J Dent Res 2003 Feb;82(2):82-90.

Verdecchia P, Angeli F, Mazzotta G, Gentile G, Reboldi G. The renin angiotensin system in the development of cardiovascular disease: role of aliskiren in risk reduction. Vascular health and Risk Manegement 2008: 4(5) 971-981.

Waldmeier F, Glaenzel U, Wirz B, Oberer L, Schmid D, Seiberling M, Valencia J, Riviere GJ, End P, Vaidyanathan S. Absorption, distribution, metabolism, and elimination of the direct renin inhibitor aliskiren in healthy volunteers. Drug Metab Dispos. 2007 Aug;35(8):1418-28.

Wayner MJ, Polan-Curtain JL, Chiu SC, Armstrong DL. Losartan reduces ethanol intoxication in the rat. Alcohol. 1994 Jul-Aug;11(4):343-6. 127.

Weinberg, MA; Bral, M. Laboratory animal models in periodontology. J Clin Periodontol. 1999; 26 (6):335-40.

Wilson M. Biological activities of lipopolysaccharides from oral bacteria and their relevance to the pathogenesis of chronic periodontitis. Sci Prog 1995;78(Pt 1):1934.

Wright JW, Yamamoto BJ, Harding JW. Angiotensin receptor subtype mediated physiologies and behaviors: New discoveries and clinical targets. Prog Neurobiol. 2008; 84(2):157-81.

Zhao Q, Ishibashi M, Hiasa K, Tan C, Takeshita A, Egashira K. Essential role of vascular endotelial growth factor in angiotensin II-induced vascular inflammation and remodeling. Hypertension 2004 Sep;44(3):264-70.

Zhuo J. et al. Maping tissue angiotensin-converting enzyme and AT1, AT2 and AT4 receptors. J Hypertension 1998, 16: 2027-37. 

Anexos 



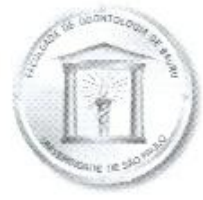

Faculdade de Odontologia de Bauru

Al. Dr. Octávio Pinheiro Brisolla, 9-75 - Bauru-SP - CEP 17012-901 - C.P. 73 PABX (0XX14)3235-8000-FAX (0XX14)3223-4679 Comissão de Ética no Ensino e Pesquisa em Animais

e-mail: mferrari@fob.usp.br

CEEPA-Proc. No 009/2008

Bauru, 5 de janeiro de 2011

Senhor Professor,

Em atenção à solicitação de alteração no título do projeto de pesquisa "Interação entre o sistema renina-angiotensina e o fator de crescimento endotelial na doença periodontal induzida experimentalmente em ratos" de autoria de Marta da Cunha Lima e Daniel Thomas Brozoski, sob sua orientação, para O SISTEMA RENINA-ANGIOTENSINA NA DOENÇA PERIODONTAL INDUZIDA EXPERIMENTALMENTE EM RATOS, informamos que esta Comissão aprovou ad referendum, considerando não haver impedimentos éticos.

Atenciosamente,

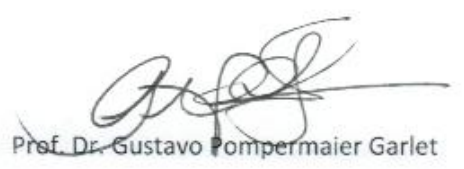

Presidente da Comissão de Ética no Ensino e Pesquisa em Animais

Prof. Dr. Carlos Ferreira dos Santos

Docente do Departamento de Ciências Biológicas 

